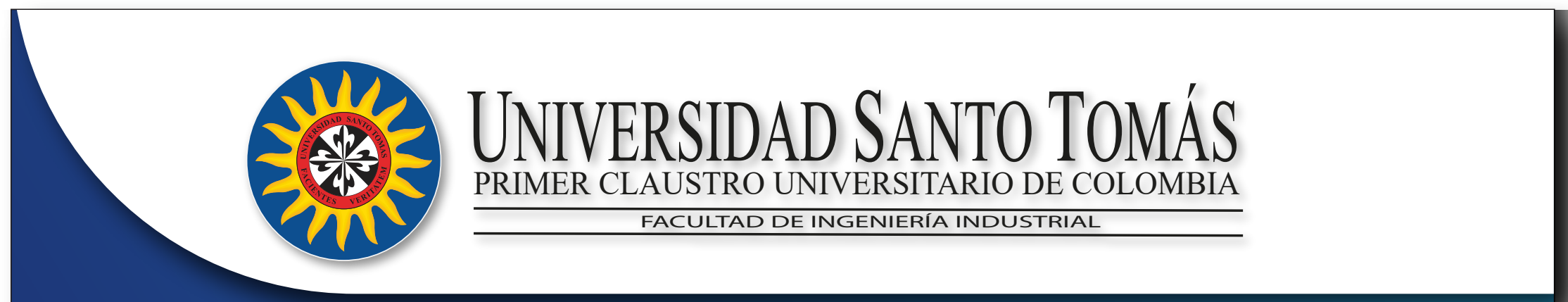

\title{
Cartilla diseño \\ paso a paso CAD \\ Campero Jeep
}

Elaborado por:

Natalia Díaz L.

Alejandro Pérez S.

Líder Investigador:

Óscar Emmanuel Granados Delgado
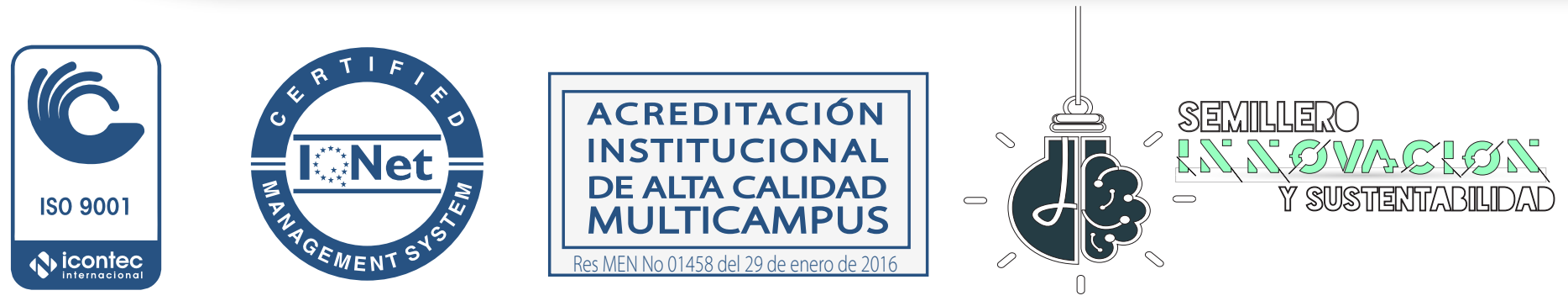


\section{CONTENIDO}

1. INTRODUCCIÓN

2. OBJETIVOS

a. Objetivo General

b. Objetivos Específicos

3. METOdOLOGíA

4. SOFTWARE

5. PROCEDIMIENTO

6. RESULTADOS

7. CONCLUSIONES 


\section{INTRODUCCIÓN}

En un mundo global, donde el conocimiento varía cada segundo debido a la velocidad a la que avanza la tecnología, se requiere por parte de nuevos ingenieros habilidades que van más allá del conocimiento técnico, las ciencias básicas y otras materias teóricas.

La presente cartilla se realiza como resultado de un proceso experimental de diseño y modelamiento 3D de un carro a escala - Jeep Wrangler Sport 2018. La cartilla muestra el procedimiento de diseño y parametrización del carro a escala, producto del Proyecto Cooperativo de Ingeniería Industrial entre la Universidad Santo Tomás de Bogotá (Colombia) y Tecnológico de Costa Rica, con la finalidad de promover la generación de nuevos proyectos de trabajo en equipo a nivel continental, sin importar la distancia de estos y con el apoyo de las nuevas tecnologías de la comunicación.

La Universidad Santo Tomás, Sede Principal, fue representada en este proyecto por el Semillero de Investigación e Innovación y Sustentabilidad (SII2).
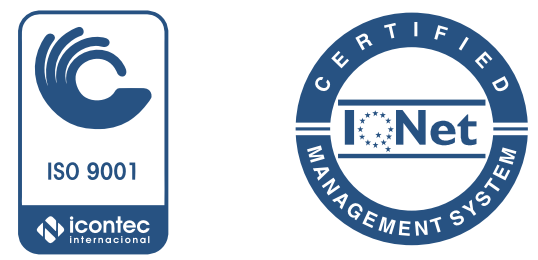


\section{OBJETIVOS}

\section{Objetivo general}

Presentar el diseño y modelamiento 3D de un prototipo a escala del Jeep Wrangler Sport 2018, que permita estandarizar el proceso de parametrización 3D, por medio del software CAD (Inventor-SOLIDWORKS) entre la Universidad Santo Tomás y Tecnológico de Costa Rica.

\section{Objetivos especifficos}

- Establecer medidas correspondientes para el diseño y modelamiento 3D del carro a escala.

- Relacionar piezas para el ensamble del CAD para tener el diseño final del carro modelo.
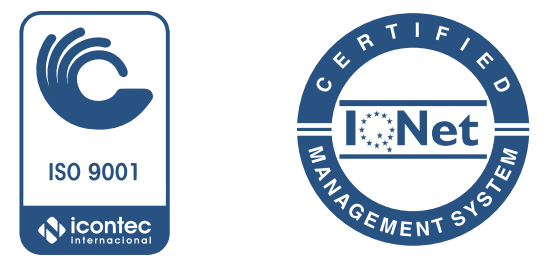


\section{METODOLOGÍA}

Se realiza un modelamiento 3D del carro a escala, por medio del software Inventor. Para establecer los lineamientos del diseño y parametrización 3D del carro, se realizó una sesión por Skype herramienta seleccionada como canal de comunicación entre las dos universidades, lo que permitió definir los parámetros de diseño y modelamiento 3D para el desarrollo del carro modelo Jeep Wrangler Sport 2018, como guía para cada uno de los grupos conformados tanto de la Universidad Santo Tomás Sede Principal como del Tecnológico de Costa Rica.

\section{Palabras clave}

Diseño, modelamiento 3D, campero Jeep, carro a escala, parametrización 3D, software CAD.
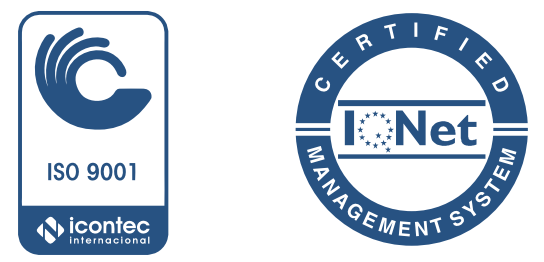


\section{SOFTWARE}

\section{AUTODESK
INVENTOR}

Autodesk Inventor es un software de diseño 3D que permite la parametrización de modelos en $2 D$ y $3 D$, de igual forma hace posible el ensamblaje de piezas o chapas y la simulación de diferentes condiciones físicas y químicas a las que se puede someter durante su funcionamiento la pieza 0 chapa que se este modelando en dicho software. Con este programa se puede conceptualizar modelos para presentaciones de proyectos, analizar propiedades de resistencia, peso, temperatura, puntos de quiebre, entre otras, para llegar a materializarlo con una impresora 3D, siempre con el fin de mejorar la productividad y reducir costos en la fabricación de los diferentes artefactos.
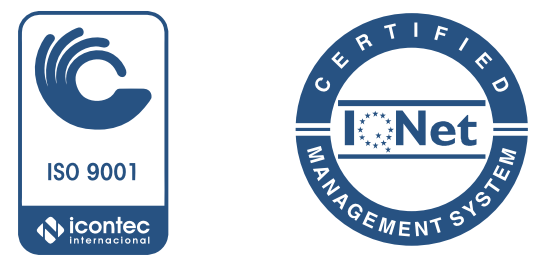


\section{PROCEDIMIENTO}

Crear un boceto sobre el plano superior a partir de un rectángulo con medidas correspondientes a $15 \mathrm{~mm}$ de alto y $55 \mathrm{~mm}$ de ancho.

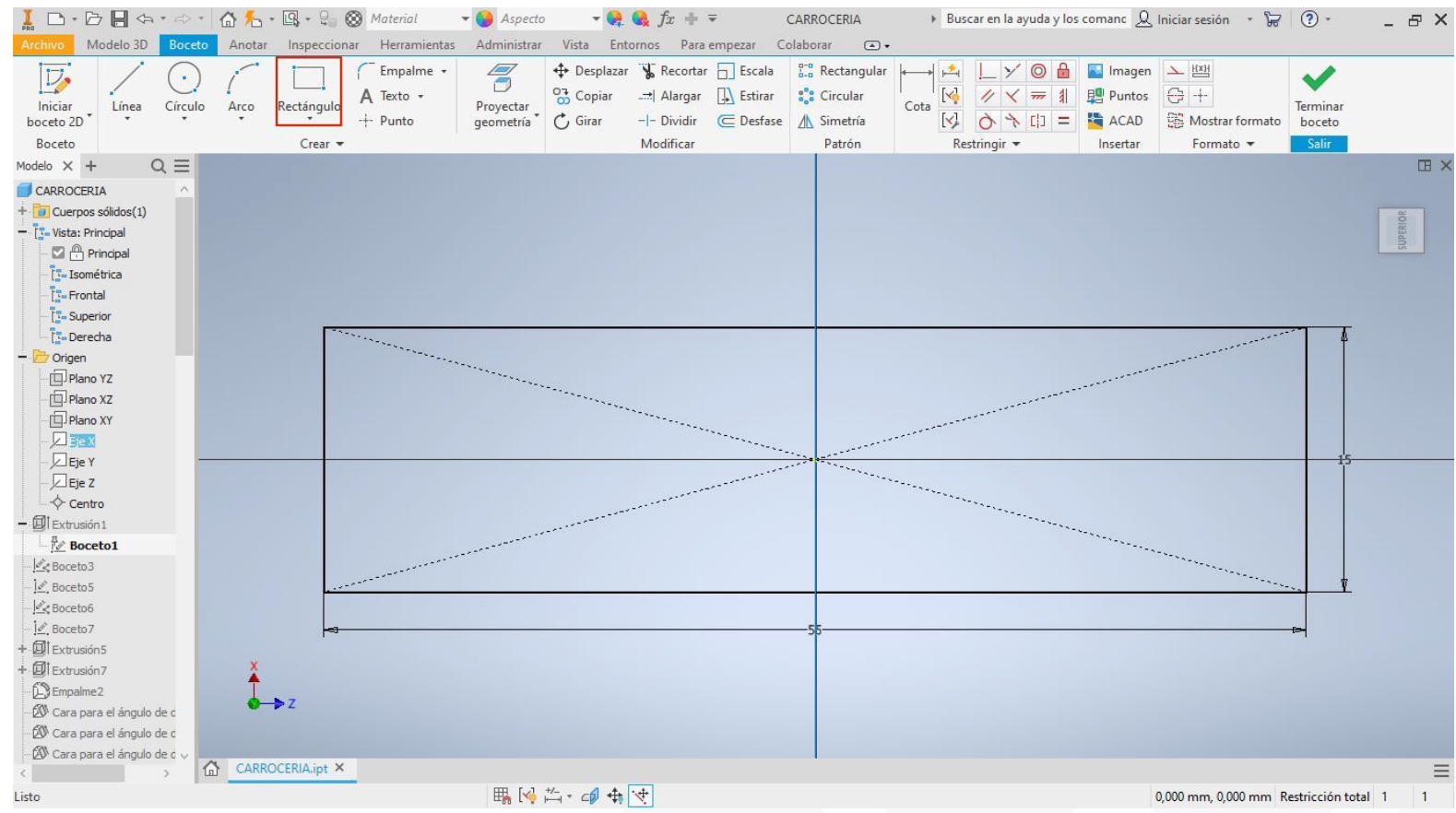

Crear una extrucción sobre el boceto activo (visible) con única dirección a una distancia de $11 \mathrm{~mm}$.
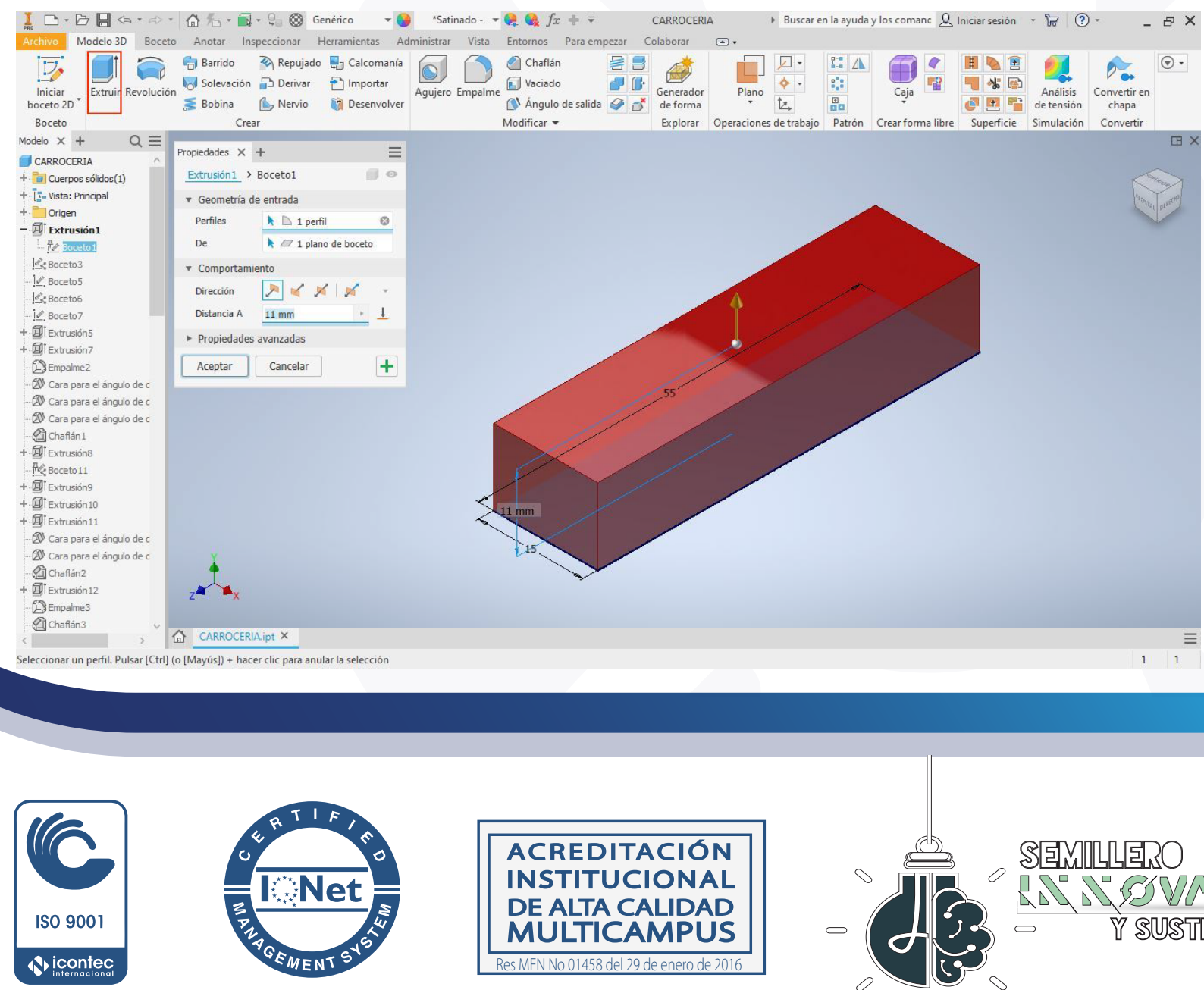

ACREDITACION INSTITUCIONAL DE ALTA CALIDAD MULTICAMPUS

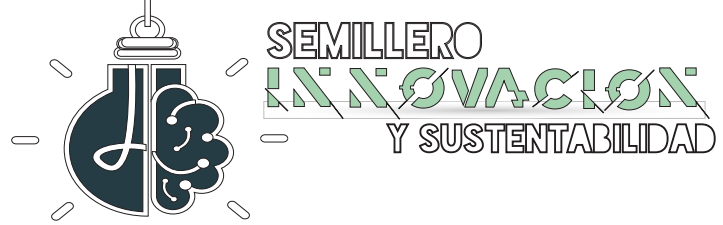




\section{Procedimiento}

Crear un boceto sobre el plano de la vista derecha a partir de líneas, empalmes y desfase con medidas correspondientes a $1 \mathrm{~mm}$ de desfase y empalmes con radio de $3 \mathrm{~mm}$.

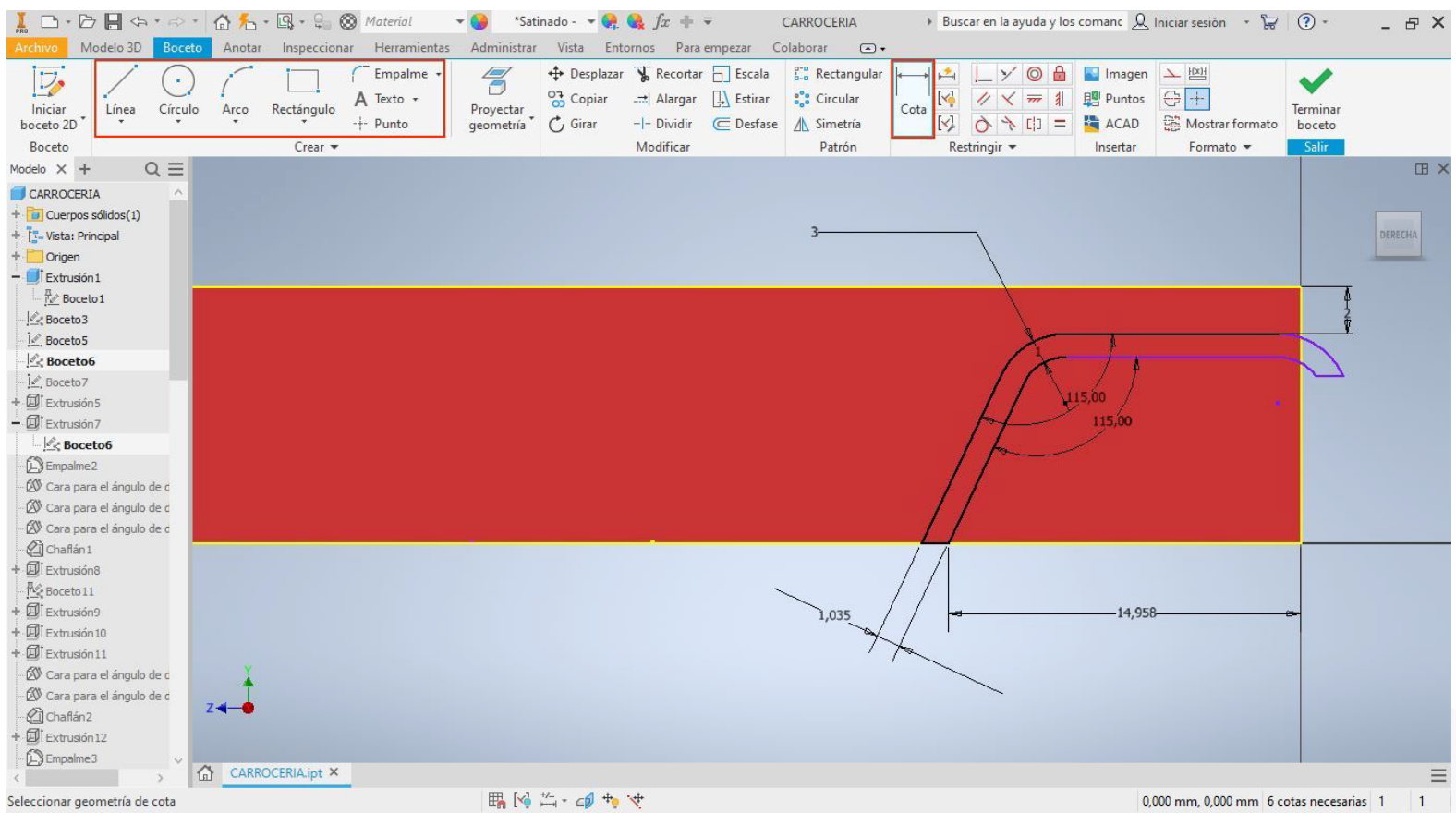

Crear un boceto sobre el plano superior a partir de un triángulo con medidas correspondientes a $\mathrm{Cl}=2,5 \mathrm{~mm}$ y $\mathrm{C} 2=17 \mathrm{~mm}$.
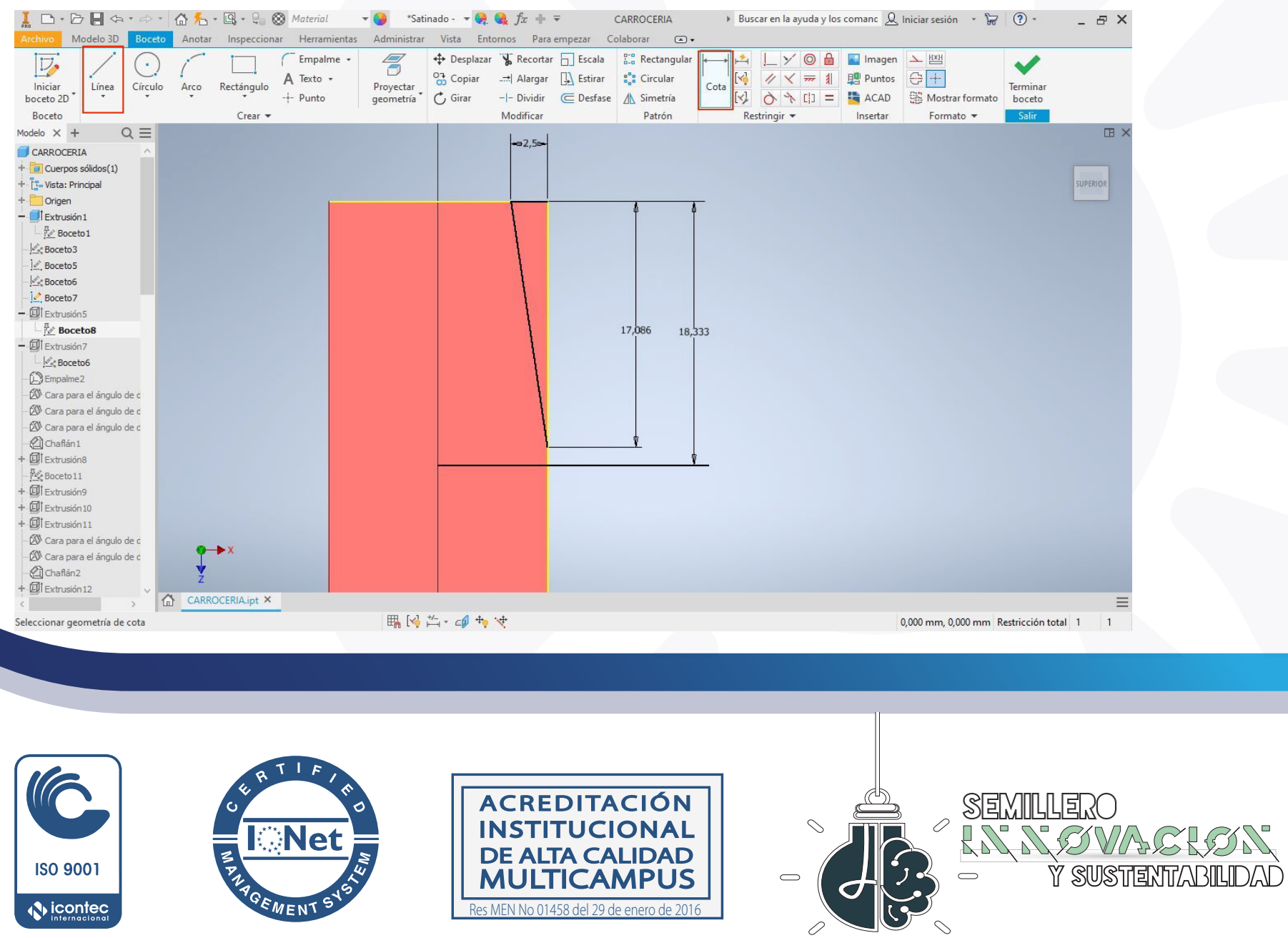


\section{Procedimiento}

Crear una extrucción sobre el boceto activo (visible) con única dirección a una distancia de $11 \mathrm{~mm}$.

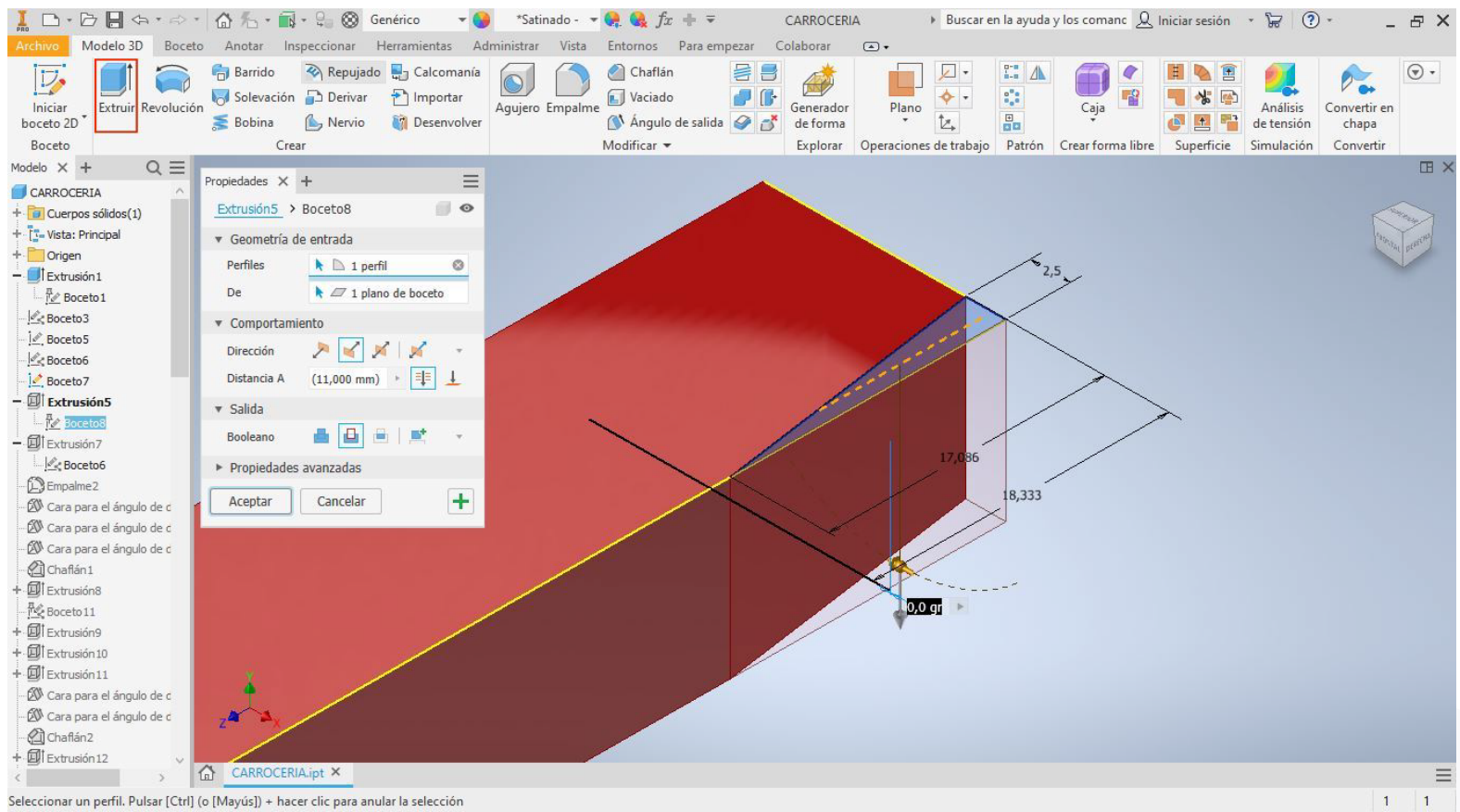

Crear una extrucción sobre el boceto activo (visible) con dirección simétrica a una distancia de 2,5 mm, esta pieza será el cubre llantas del Jeep.
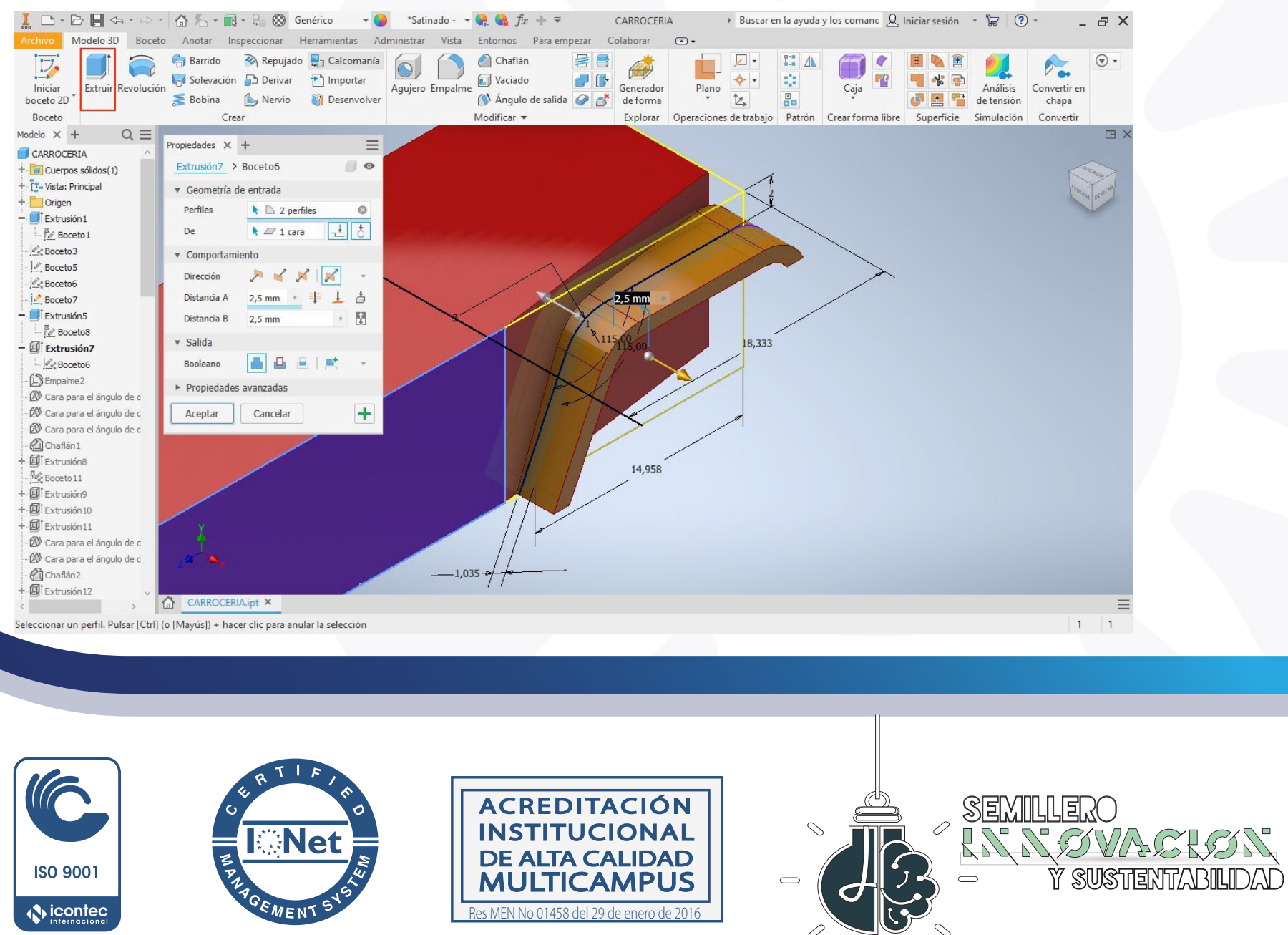


\section{Procedimiento}

Crear un empalme de $6 \mathrm{~mm}$ en el vértice del triángulo.

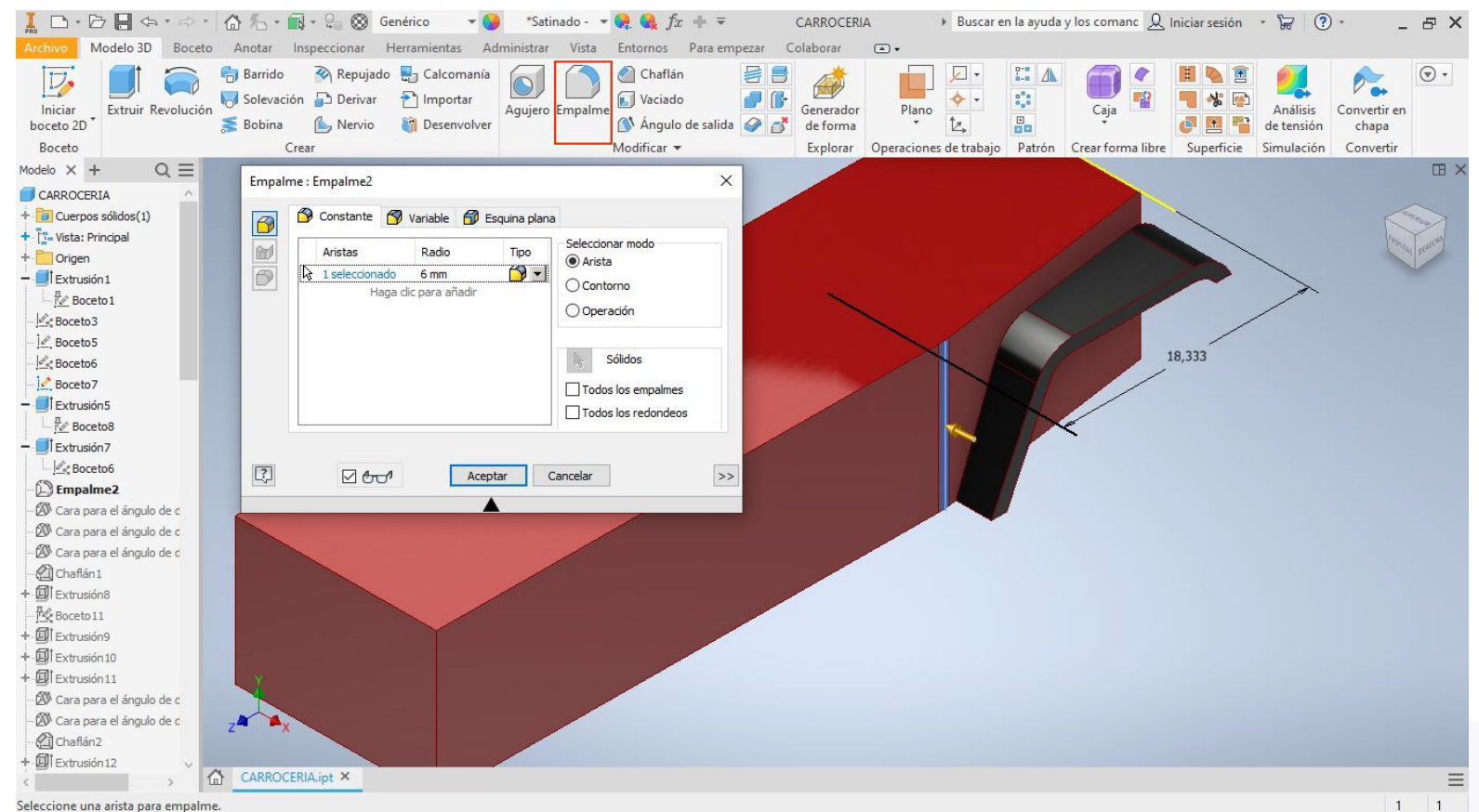

Creamos un chaflán en el vértice superior del cubre llantas.
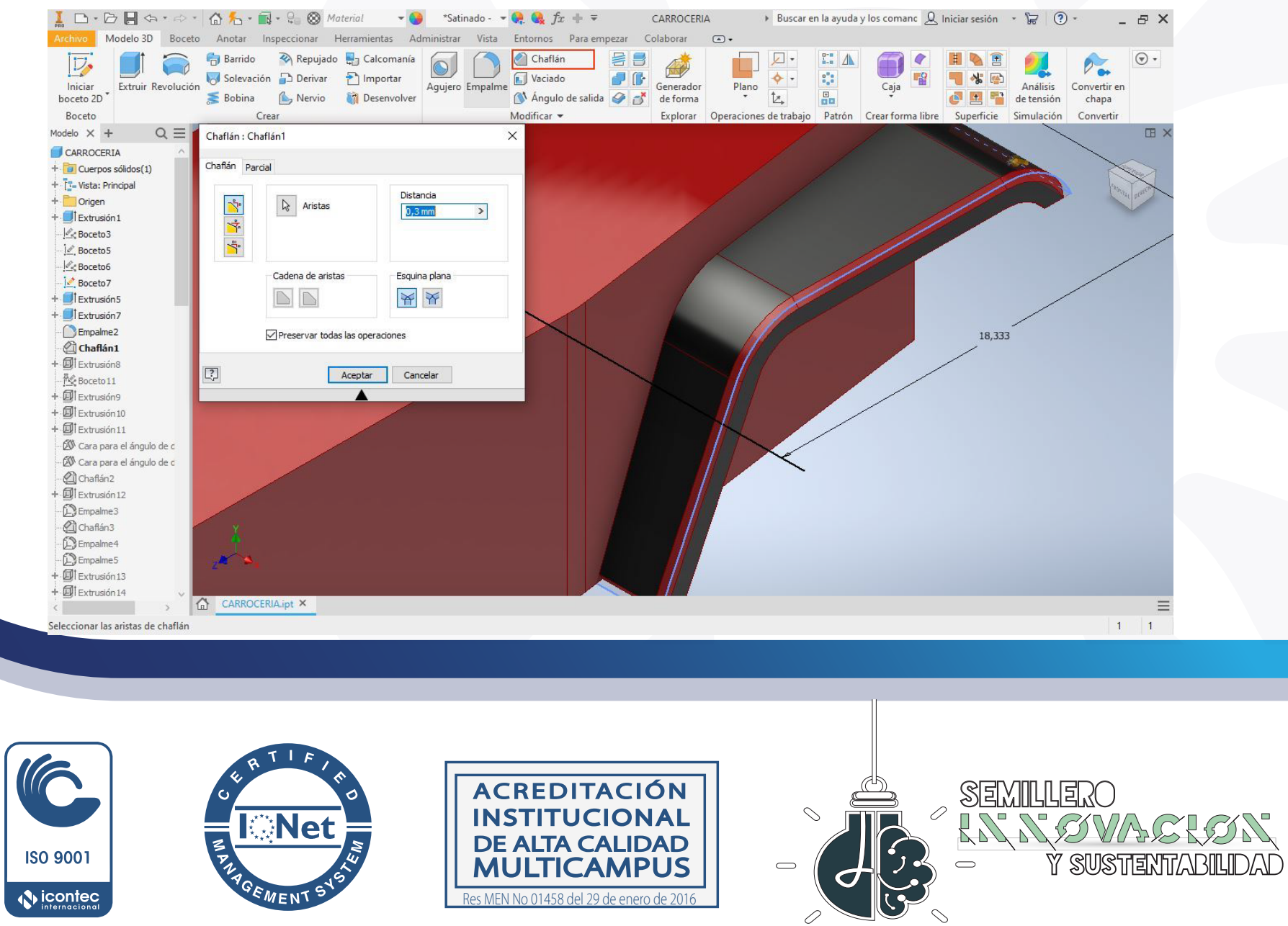


\section{Procedimiento}

Crear un boceto en la vista derecha del Jeep y con líneas, empalmes y un desfase, teniendo en cuenta las cotas de la ilustración.

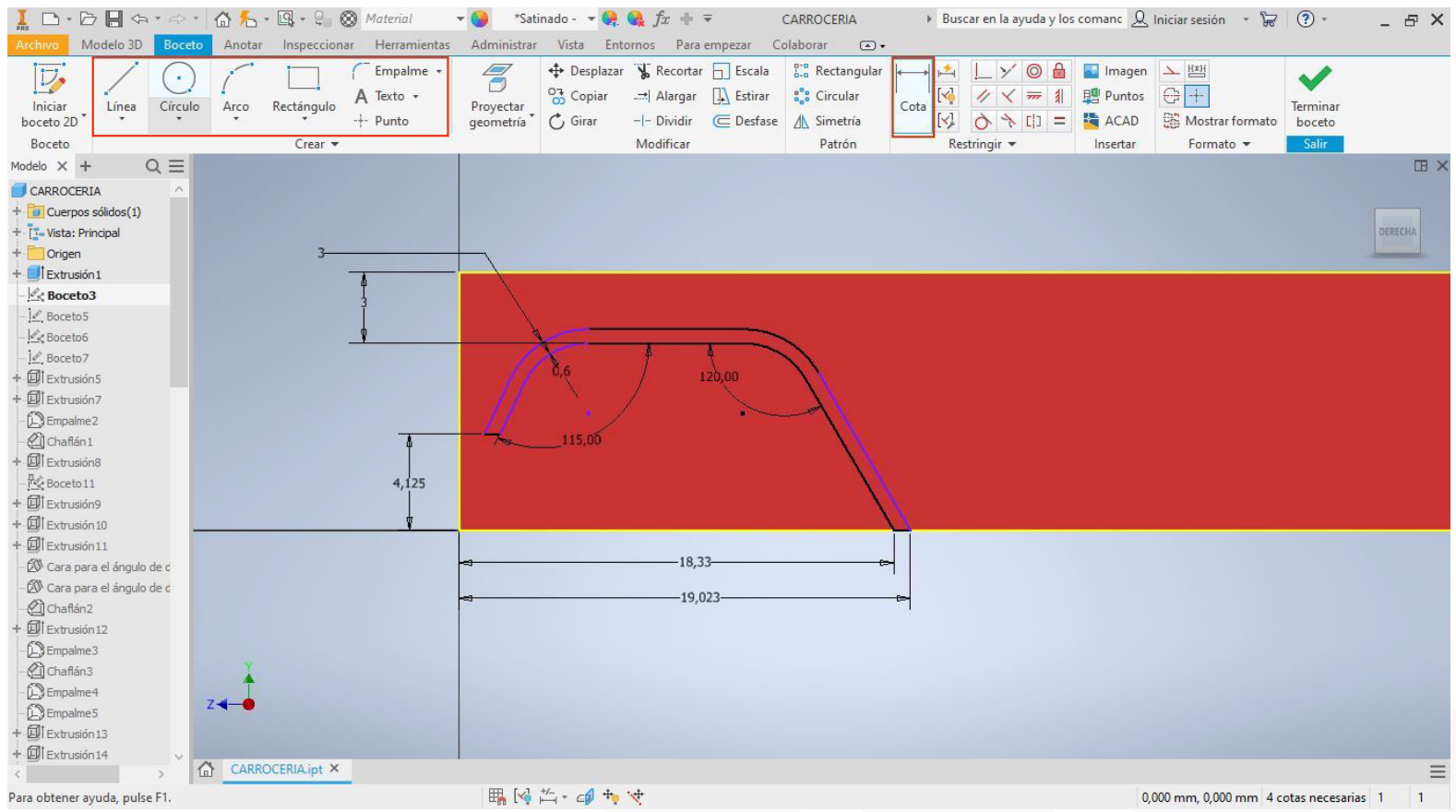

Crear una extrucción sobre el boceto activo (visible) con única dirección a una distancia de $2,5 \mathrm{~mm}$.
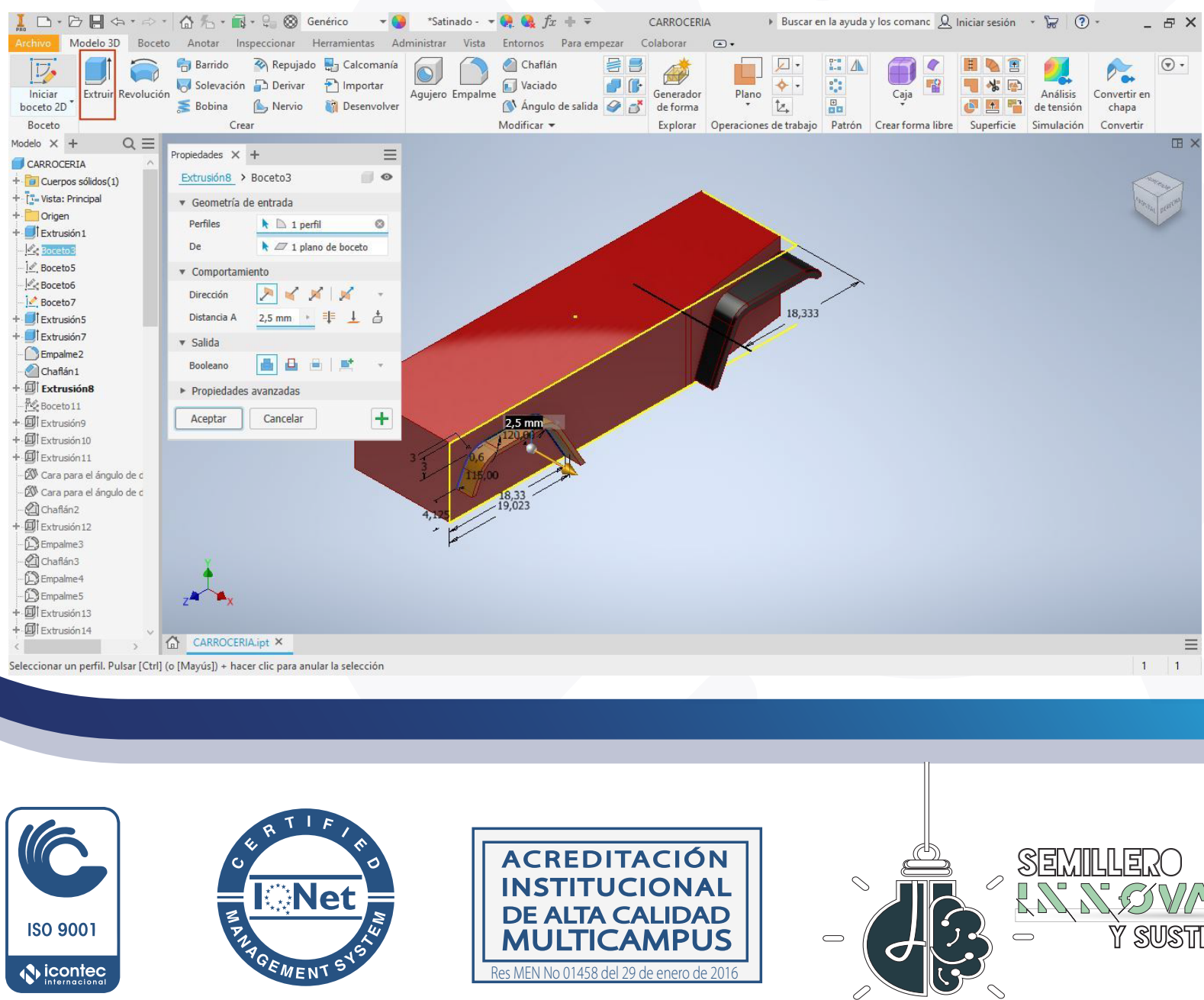

ACREDITACION INSTITUCIONAL DE ALTA CALIDAD MULTICAMPUS

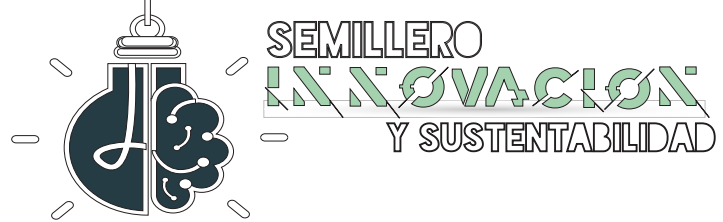




\section{Procedimiento}

Crear un boceto en la vista derecha del Jeep, con líneas y proyectar geometría teniendo en cuenta las cotas de la ilustración, aquí se realiza lo que sería el espacio de la llanta.

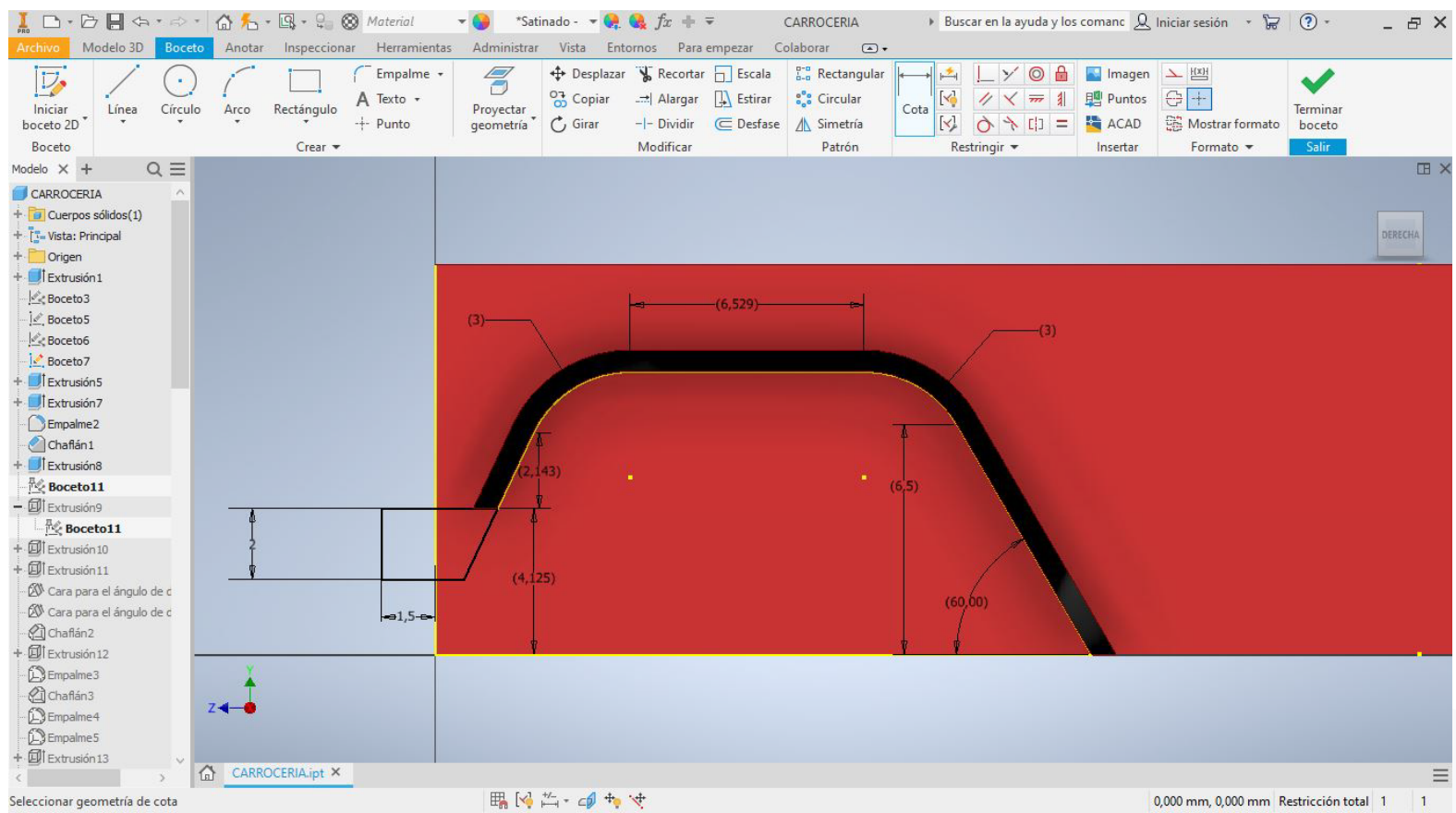

Crear una extrucción sobre el boceto activo (visible) con única dirección a una distancia de $2,5 \mathrm{~mm}$.
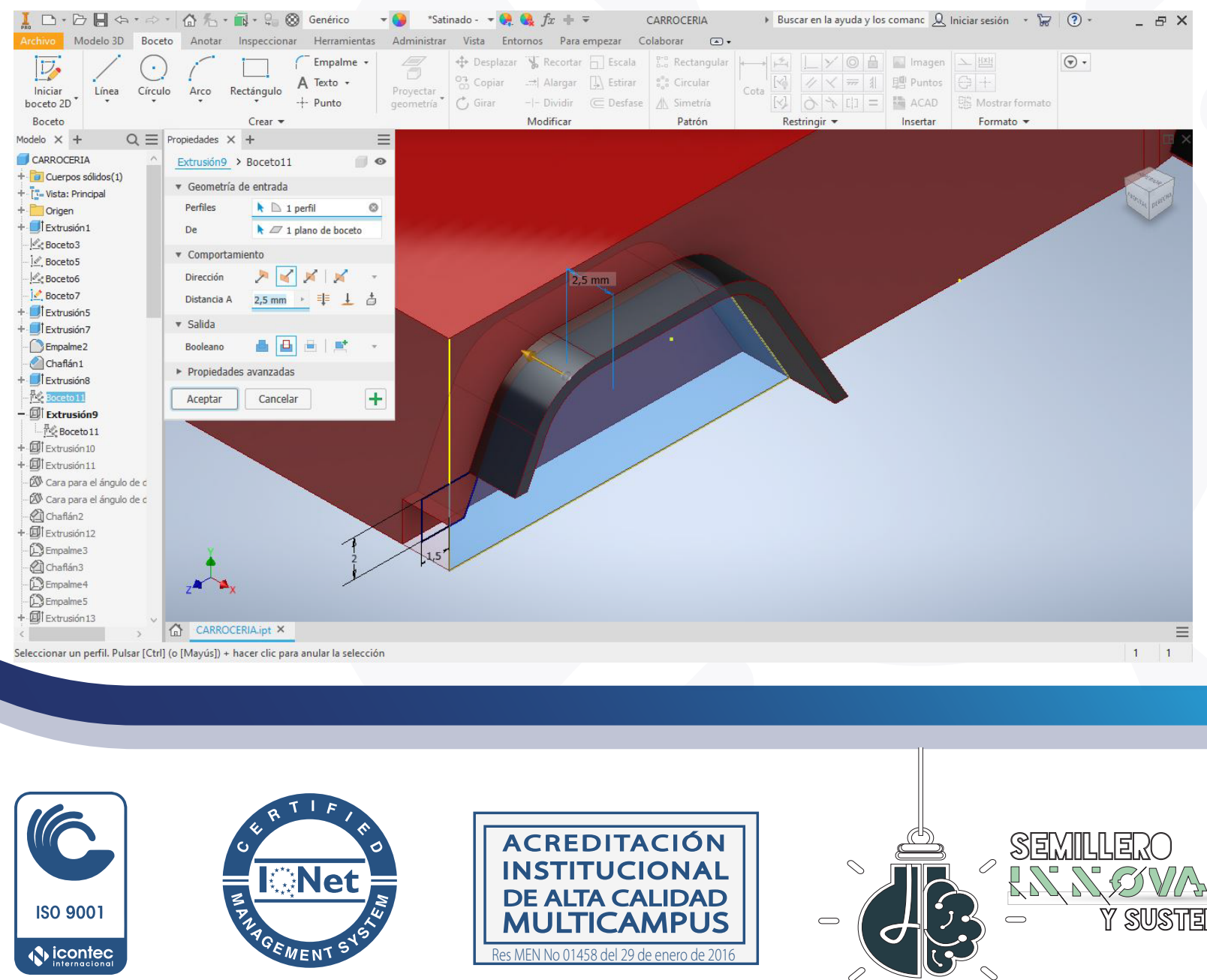

ACREDITACION INSTITUCIONAL DE ALTA CALIDAD MULTICAMPUS

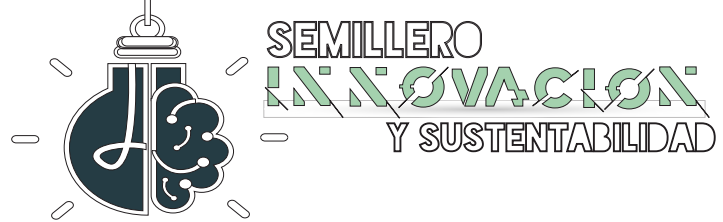




\section{Procedimiento}

Crear una extrucción sobre el boceto anterior, para esto hay que activar la visibilidad del boceto y seleccionar extruir, se hará la extrucción en sentido único de 2,5 mm.

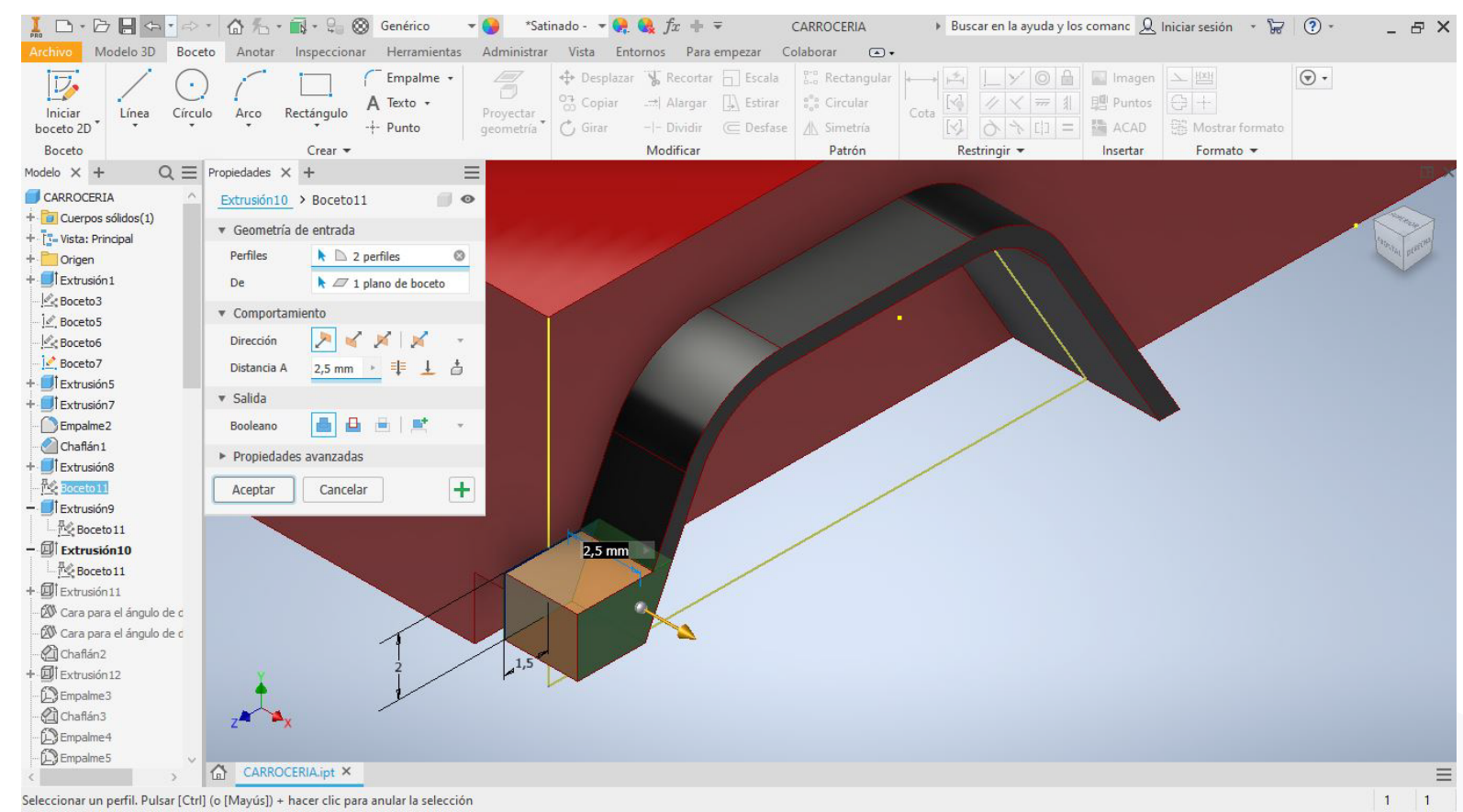

Con el mismo boceto que trabajamos anteriormente se hará una extrucción hacia el lado opuesto al de la anterior operación y será de $15 \mathrm{~mm}$.
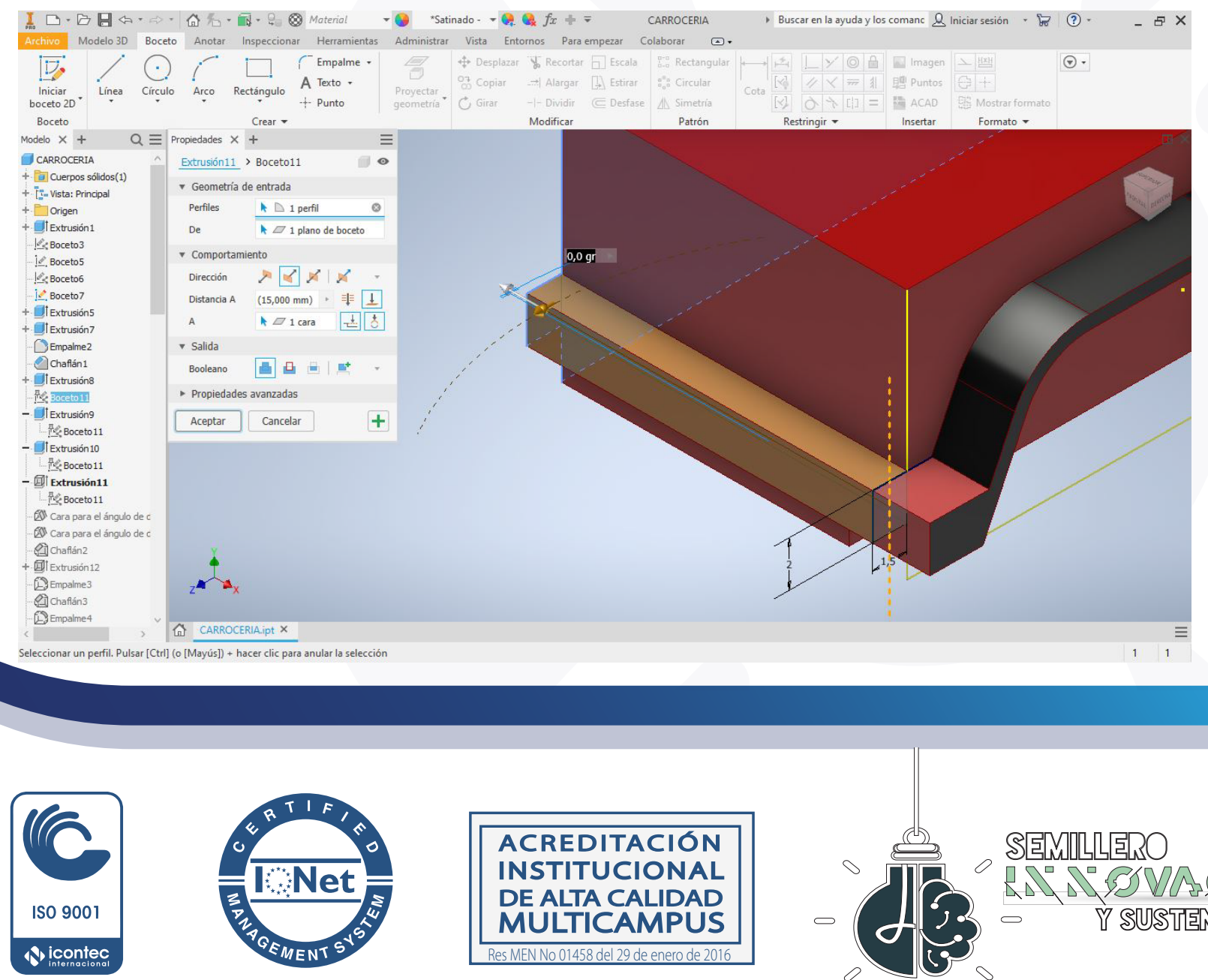

ACREDITACION

INSTITUCIONAL

DE ALTA CALIDAD

MULTICAMPUS

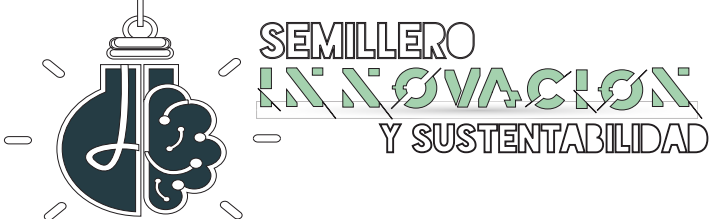




\section{Procedimiento}

Creamos un chaflán en el vértice superior del cubre llantas.

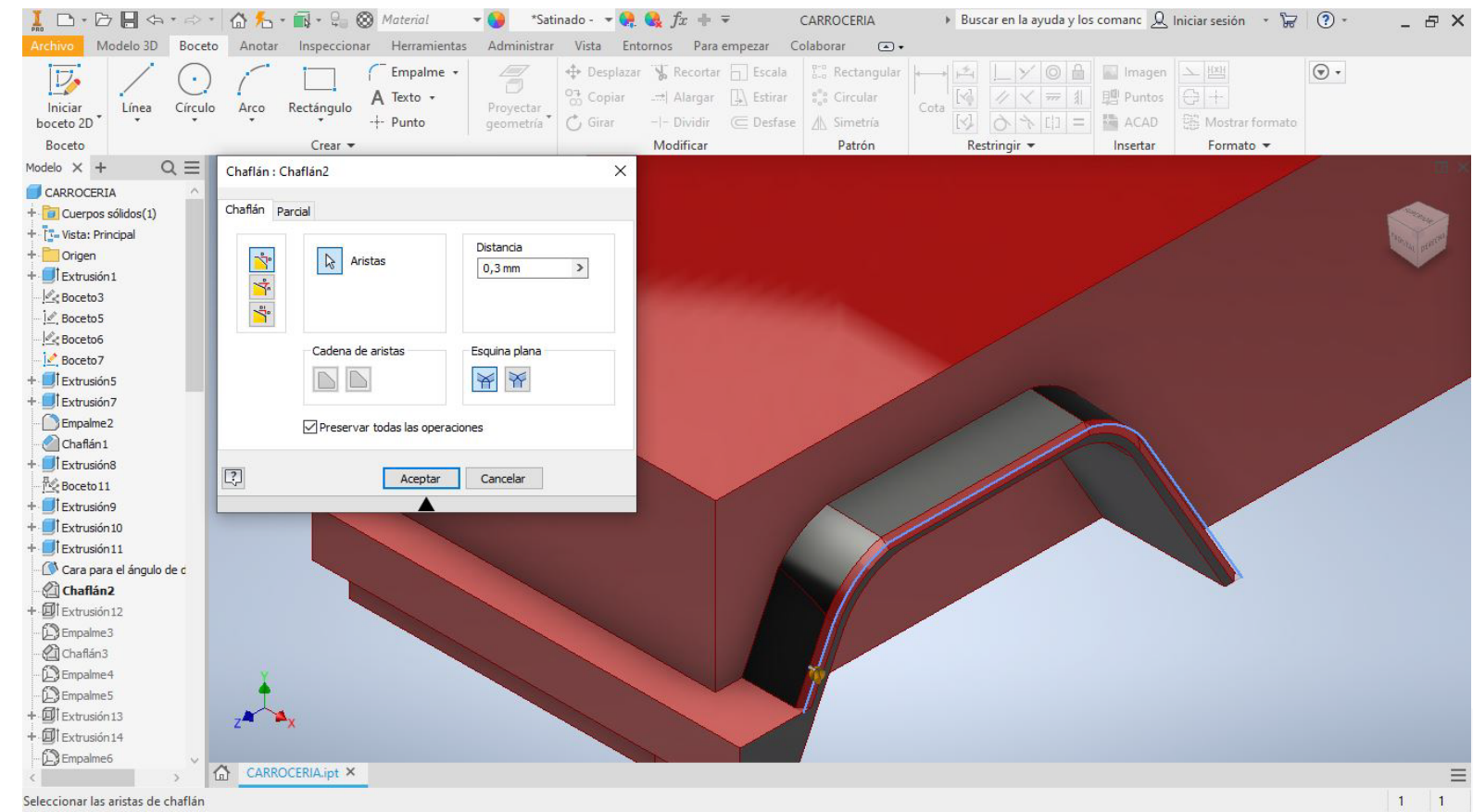

Crear un boceto en la vista derecha del Jeep, con líneas y proyectar geometría, dibujando un triángulo teniendo en cuenta las cotas de la ilustración.
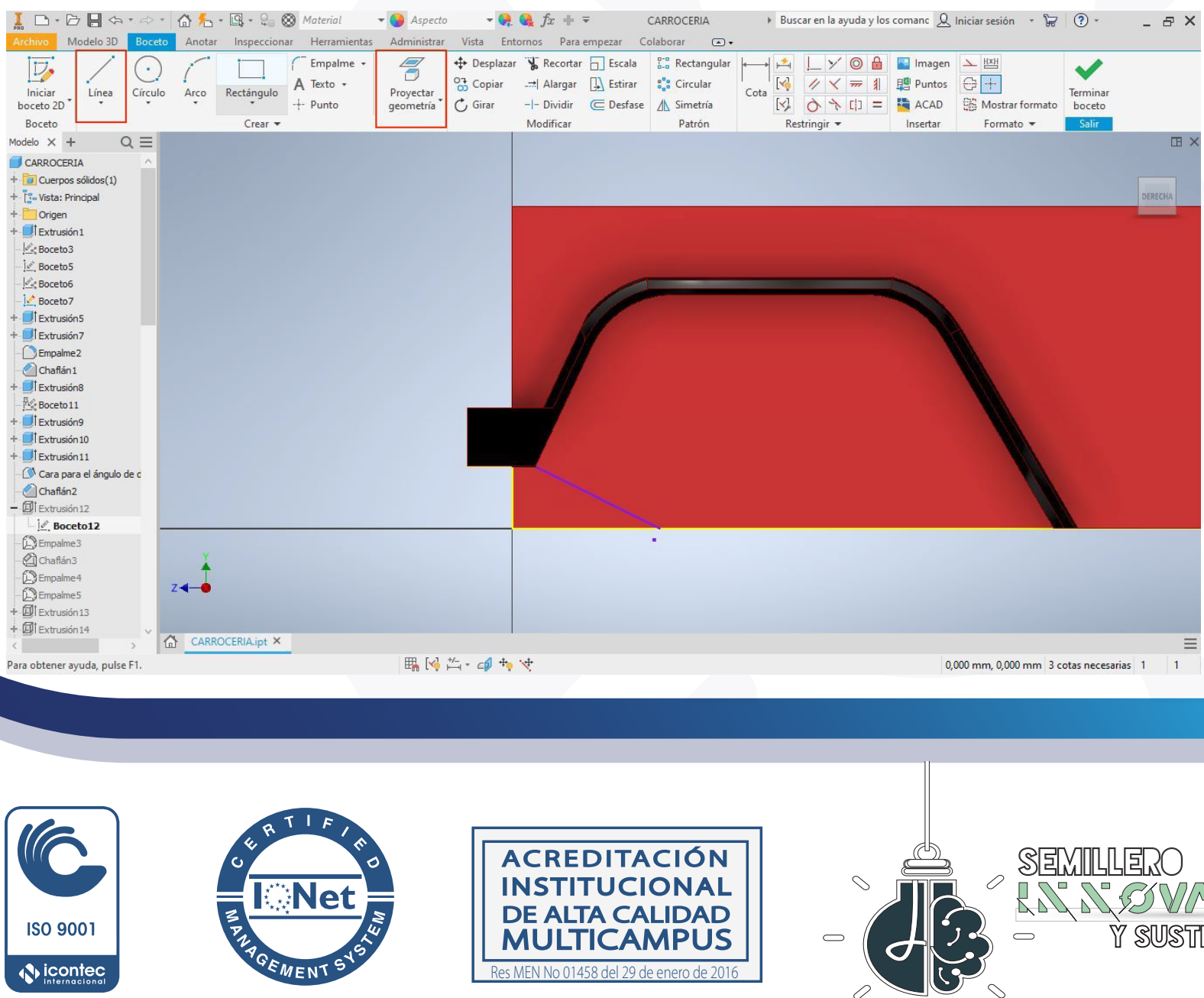

ACREDITACION INSTITUCIONAL DE ALTA CALIDAD MULTICAMPUS 


\section{Procedimiento}

Crear una extrucción sobre el boceto activo (visible) con única dirección a una distancia de $12,5 \mathrm{~mm}$.

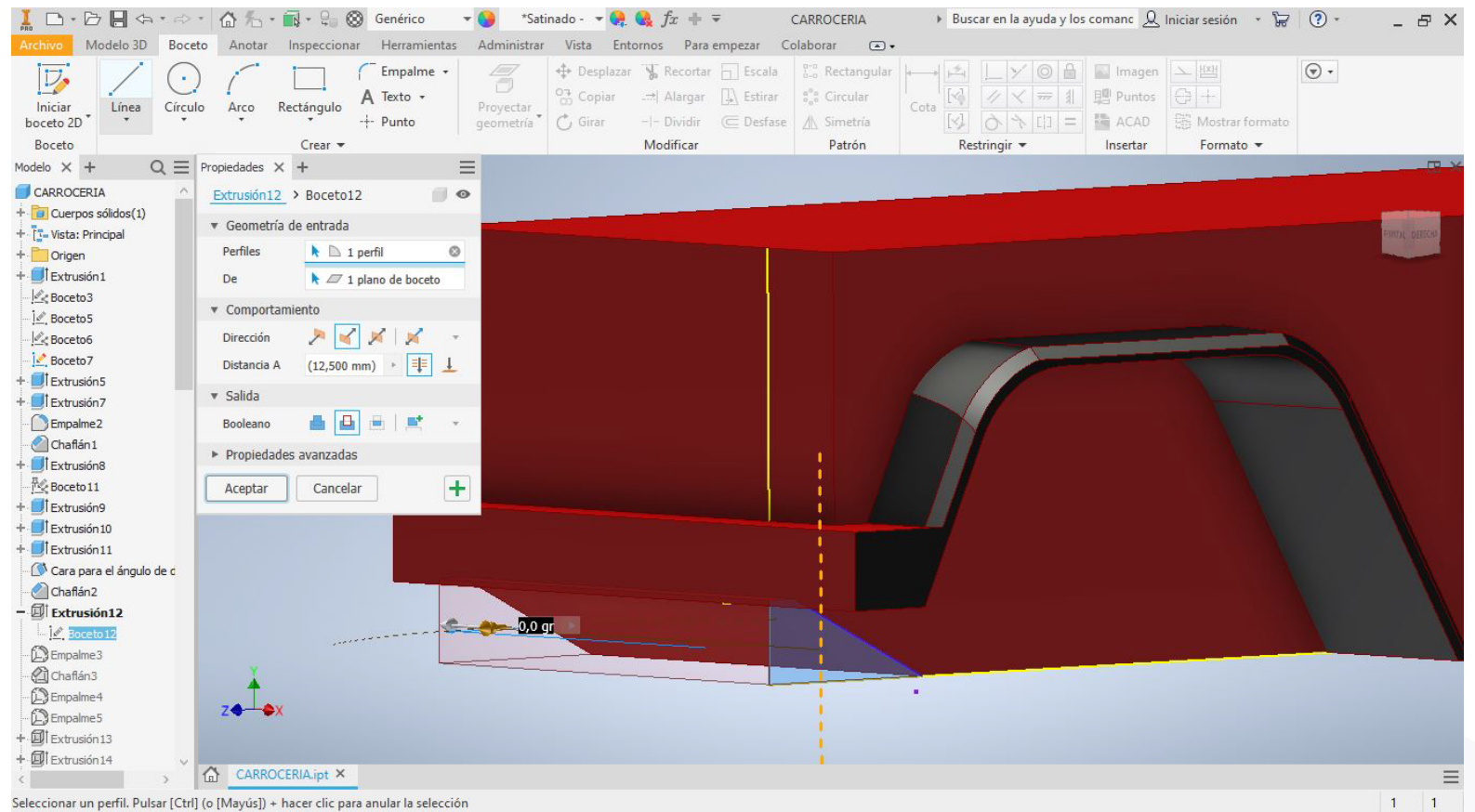

Crear un empalme de $2 \mathrm{~mm}$ en la arista vertical esquinera del parachoques trasero.
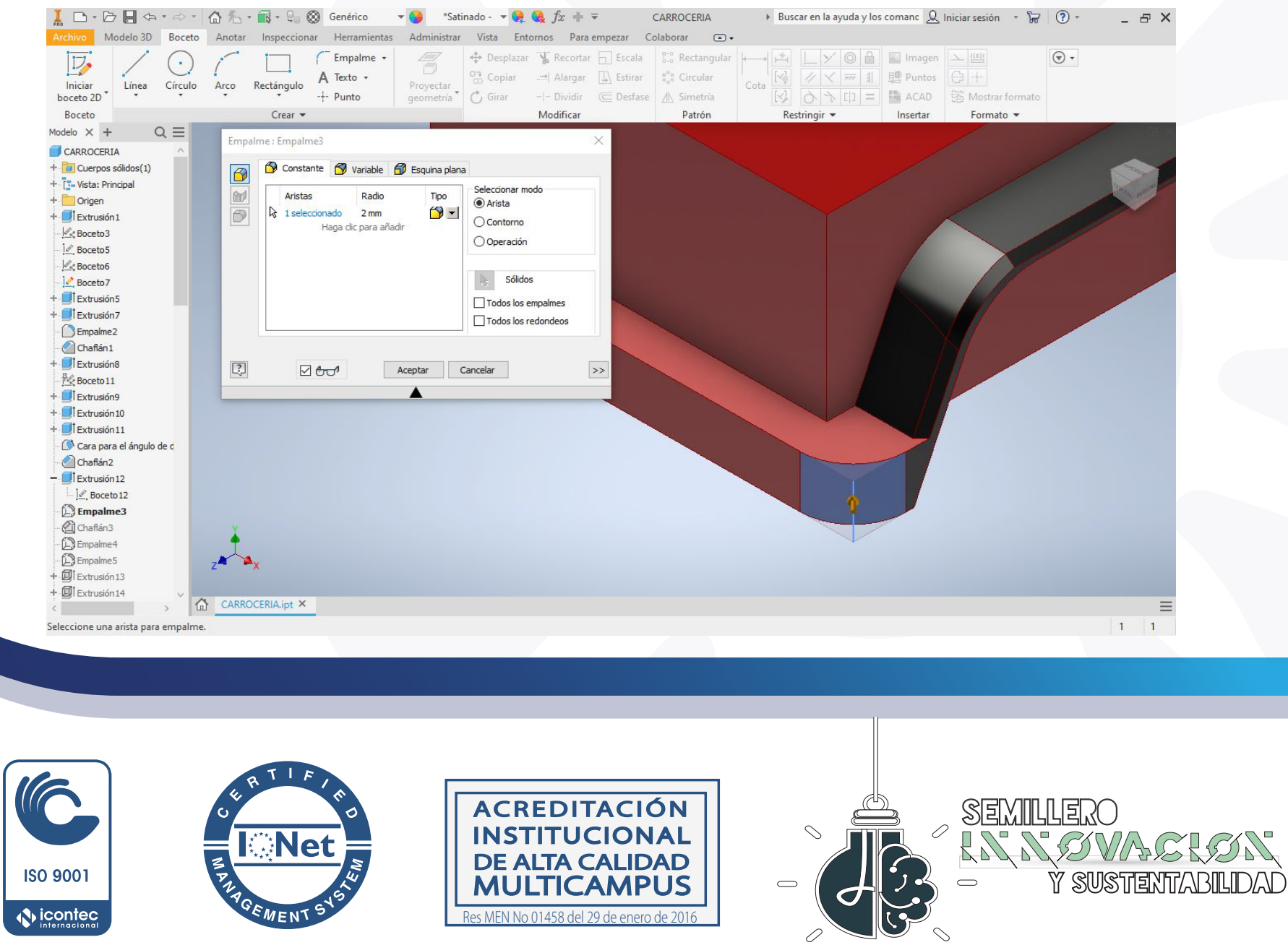


\section{Procedimiento}

Crear un chaflán de dos distancias sobre la arista horizontal inferior del parachoques trasero, distancia $1=0,8 \mathrm{~mm}$ y distancia $2=0,5 \mathrm{~mm}$.

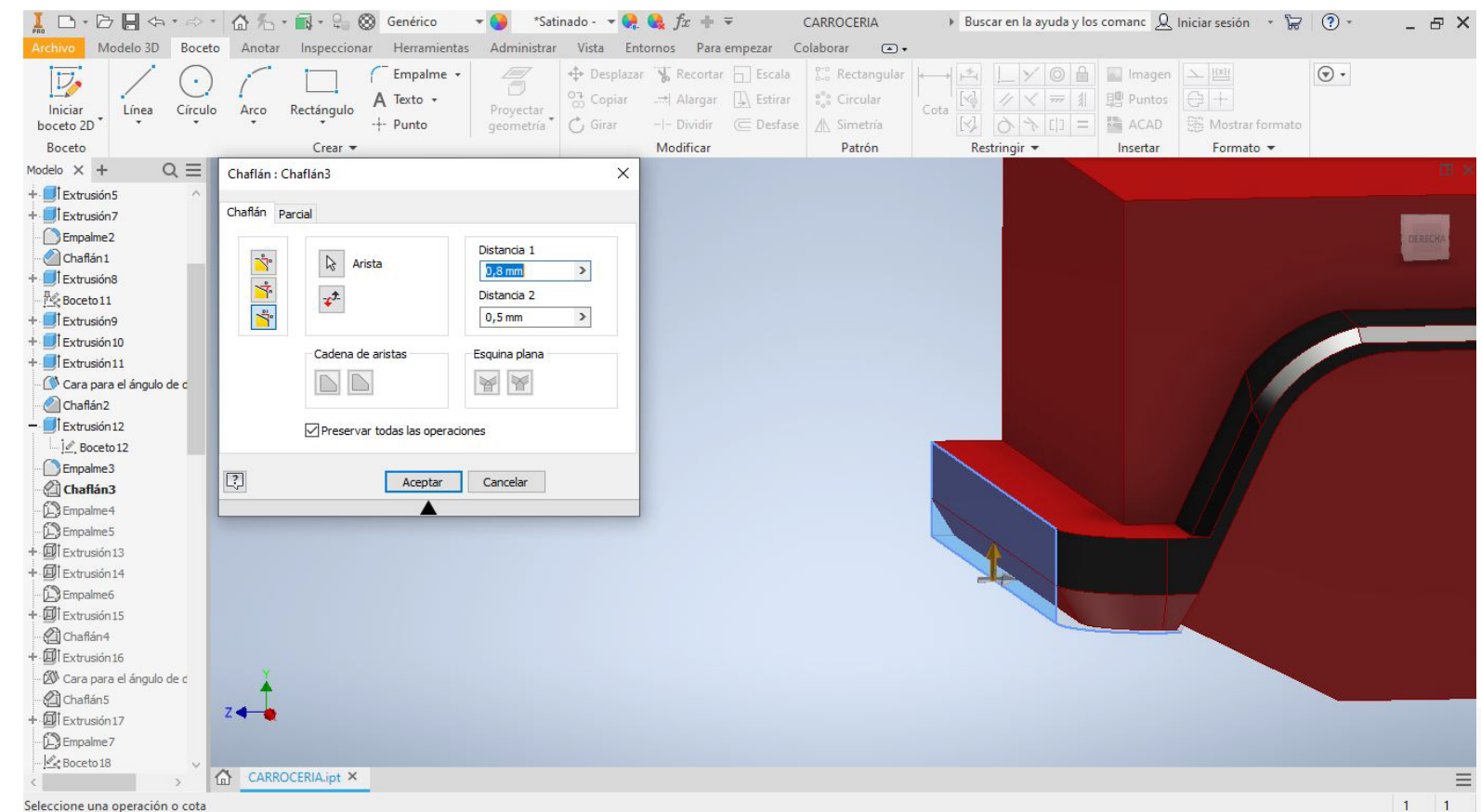

Crear un empalme de $2 \mathrm{~mm}$ en la arista vertical esquinera de la carrocería Jeep.
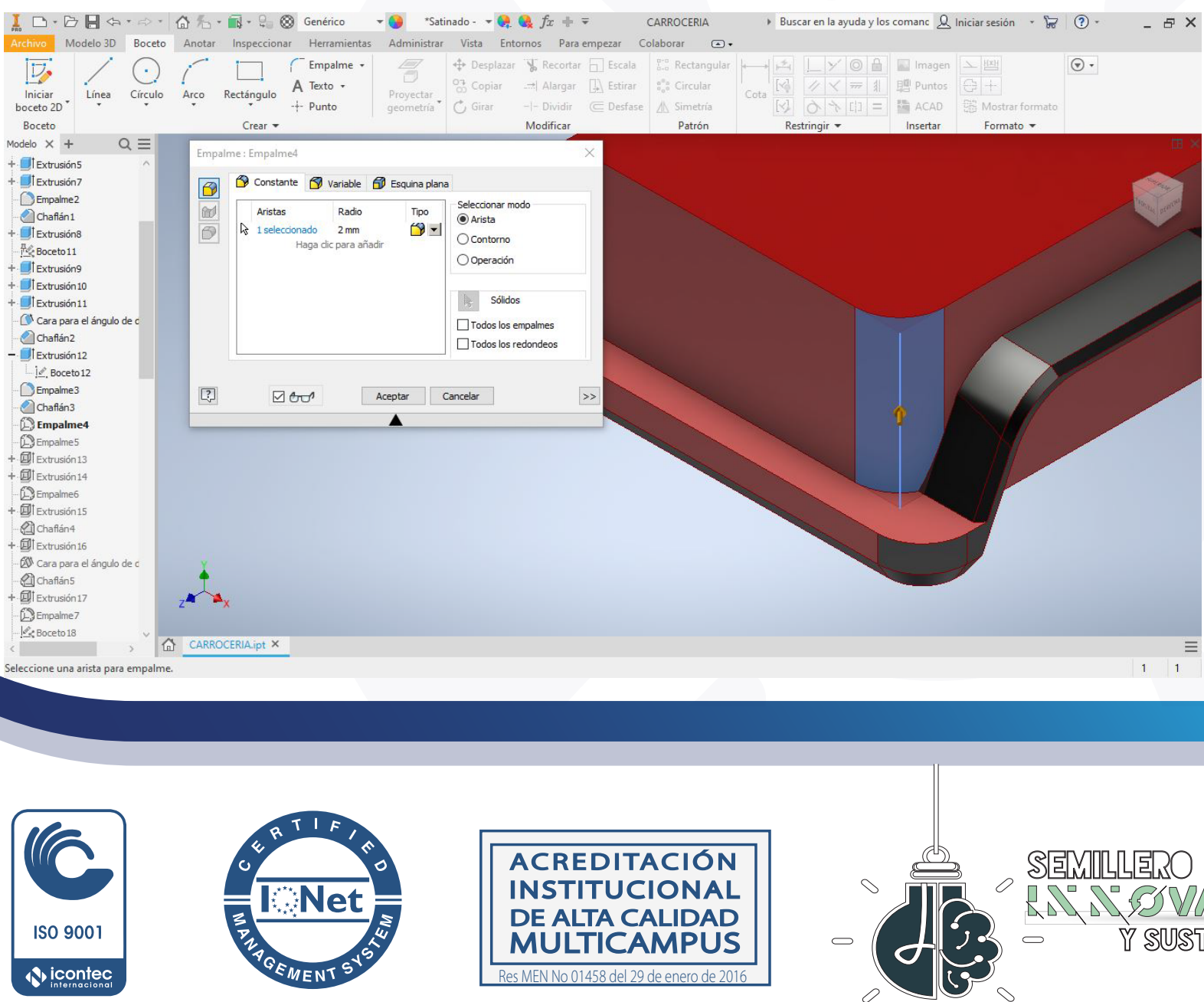

ACREDITACIÓN INSTITUCIONAL DE ALTA CALIDAD MULTICAMPUS

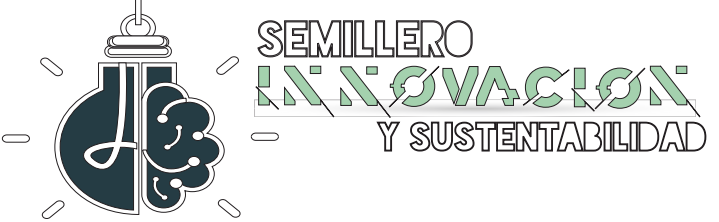




\section{Procedimiento}

Crear un empalme de 1,5 mm en la arista horizontal inferior entre los cubre llantas del Jeep.

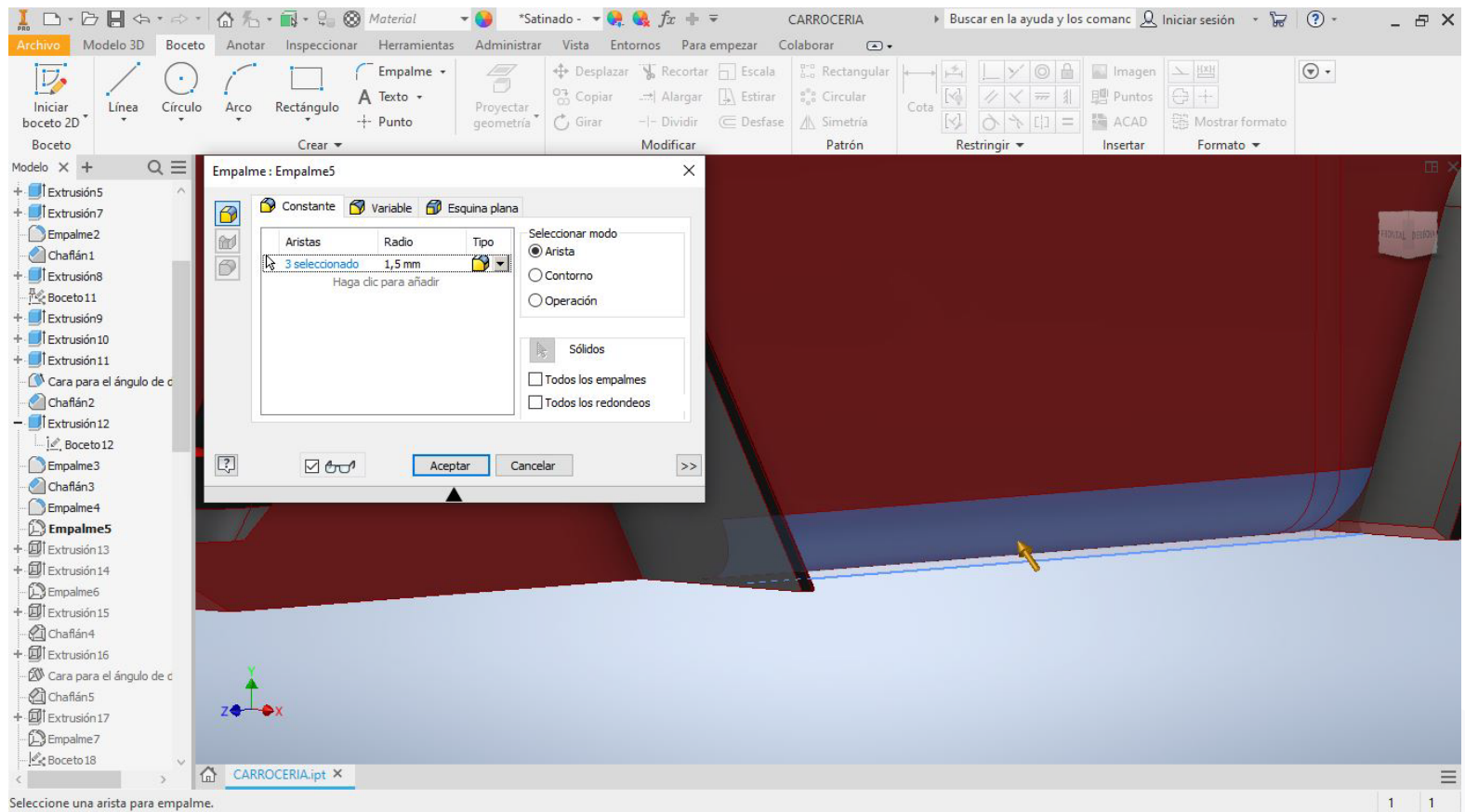

Crear un boceto en la vista posterior del parachoques trasero por medio de un círculo o curva con radio de $12 \mathrm{~mm}$ y con proyectar geometría se cerrará el esquema, considerando las cotas de la ilustración.
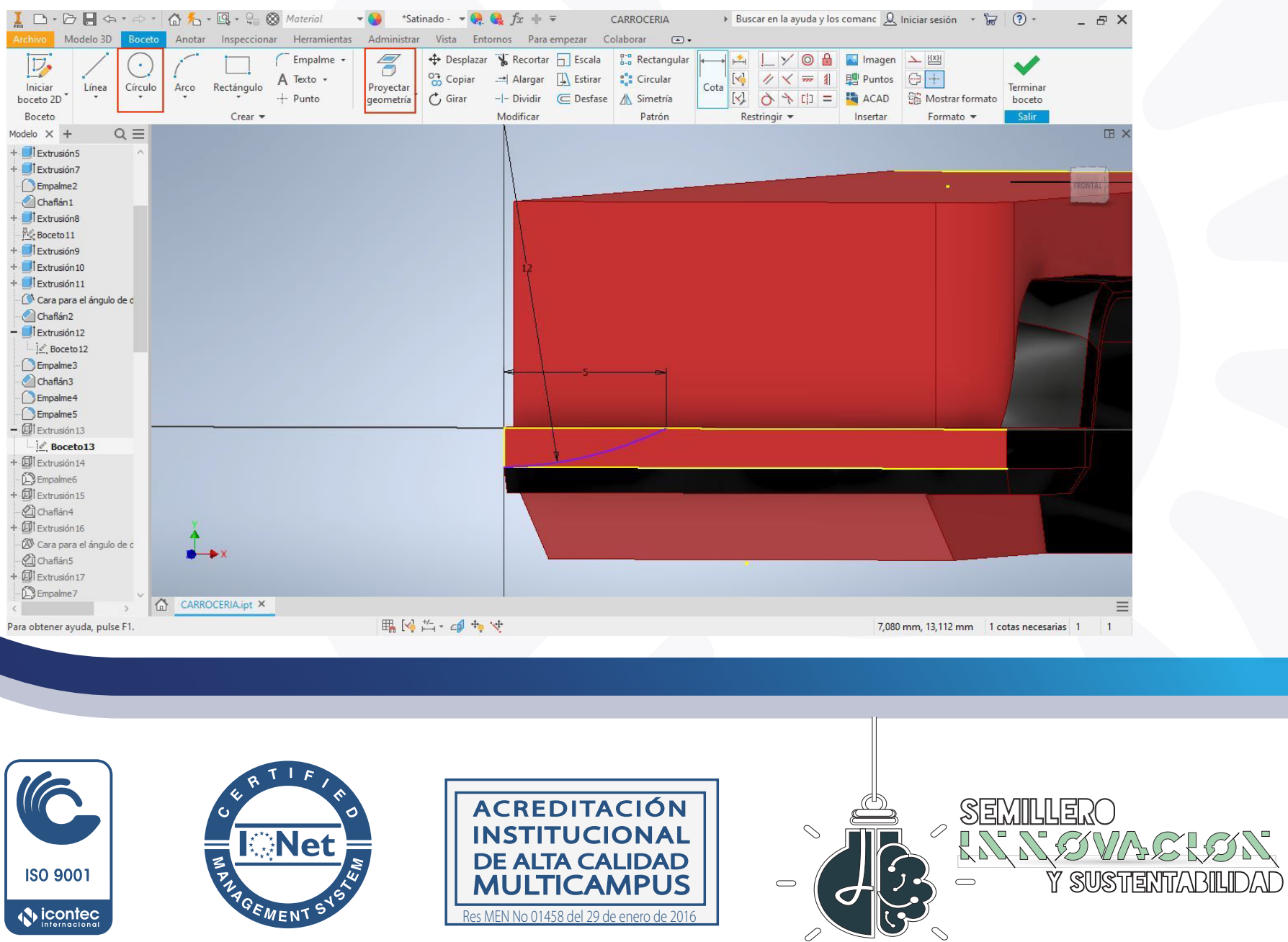


\section{Procedimiento}

Crear una extrucción sobre el boceto activo (visible) con única dirección a una distancia de $1 \mathrm{~mm}$.

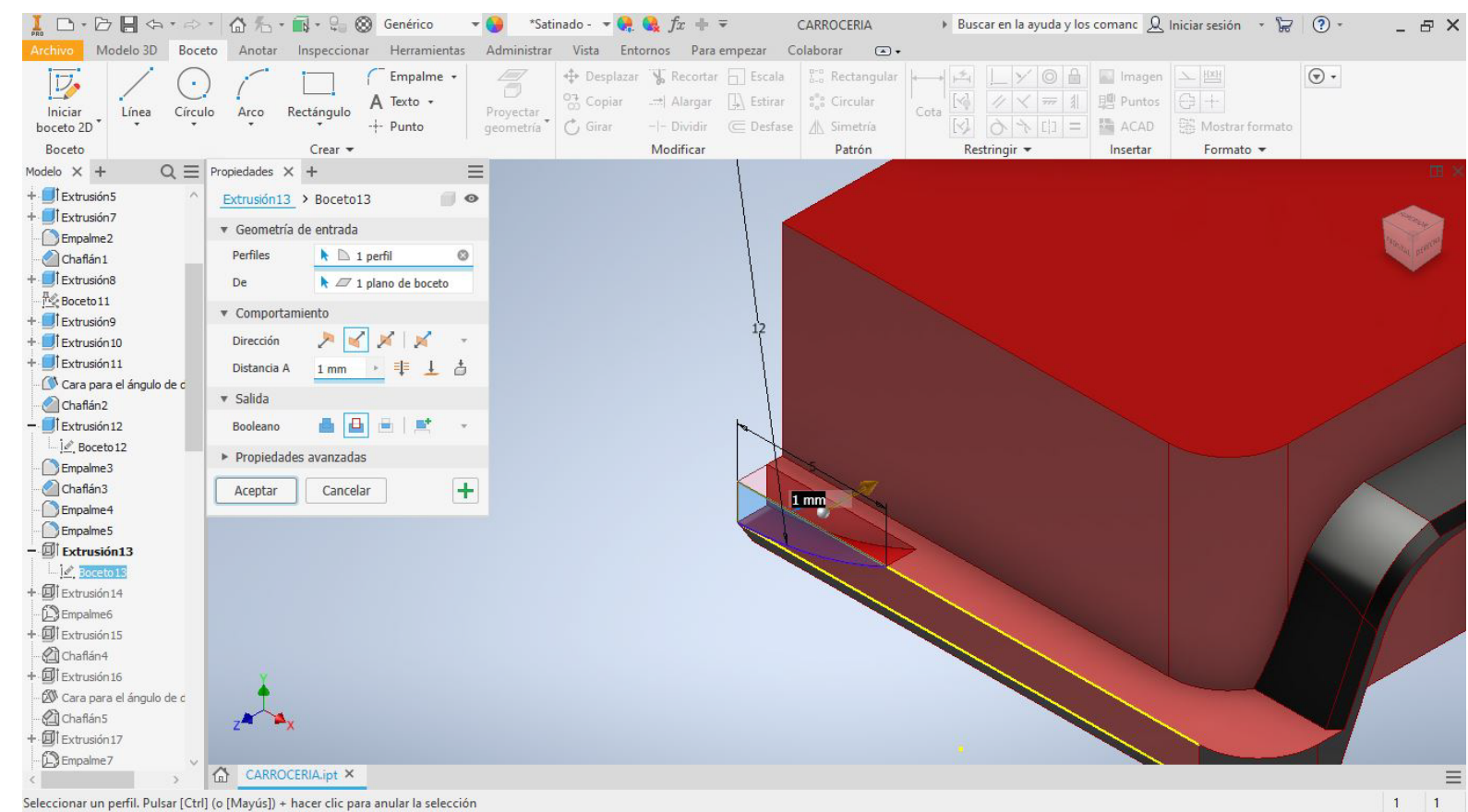

Crear un boceto en la vista derecha sobre el cubre llanta del Jeep con ayuda de curvas, líneas, cotas y proyección de geometría.
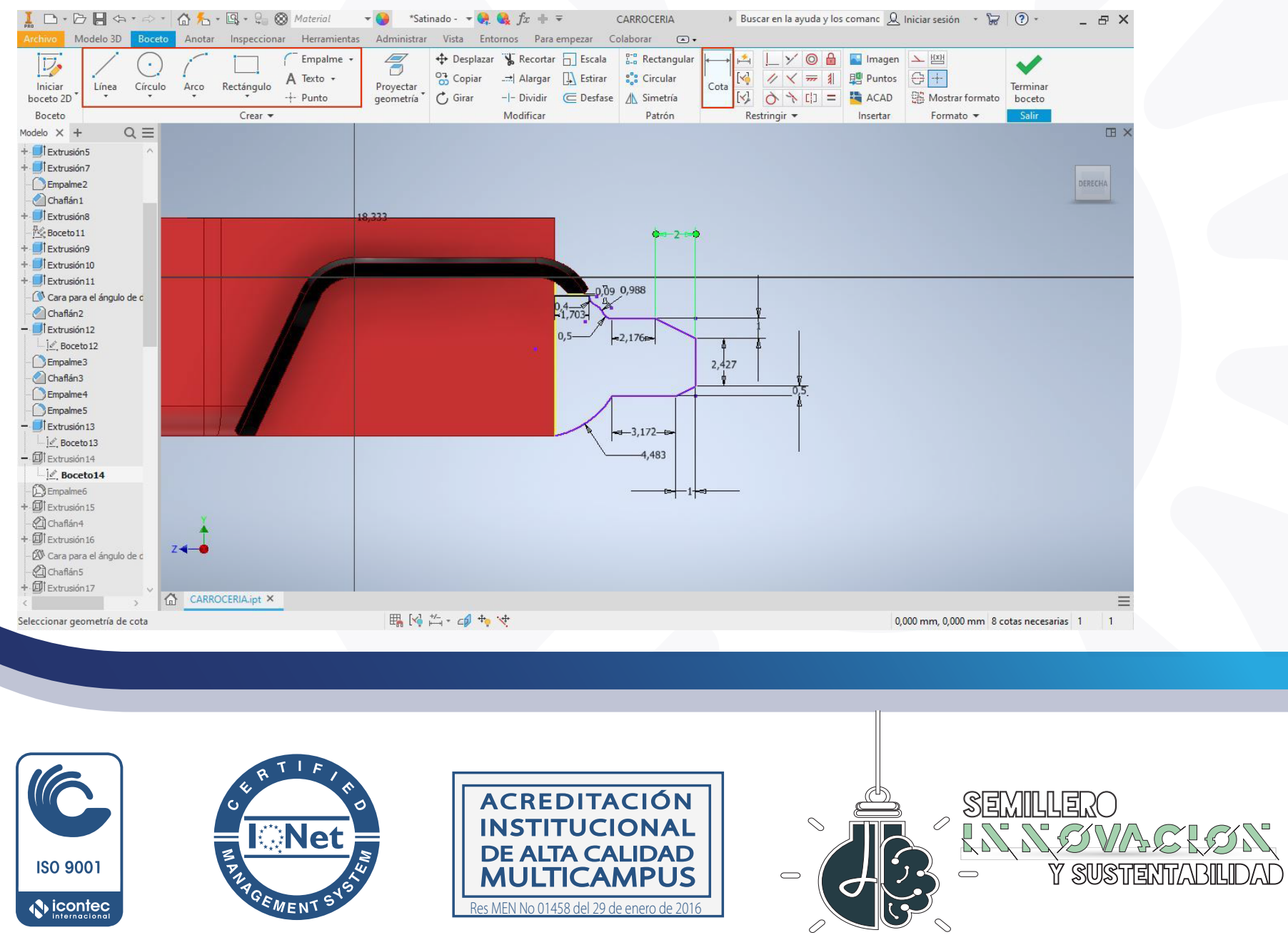


\section{Procedimiento}

Crear una extrucción sobre el boceto activo (visible) con única dirección a una distancia a la cara izquierda $(17,5 \mathrm{~mm})$.

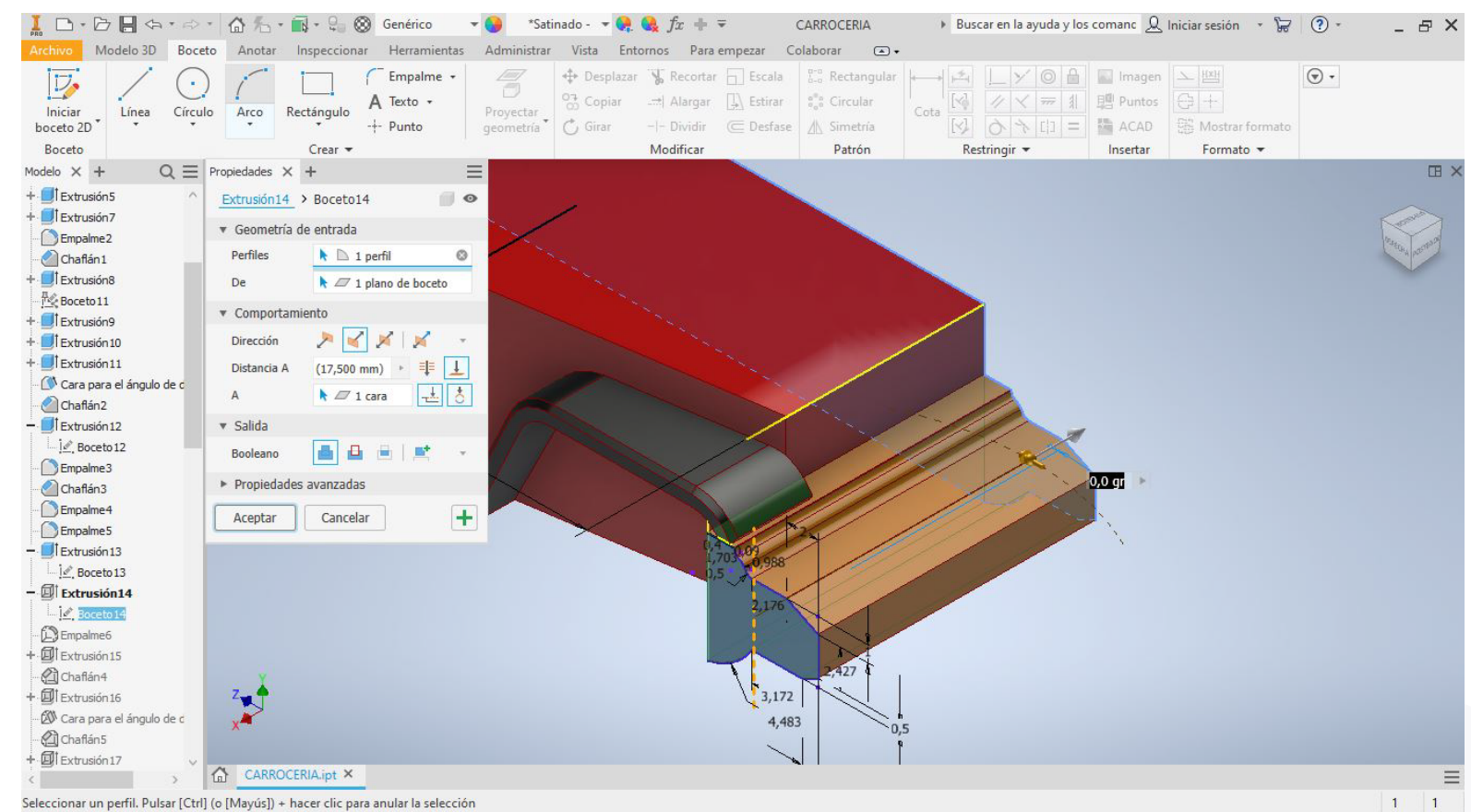

Crear un empalme de $5 \mathrm{~mm}$ en la arista vertical esquinera del parachoques frontal del Jeep.
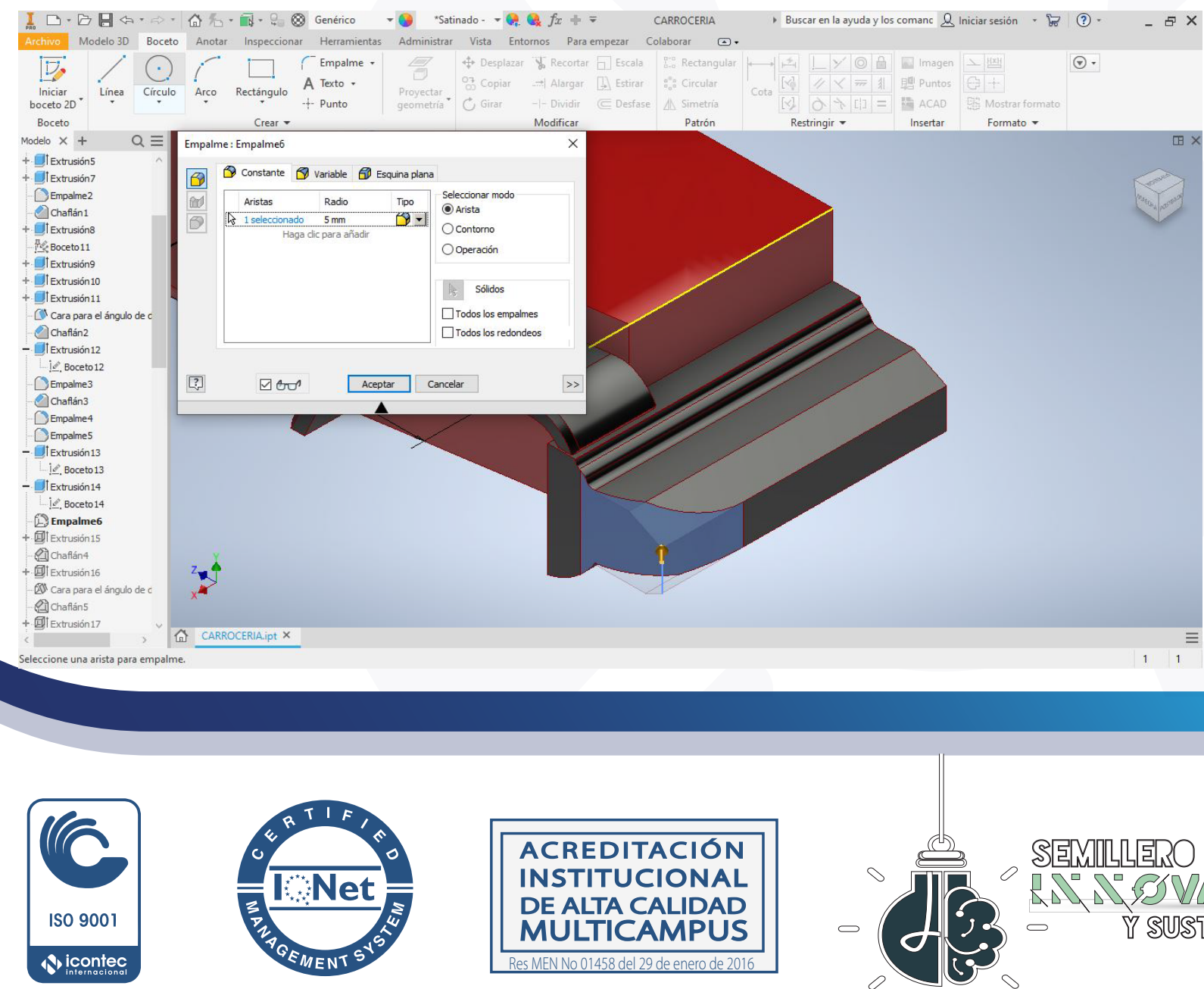

ACREDITACION

INSTITUCIONAL

DE ALTA CALIDAD

MULTICAMPUS

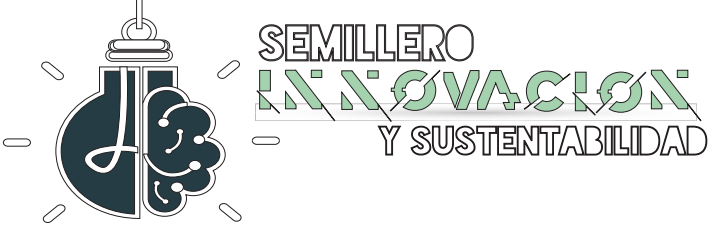




\section{Procedimiento}

Crear un boceto en la vista superior sobre la carrocería del Jeep con ayuda de líneas, cotas y proyección de geometría.

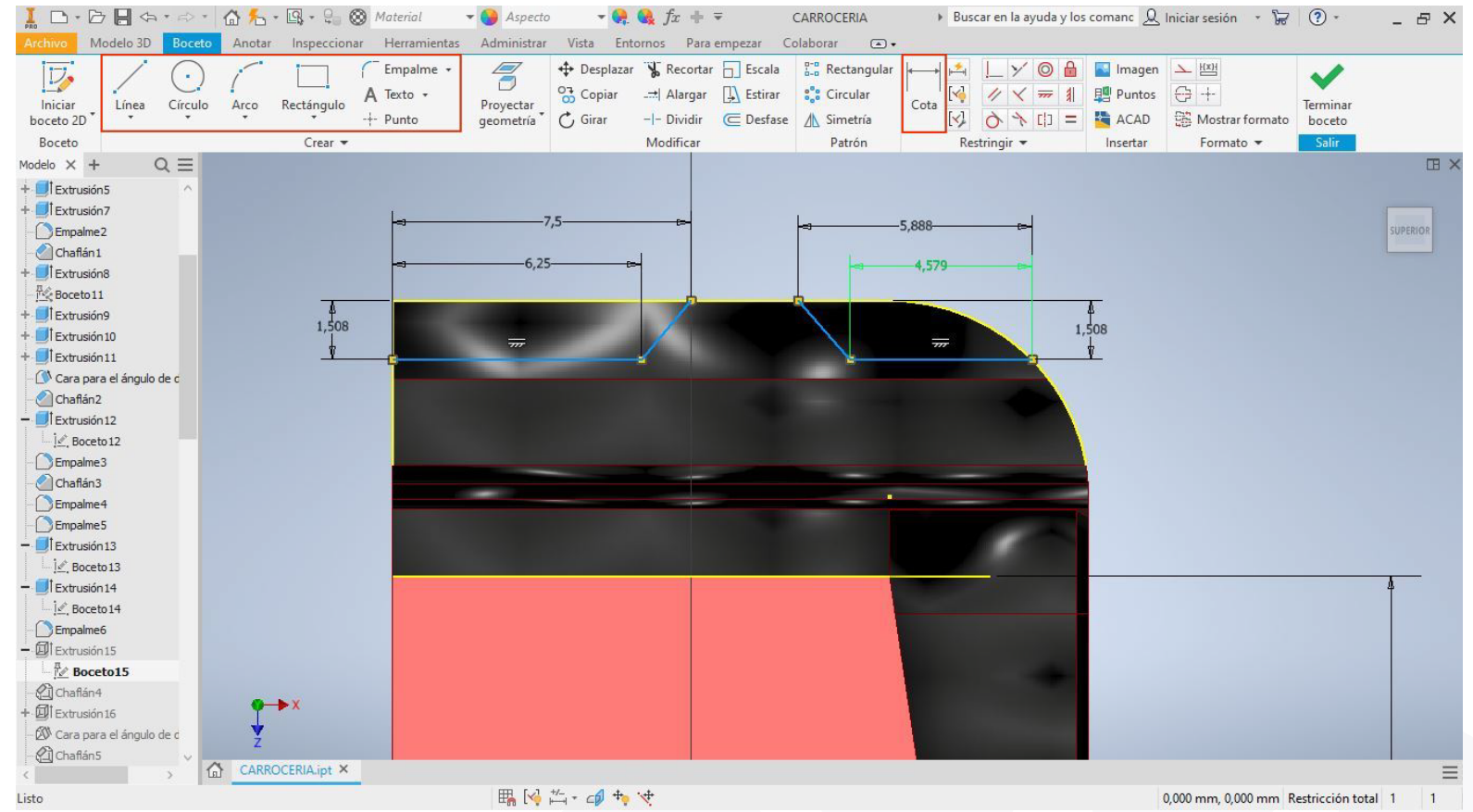

Crear una extrucción de vaciado sobre el boceto activo (visible) con dirección única a una distancia de $9 \mathrm{~mm}$.
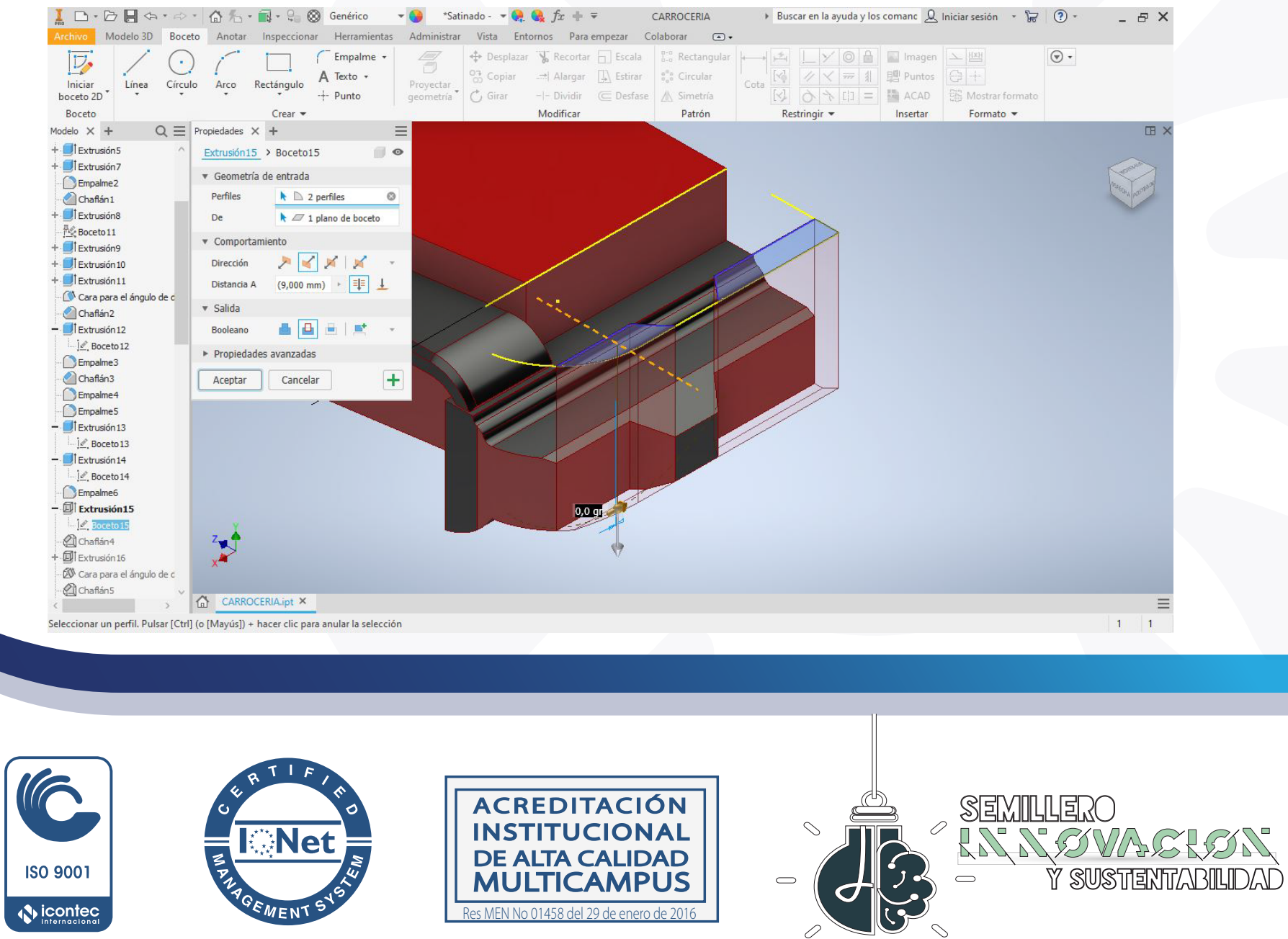


\section{Procedimiento}

Crear un chaflán de dos distancias sobre la arista vertical esquinera del parachoques frontal, distancia $1=0,8 \mathrm{~mm}$ y distancia $2=0,5 \mathrm{~mm}$.

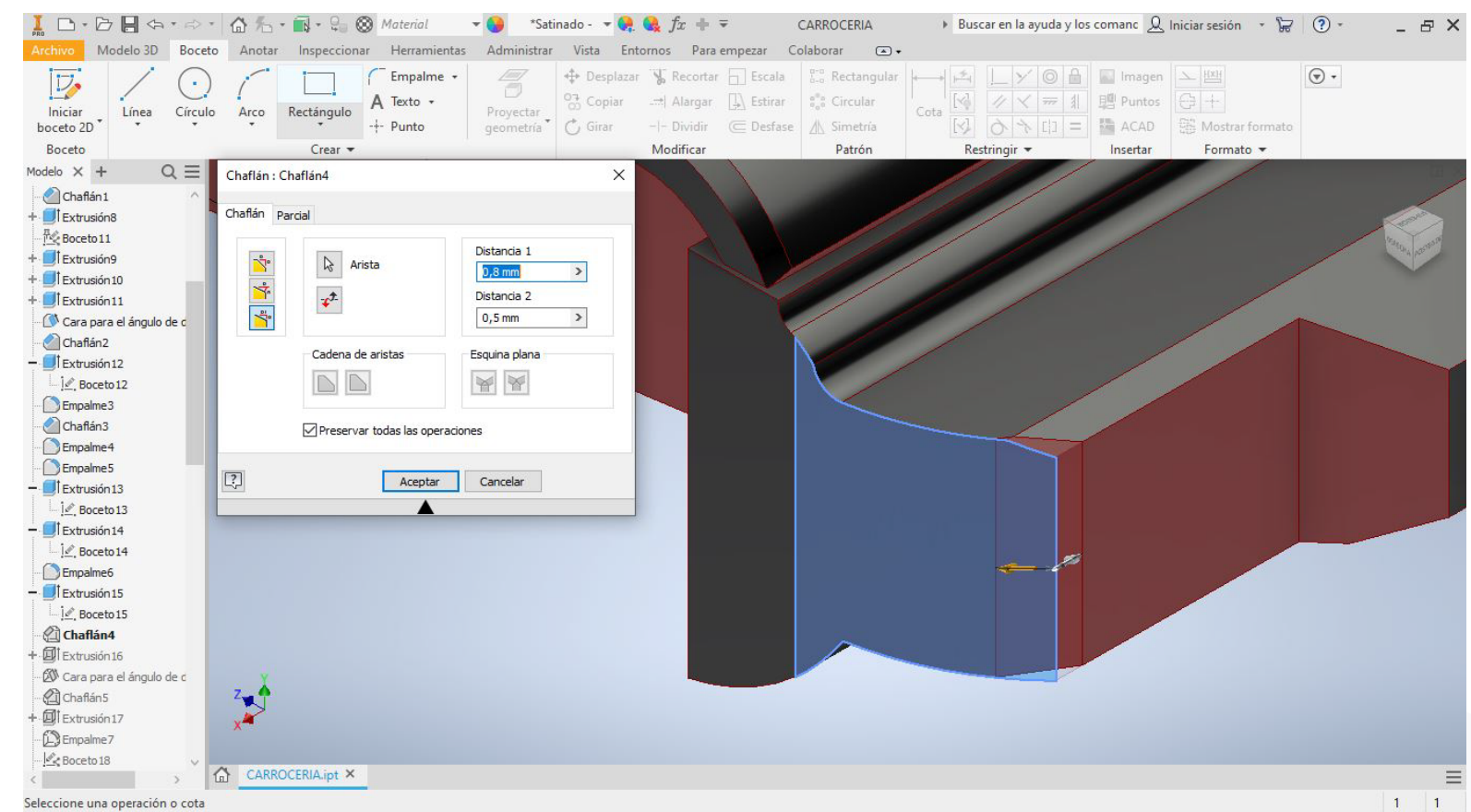

Crear un boceto en la vista frontal sobre la carrocería del Jeep con ayuda de un rectángulo de 2,452 mm x 1,255 mm, cotas y proyectar geometría, como se observa en la ilustración.
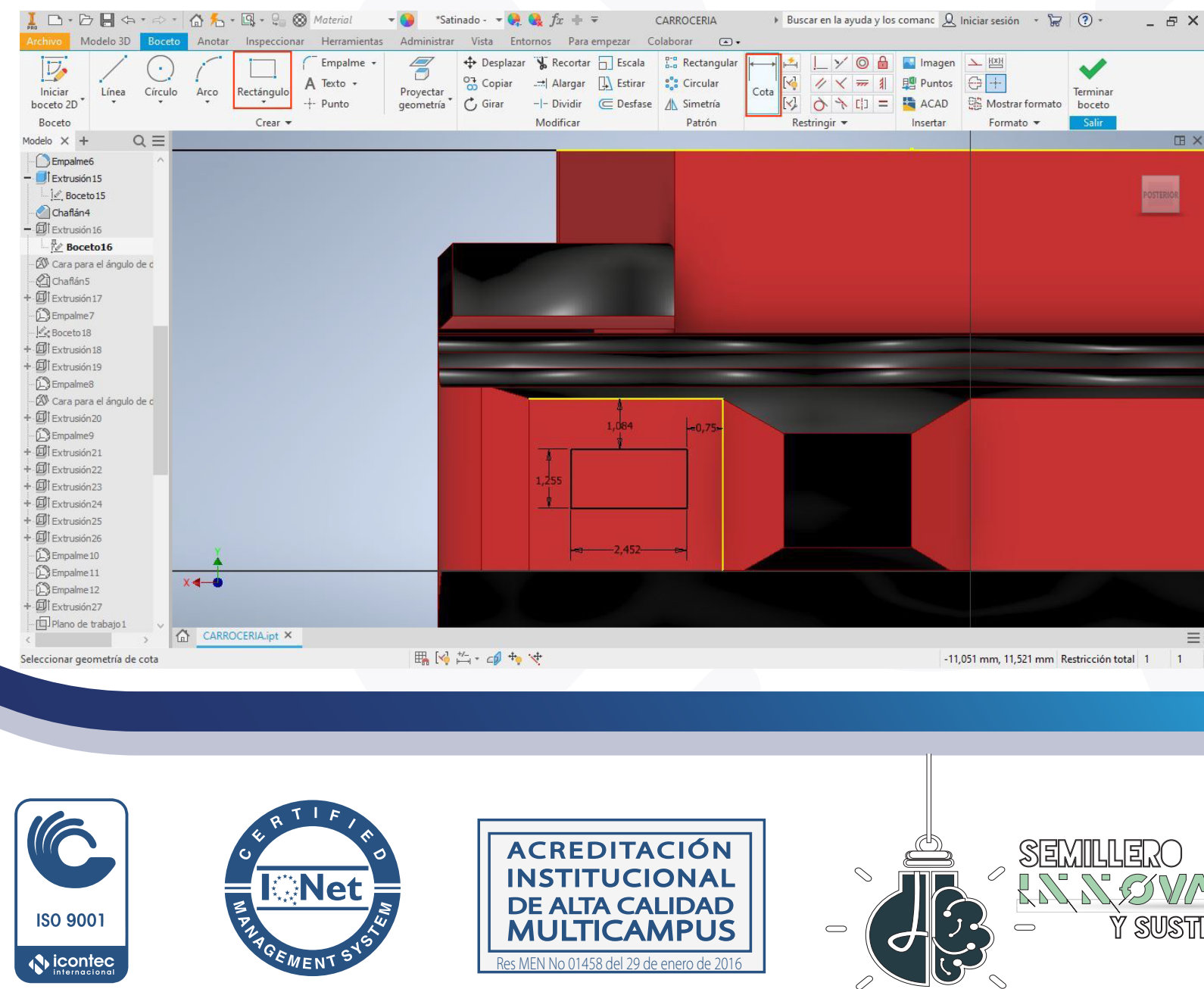

ACREDITACION INSTITUCIONAL DE ALTA CALIDAD MULTICAMPUS 


\section{Procedimiento}

Crear una extrucción de vaciado sobre el boceto activo (visible) con única dirección a una distancia de $1,5 \mathrm{~mm}$.

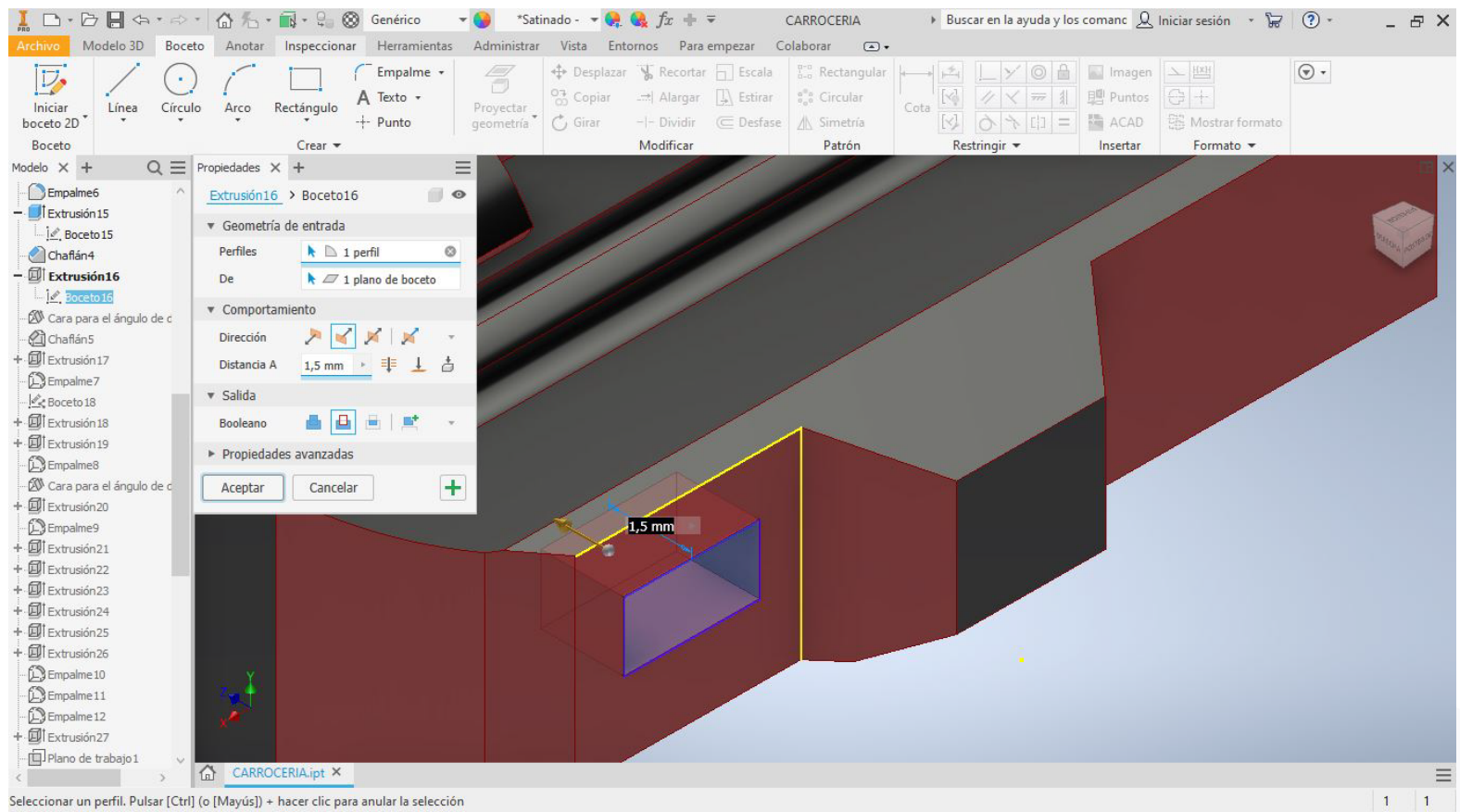

Crear un ángulo de $45^{\circ}$ de salida, seleccionando las caras interiores del cubo vacío.
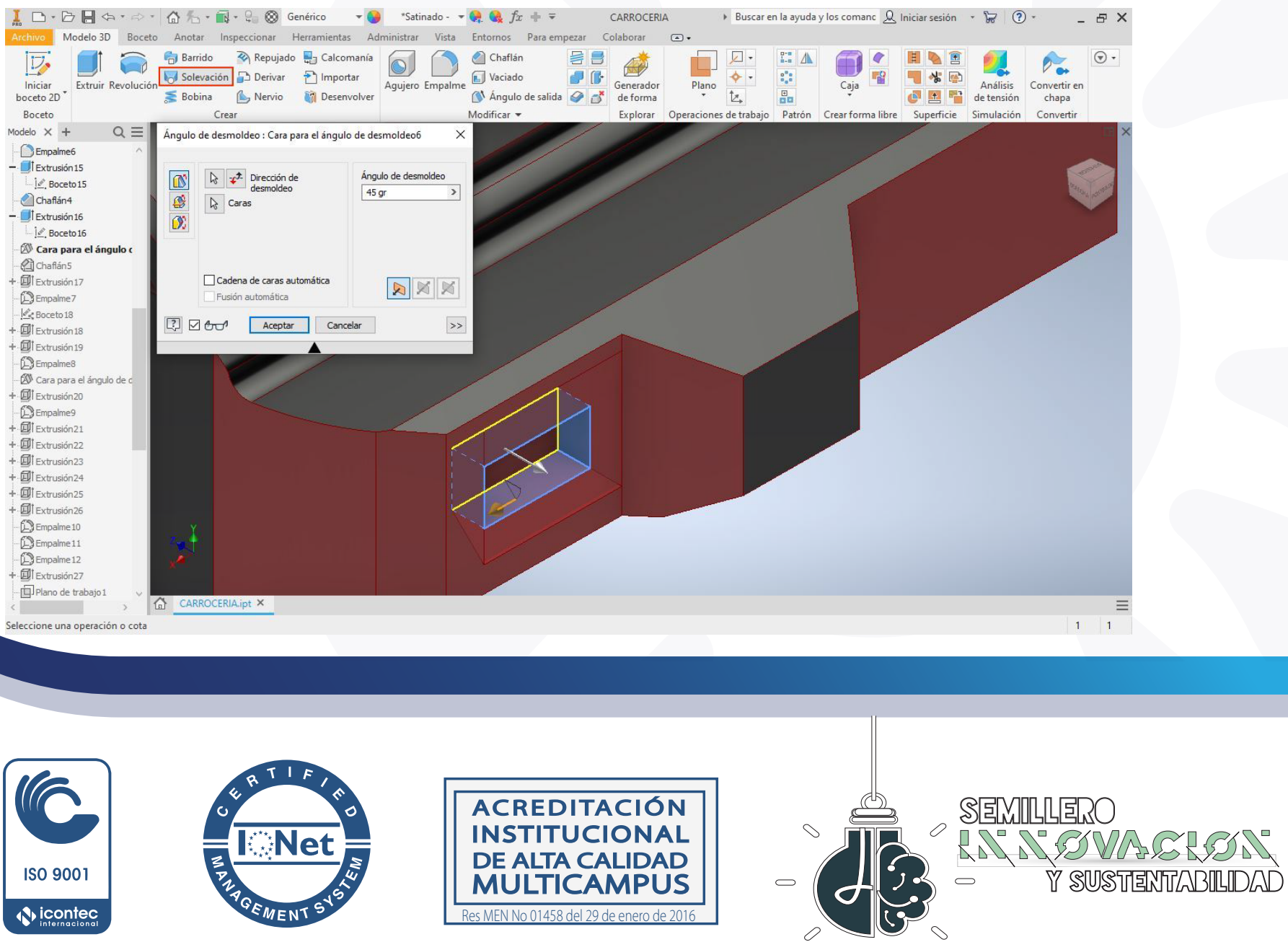


\section{Procedimiento}

Crear un chaflán de 0,3 mm sobre las aristas del cubo vacío.

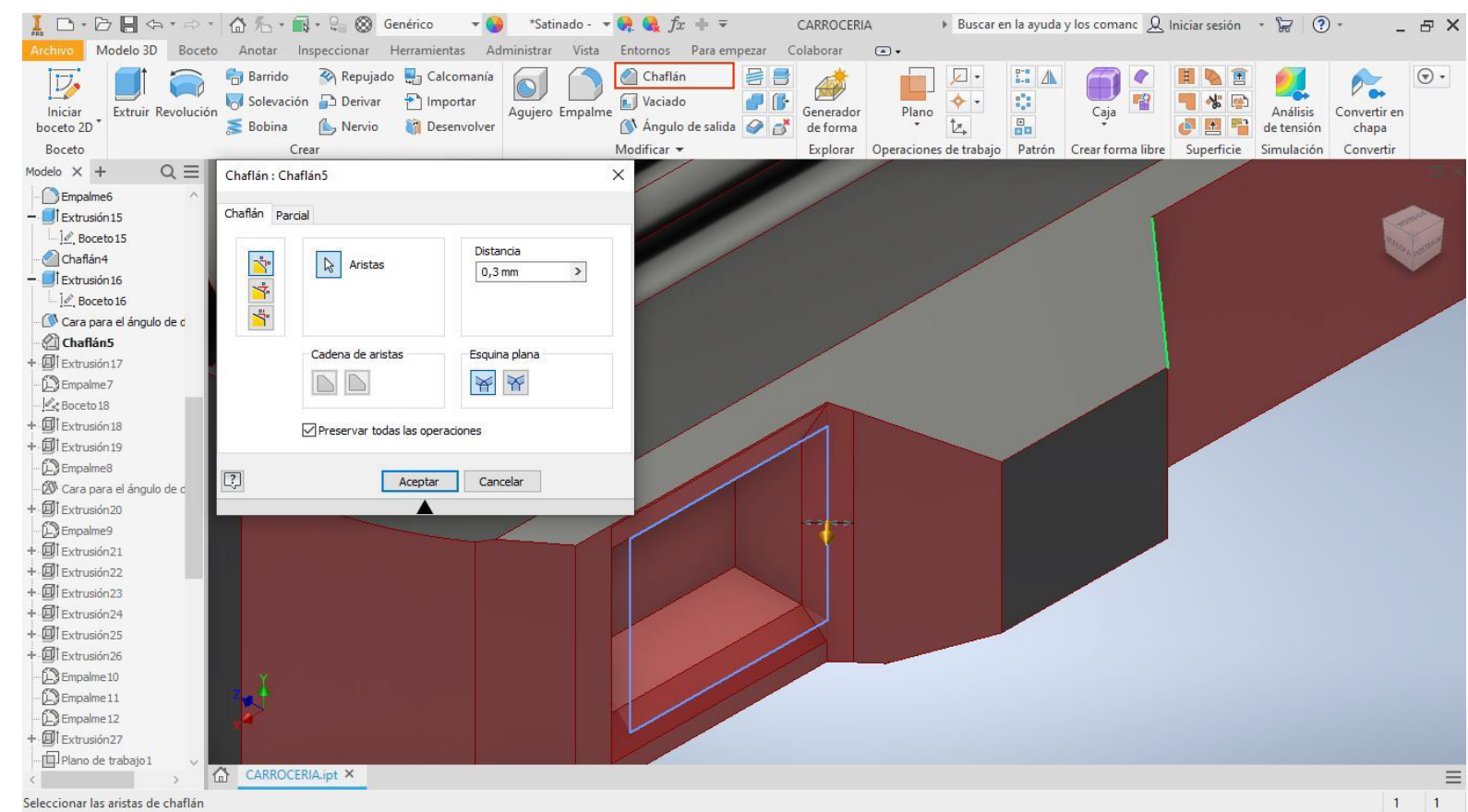

Crear un boceto en la vista frontal sobre el interior del cubo vacío en el parachoques frontal del Jeep por medio de un círculo con radio de $1 \mathrm{~mm}$, con la herramienta cota y proyectar geometría se ubica el boceto como se observa en la ilustración.

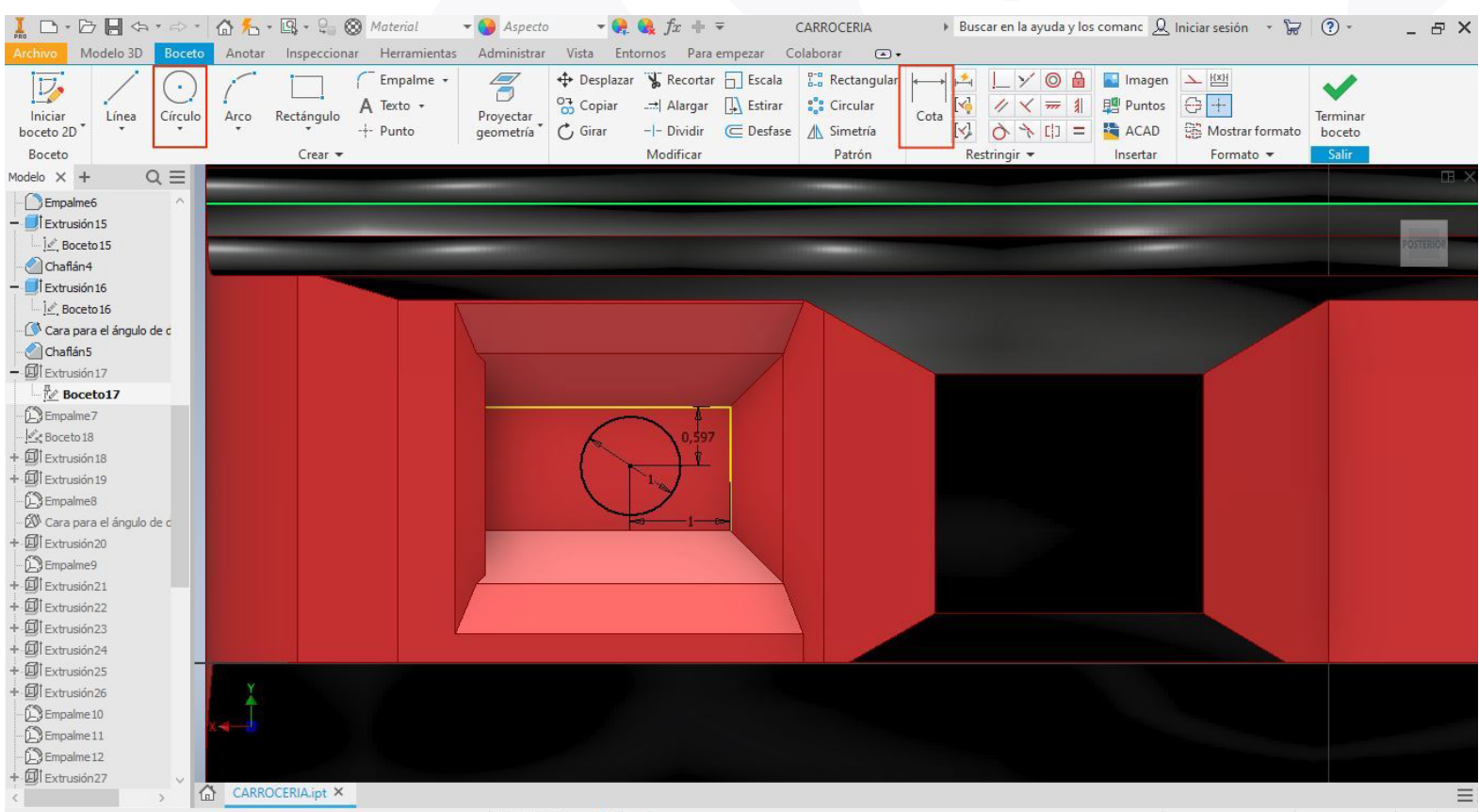

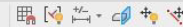

$5,640 \mathrm{~mm}, 6,591 \mathrm{~mm}$ Restricción total 1
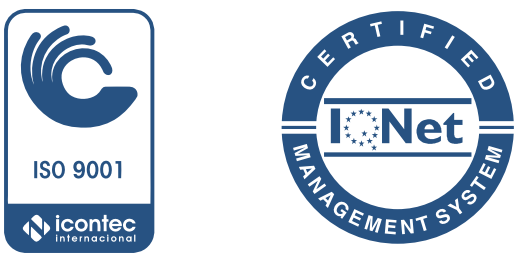

ACREDITACION INSTITUCIONAL DE ALTA CALIDAD MULTICAMPUS

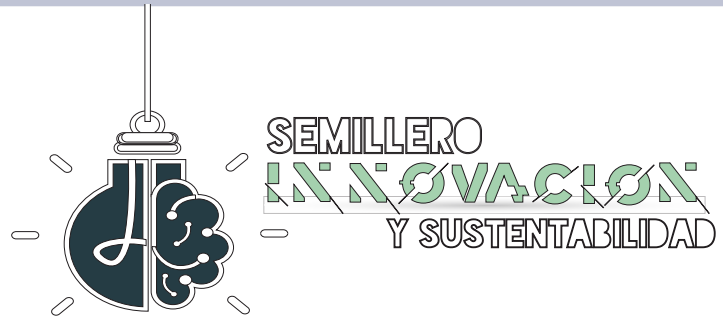




\section{Procedimiento}

Crear una extrucción sobre el boceto activo (visible) con única dirección a una distancia de $0,1 \mathrm{~mm}$.

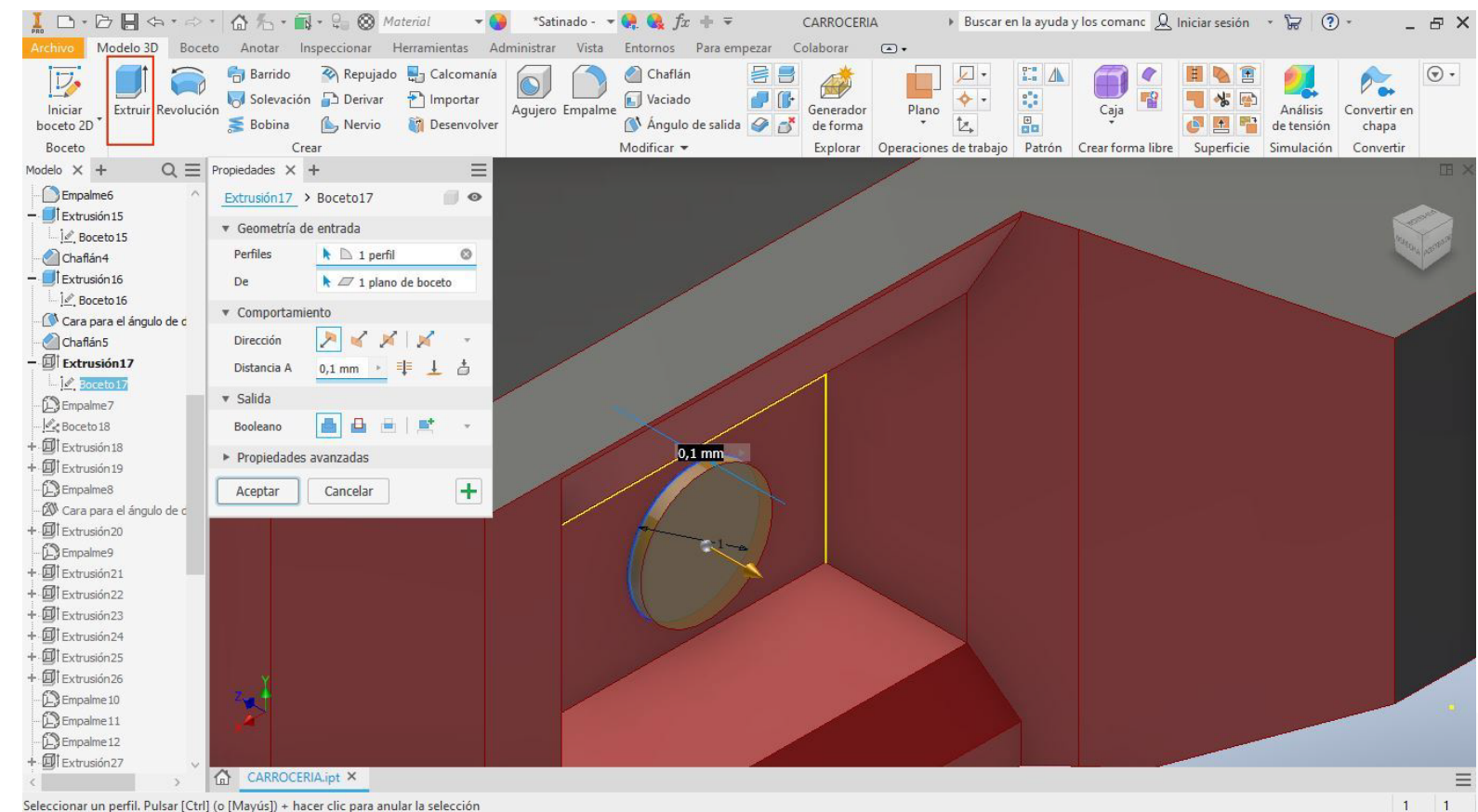

Crear un empalme de 0,2 mm sobre la arista del cilindro extruido anteriormente.

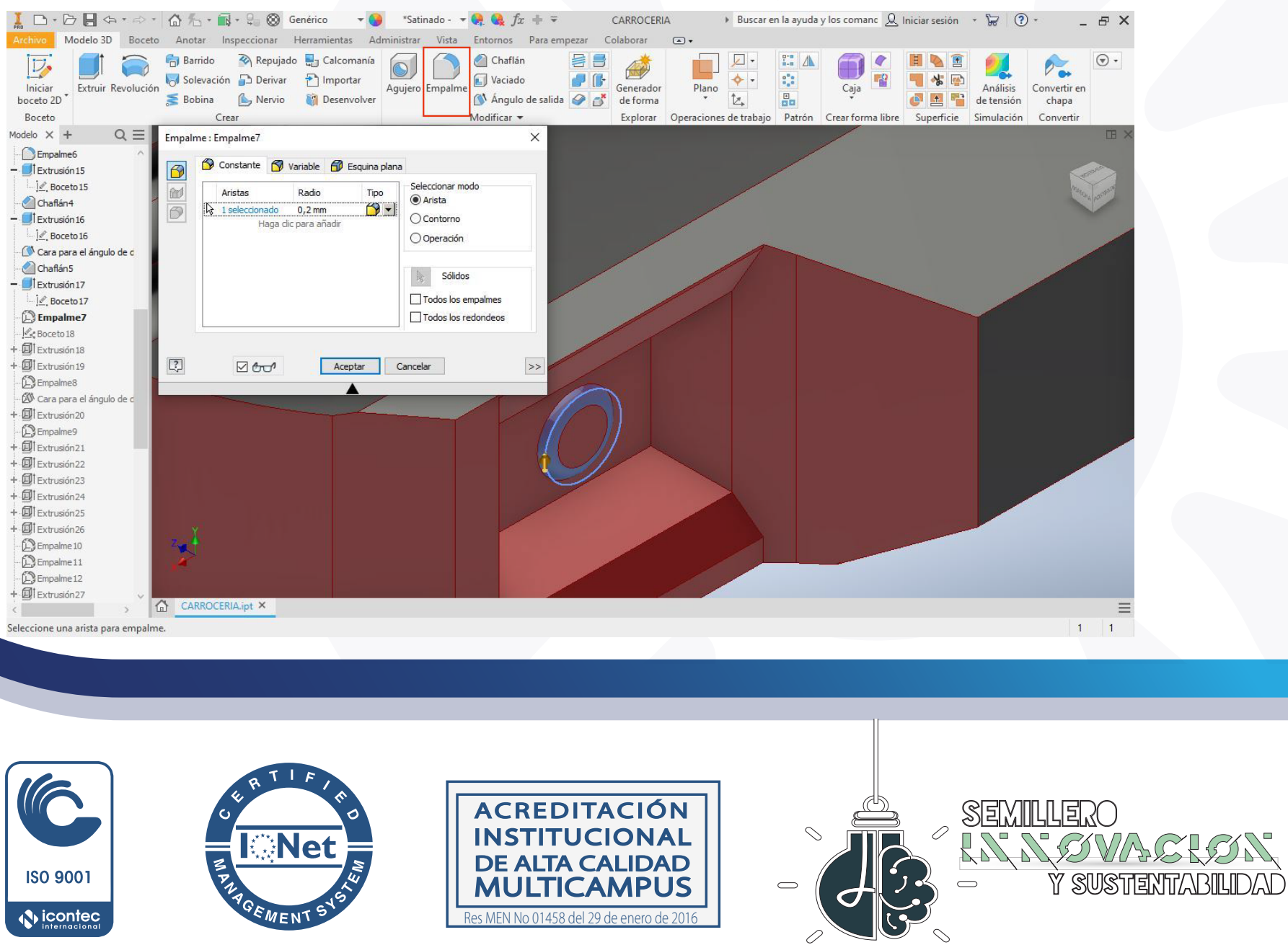




\section{Procedimiento}

Crear un boceto en la vista derecha sobre la carrocería del Jeep con ayuda de líneas curvas, desfase al exterior de 0,1 mm y por medio de la herramienta cota y proyectar geometría se parametrizará el diseño 2D.

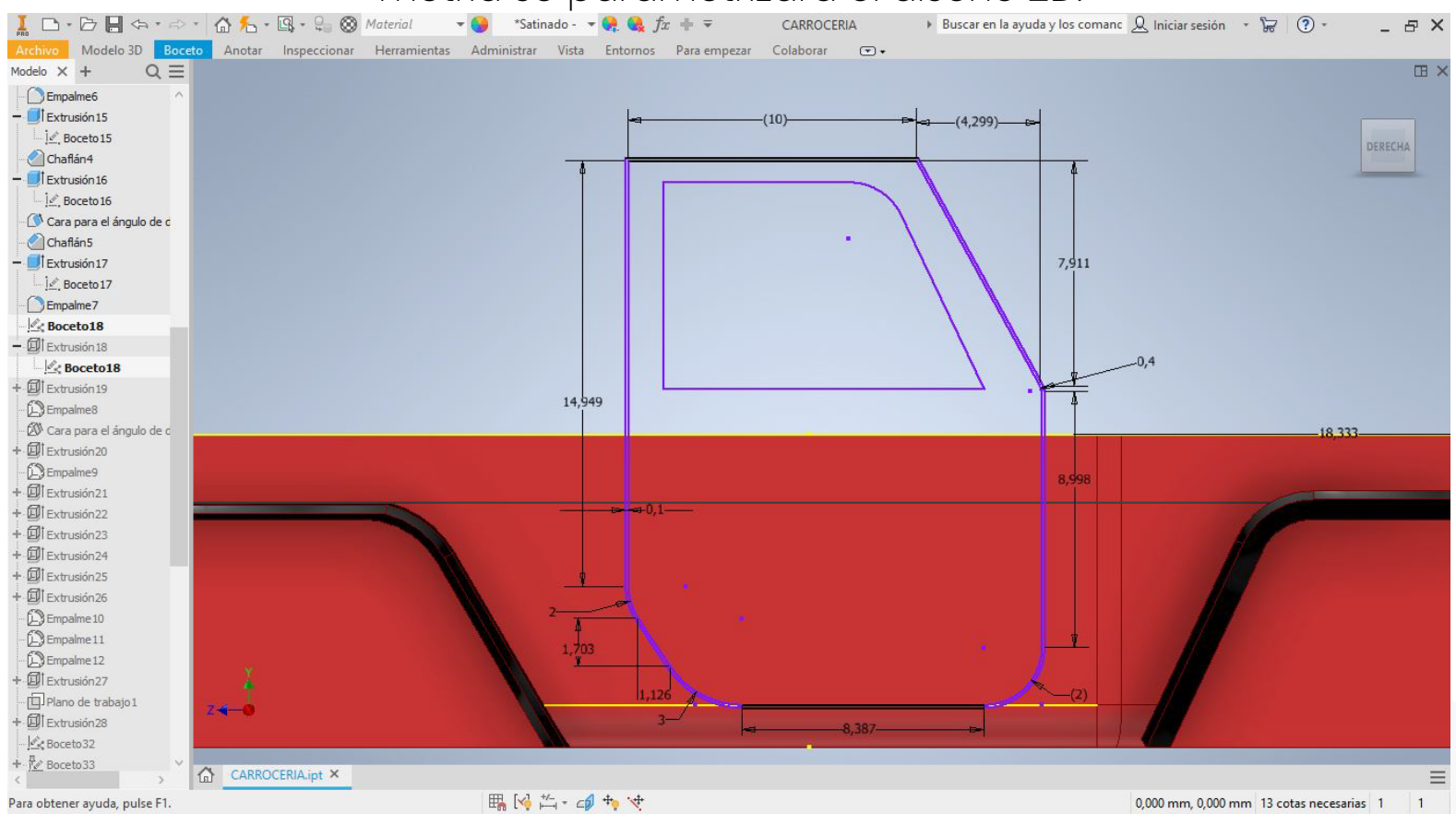

Crear un boceto en la vista derecha sobre la carrocería del Jeep con ayuda de líneas curvas y cotas como se observa en la ilustración.
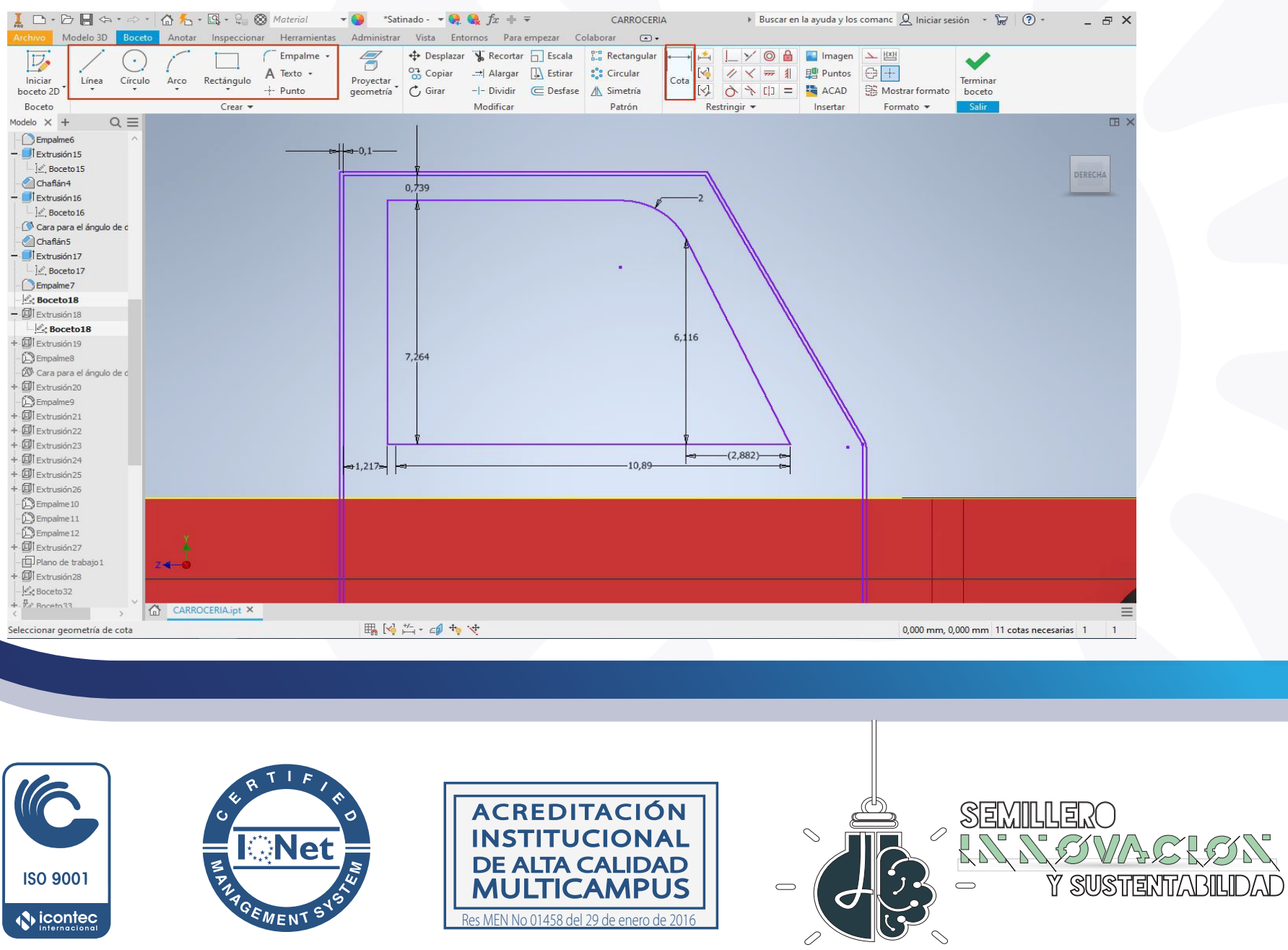


\section{Procedimiento}

Crear un boceto en la vista superior sobre la carrocería del Jeep con ayuda de líneas, cotas y proyectar geometría como se observa en la ilustración.

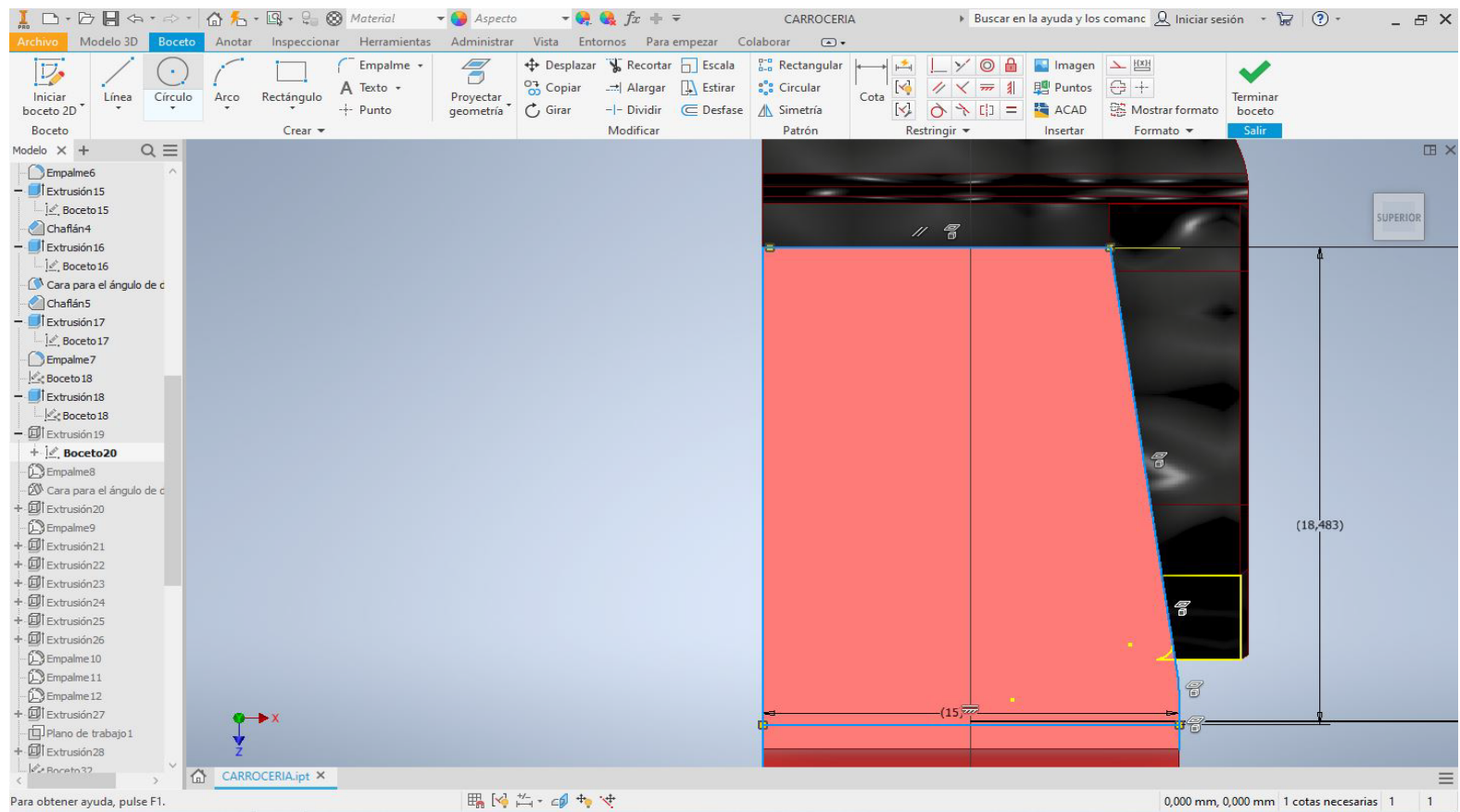

Crear una extrucción sobre el boceto activo (visible) con dirección única a una distancia de 1 mm, esta pieza será el capó del Jeep.
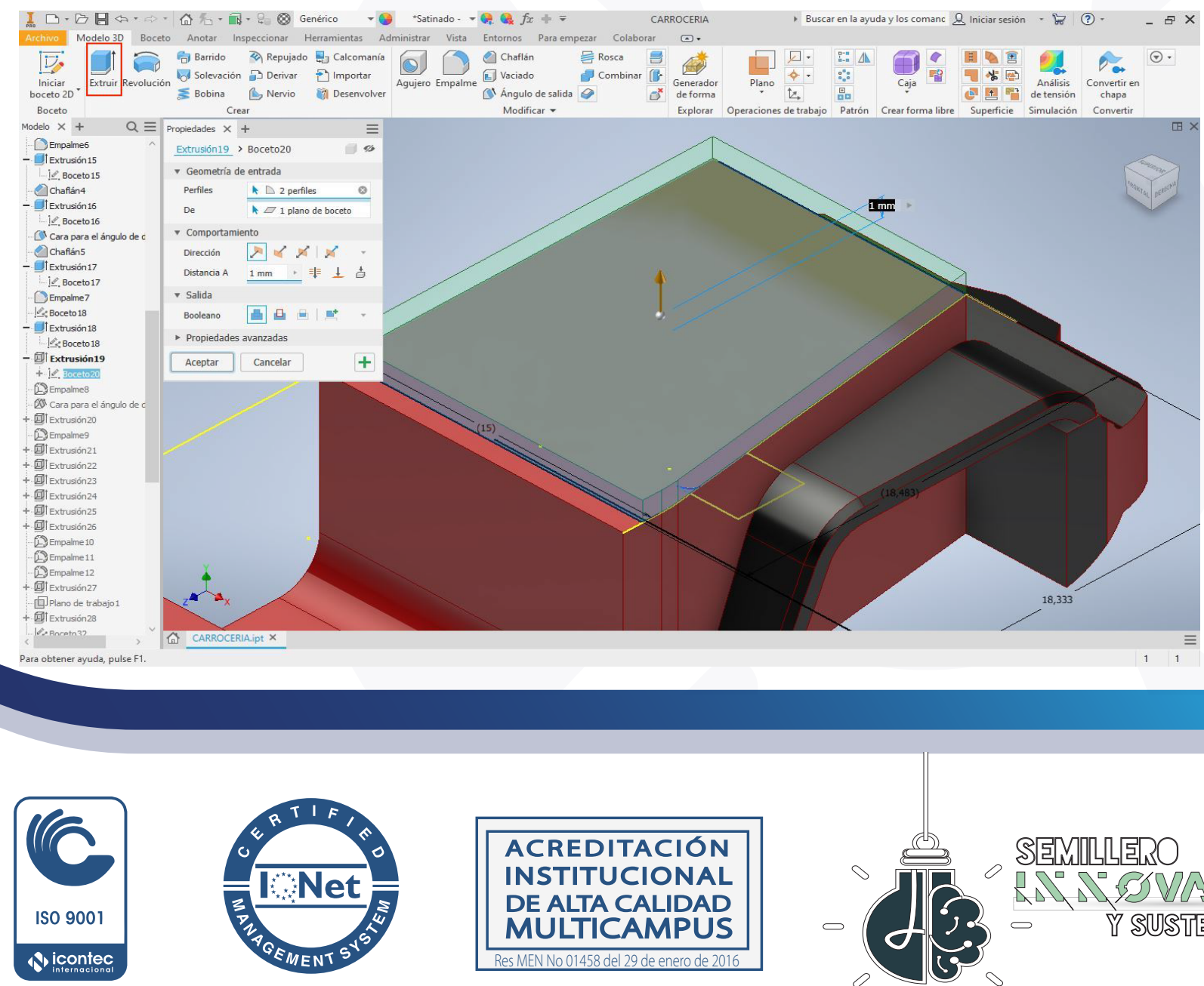

ACREDITACION INSTITUCIONAL DE ALTA CALIDAD MULTICAMPUS

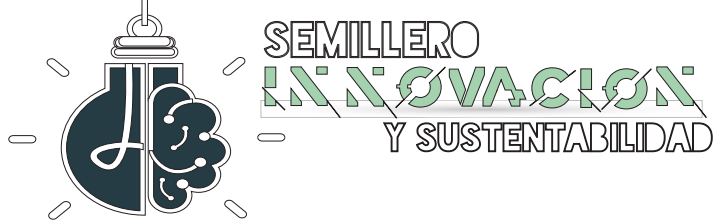




\section{Procedimiento}

Crear un empalme de $1 \mathrm{~mm}$ en la arista horizontal esquinera del capó del Jeep.

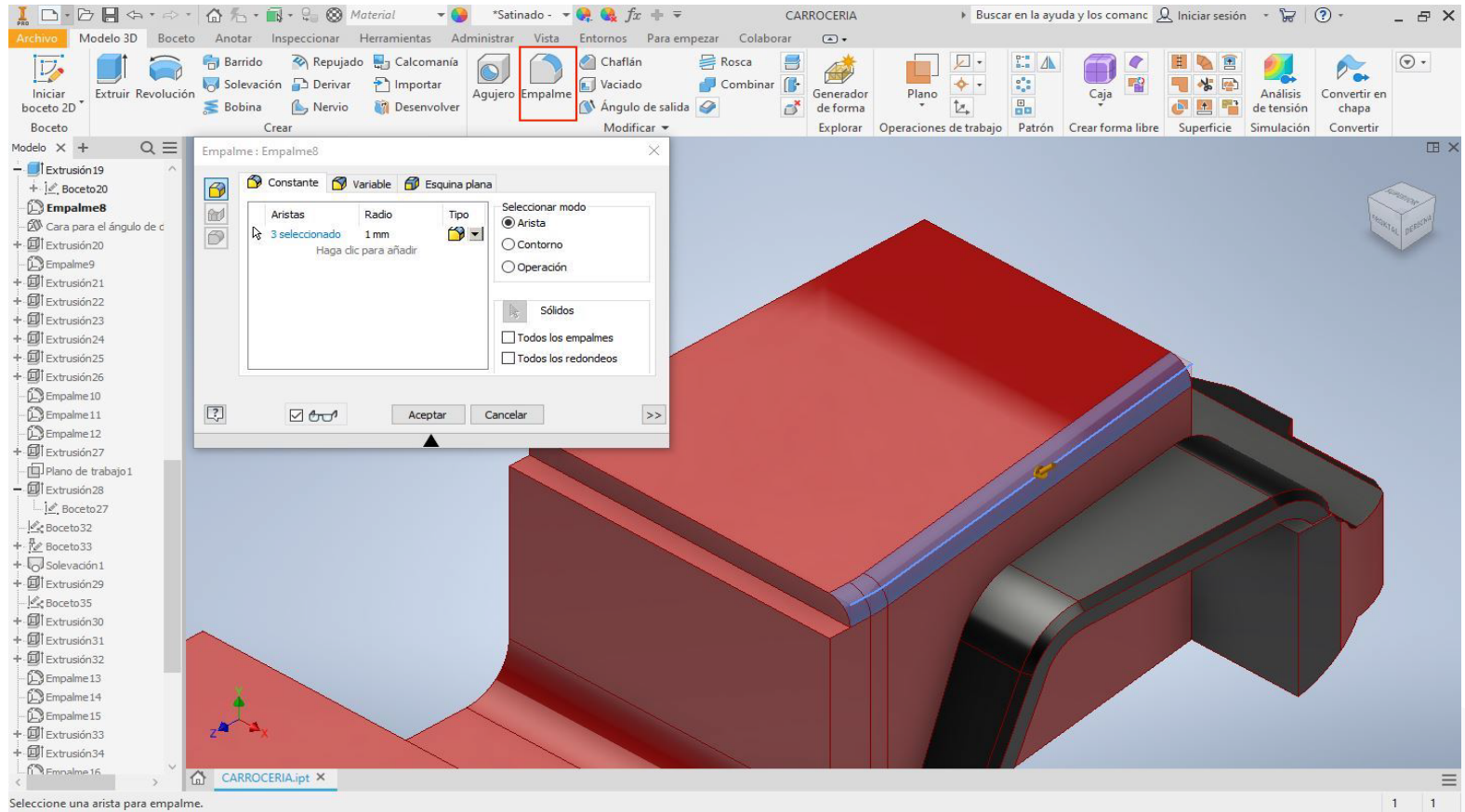

Crear un ángulo de $8^{\circ}$ de salida seleccionando la cara frontal de la carrocería.
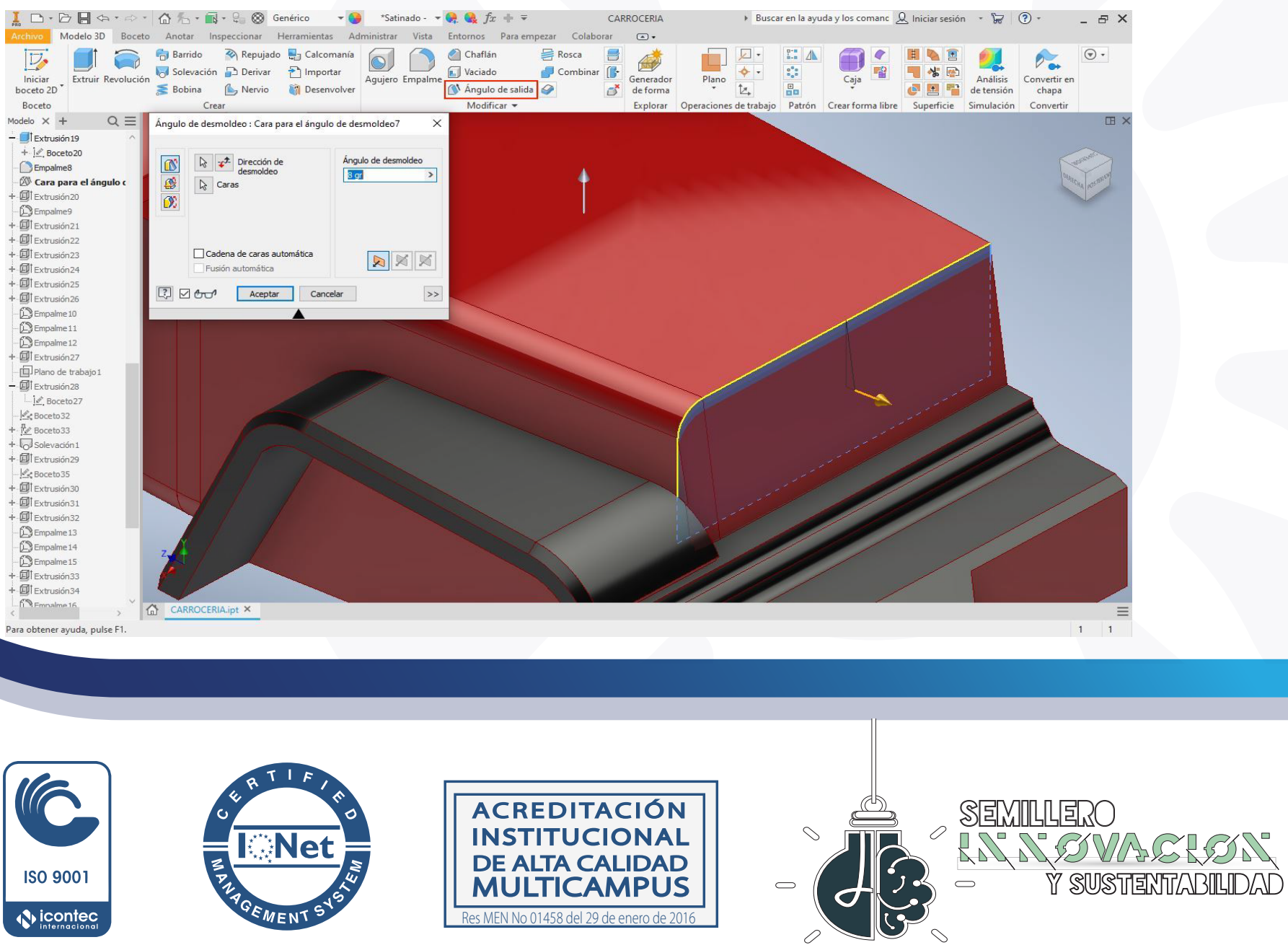


\section{Procedimiento}

Crear un boceto en la vista frontal sobre la carrocería frontal del Jeep, con ayuda de un círculo de radio $3 \mathrm{~mm}$, usando las herramientas cota y proyectar geometría se ubicará el diseño 2D como se observa en la ilustración.

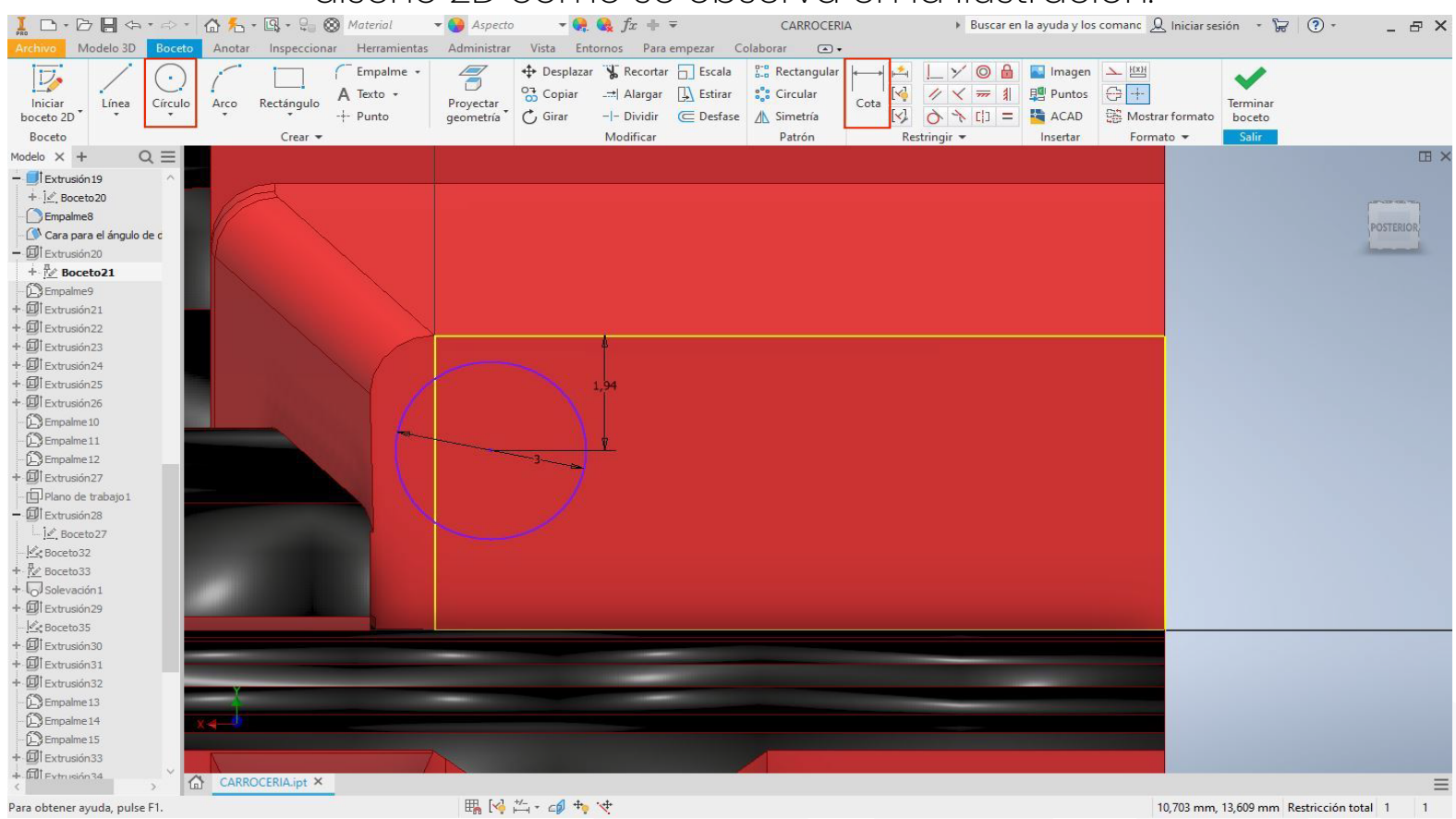

Crear una extrucción de corte sobre el boceto activo (visible) con dirección única a una distancia de 0,6 mm, esta pieza será el faro del Jeep.
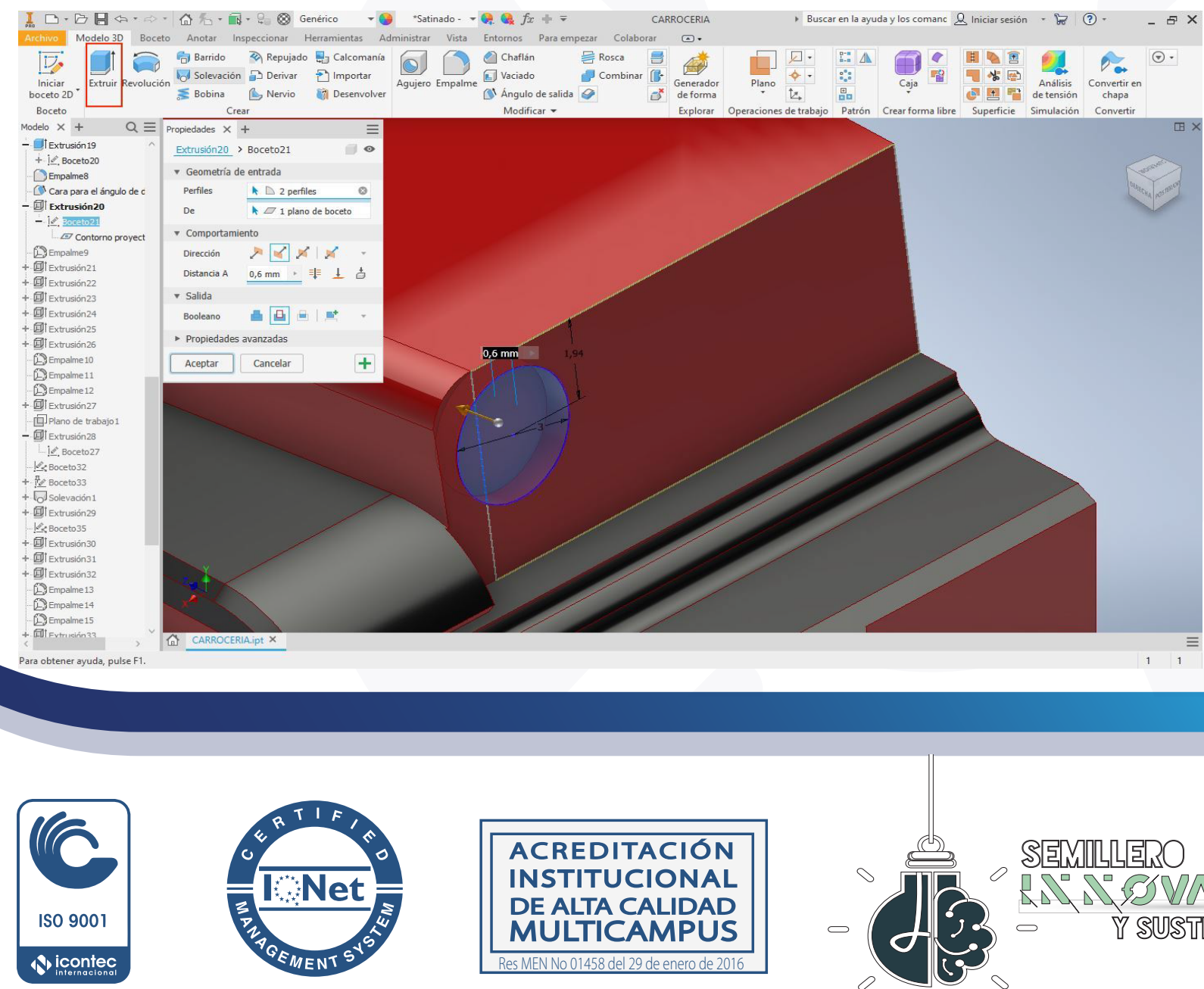

ACREDITACION INSTITUCIONAL DE ALTA CALIDAD MULTICAMPUS

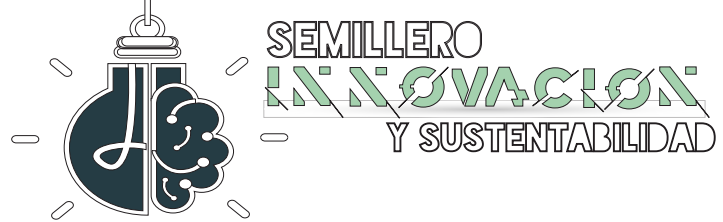




\section{Procedimiento}

Crear un boceto en la vista frontal sobre la carrocería frontal del Jeep con ayuda de una ranura de ancho 1,5 mm y de centro a centro de 3,5 mm, con las heramientas cota, proyectar geometría y patrón rectangular se realizará el boceto de la ilustración.

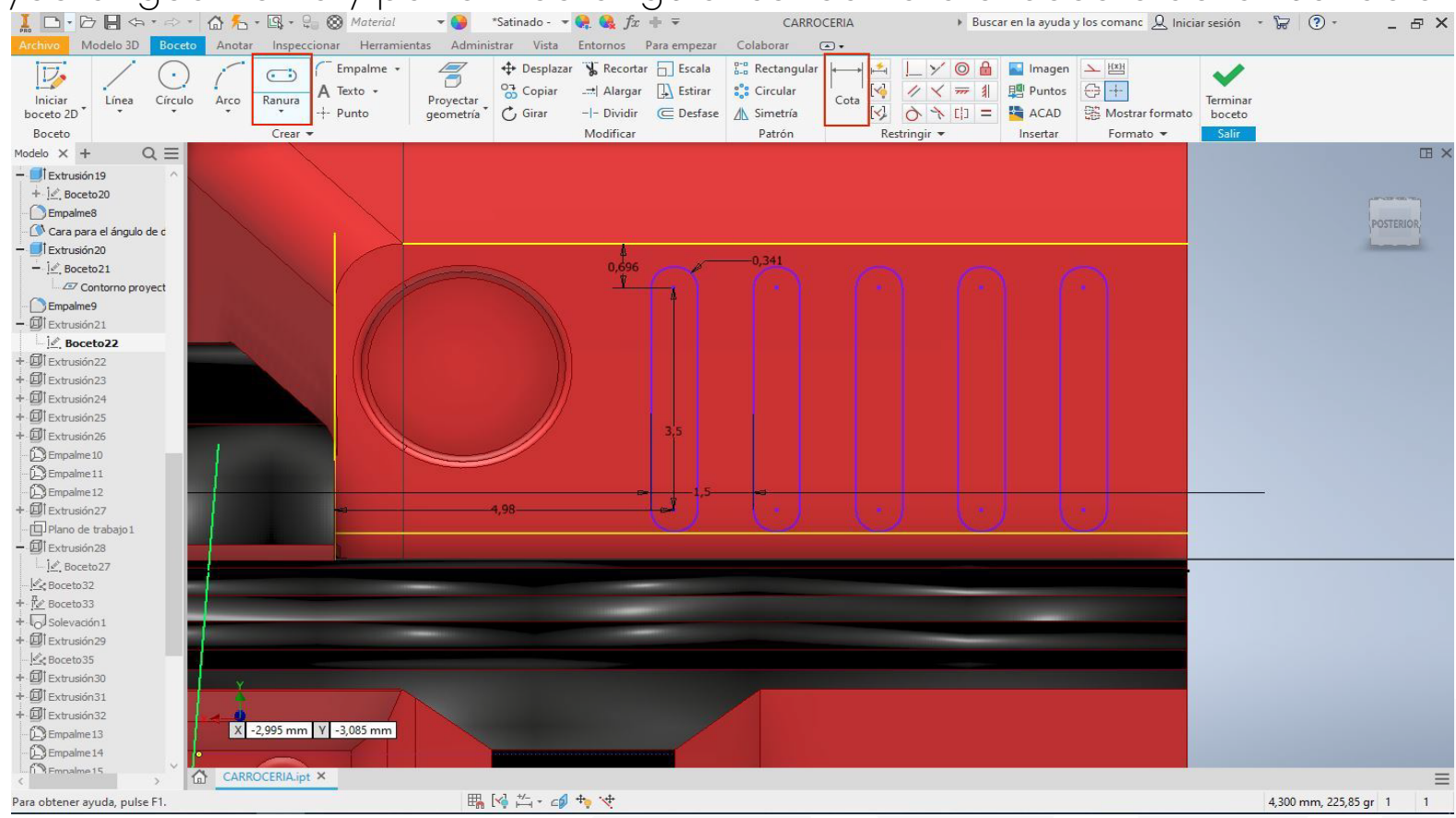

Crear un boceto en la vista superior de la carrocería del Jeep con ayuda de proyectar geometría y desfase d:0,667 mm como se observa en la ilustración.
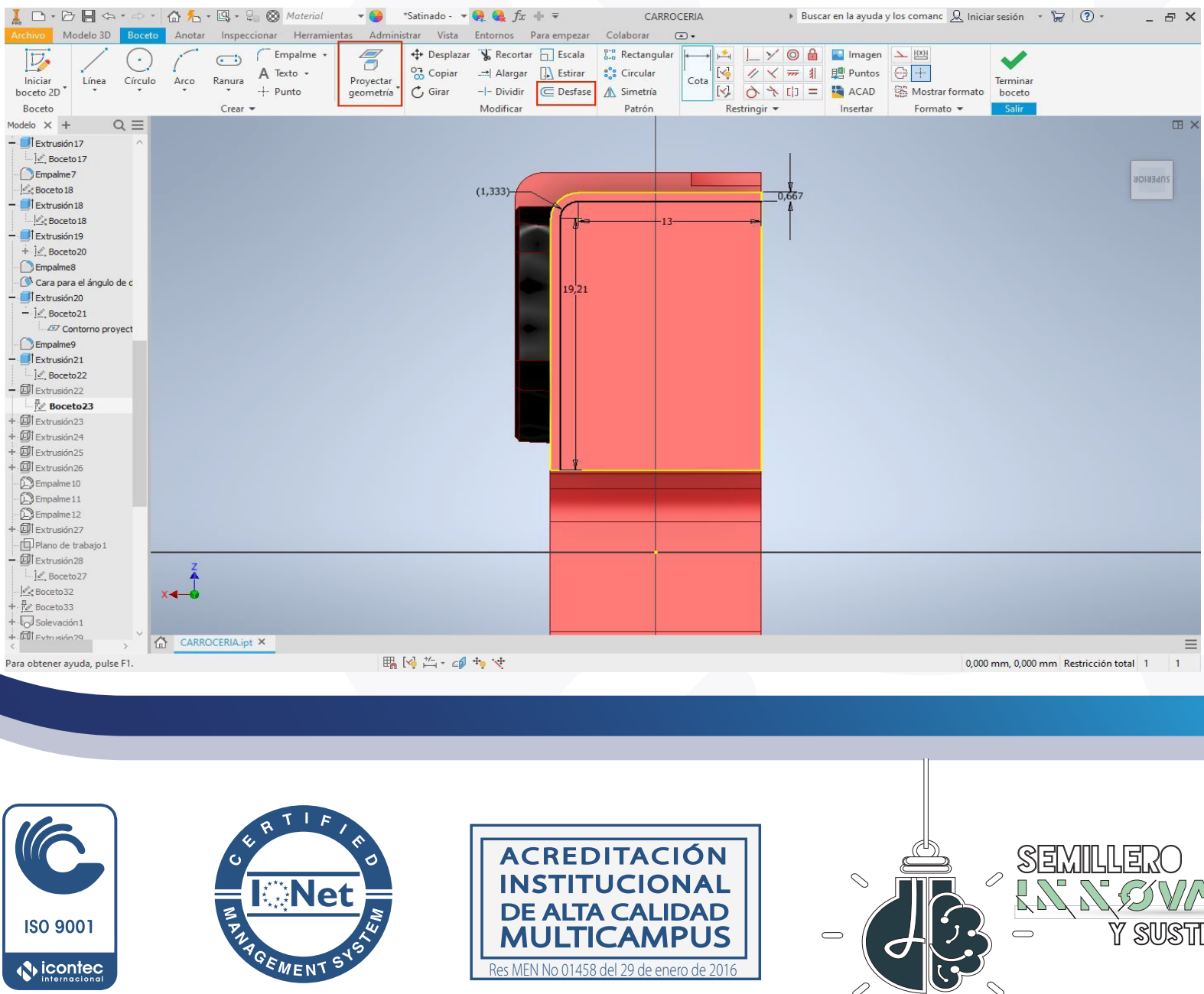

ACREDITACION INSTITUCIONAL DE ALTA CALIDAD MULTICAMPUS 


\section{Procedimiento}

Crear una extrucción sobre el boceto activo (visible) con única dirección a una distancia de $3 \mathrm{~mm}$.

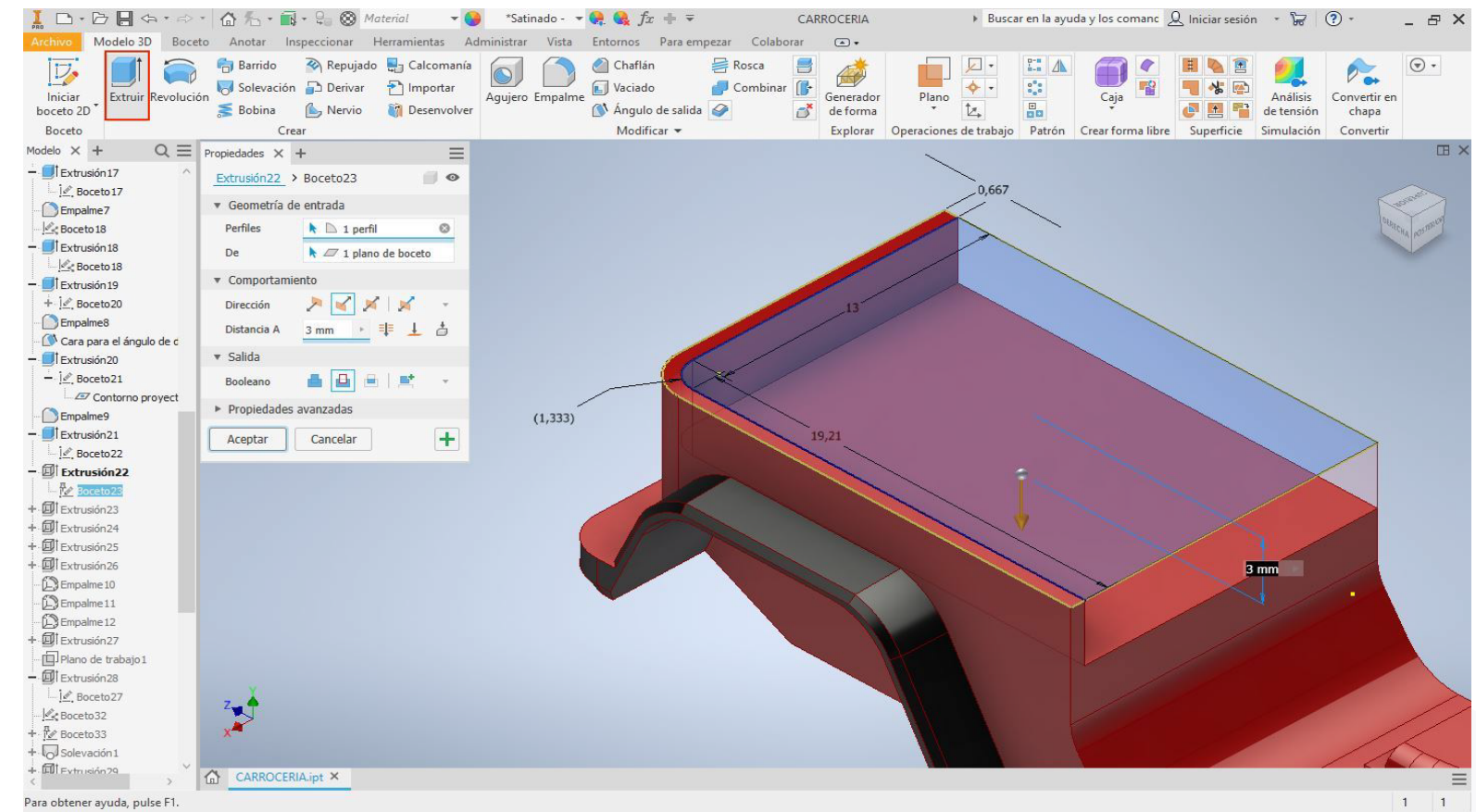

Retomar el boceto de la puerta.

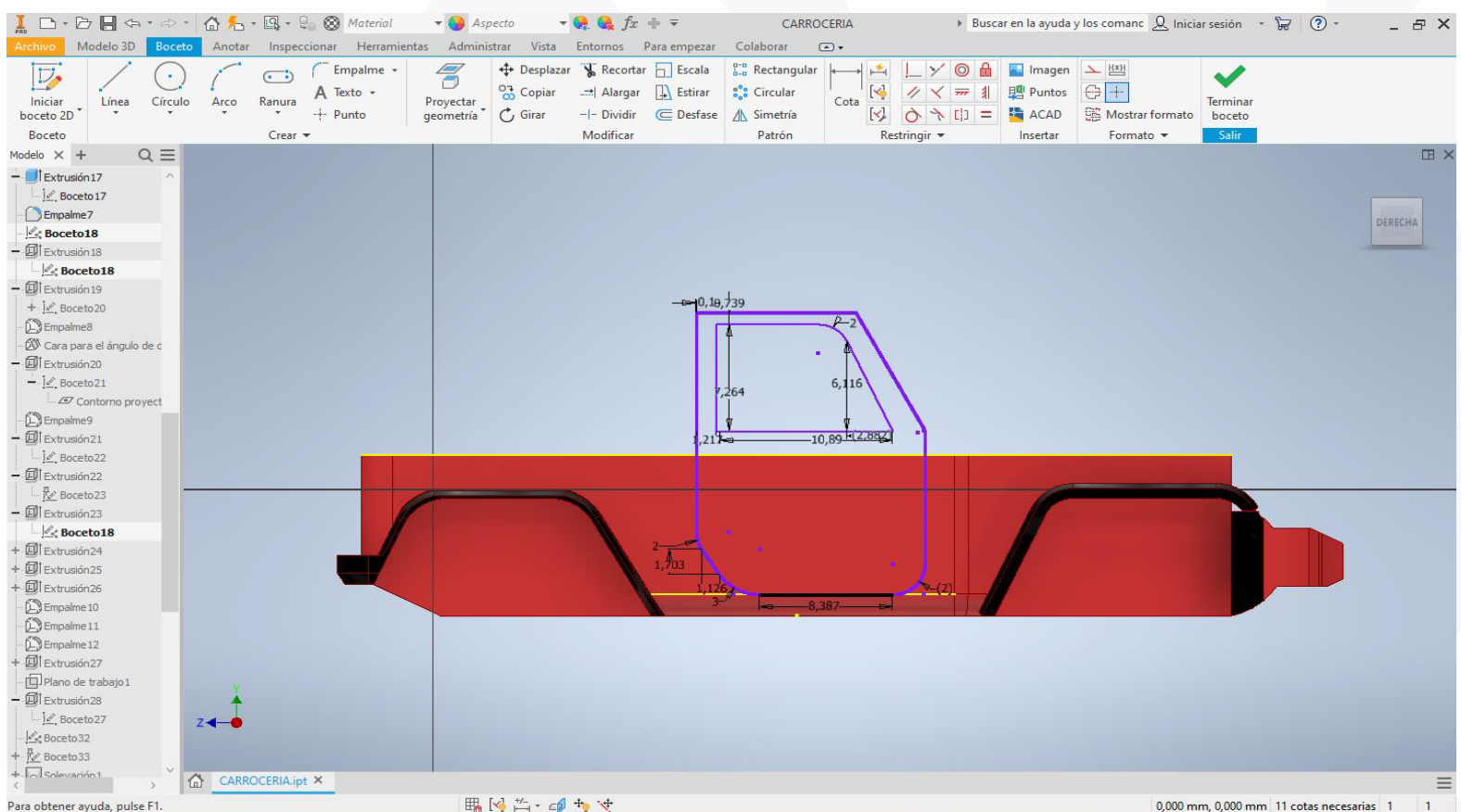

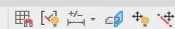
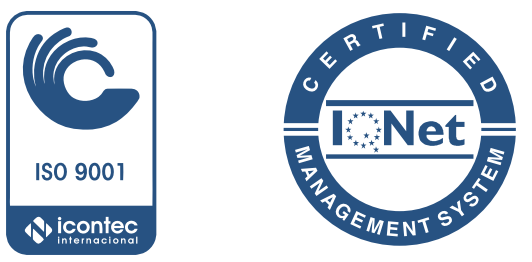

ACREDITACION INSTITUCIONAL DE ALTA CALIDAD MULTICAMPUS

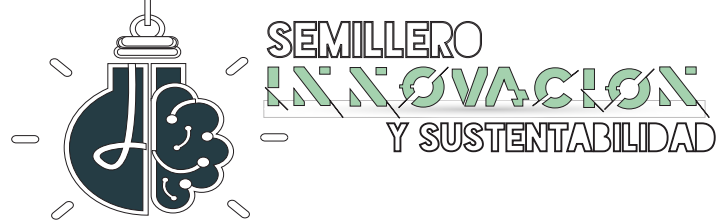




\section{Procedimiento}

Crear una extrucción sobre el boceto interior activo (visible) con única dirección a una distancia de 0,5 mm.

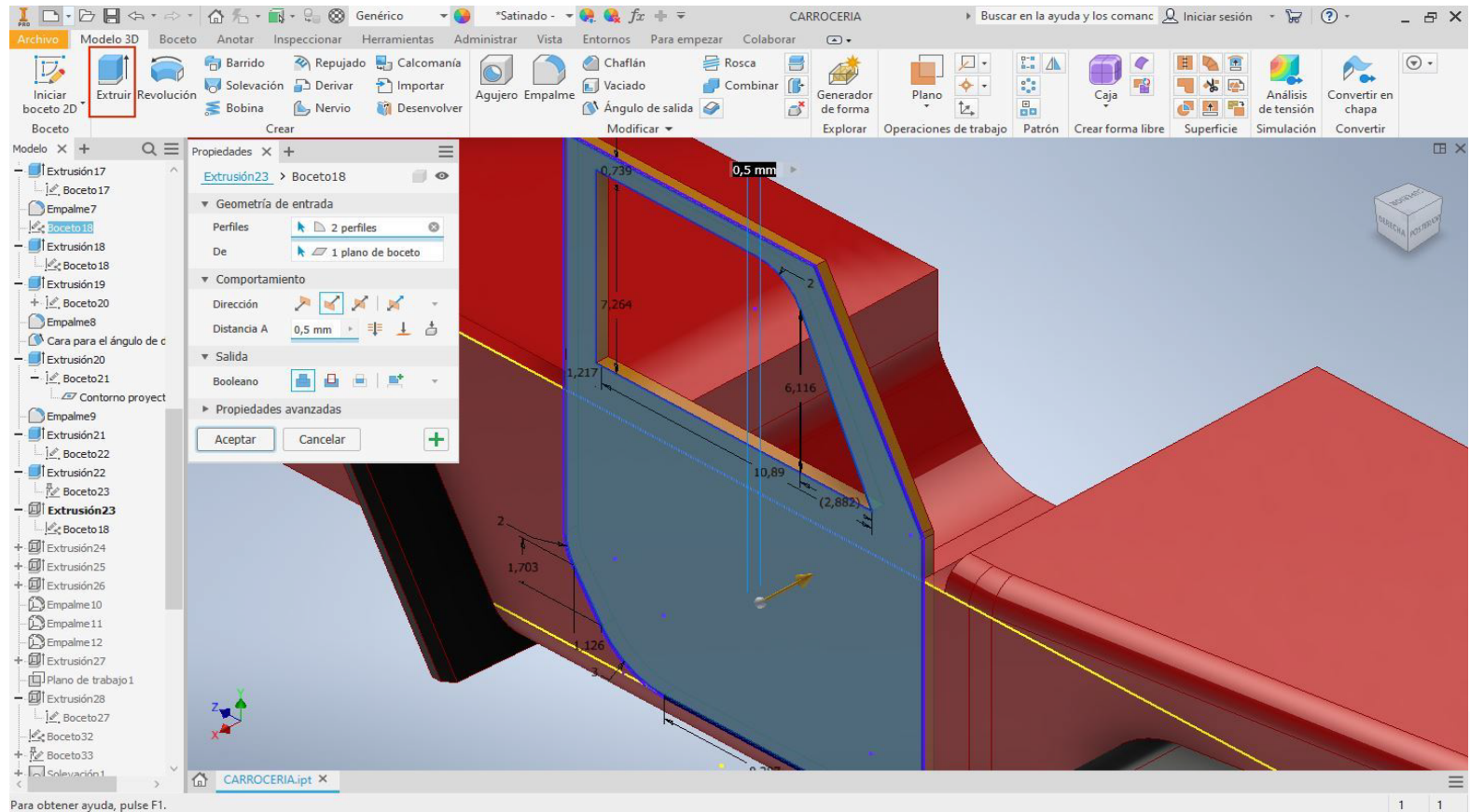

Activar la visibilidad del boceto anterior y realizar una extrucción sobre el boceto exterior

(desfase) activo (visible) con dirección única a una distancia de 0,2 mm.
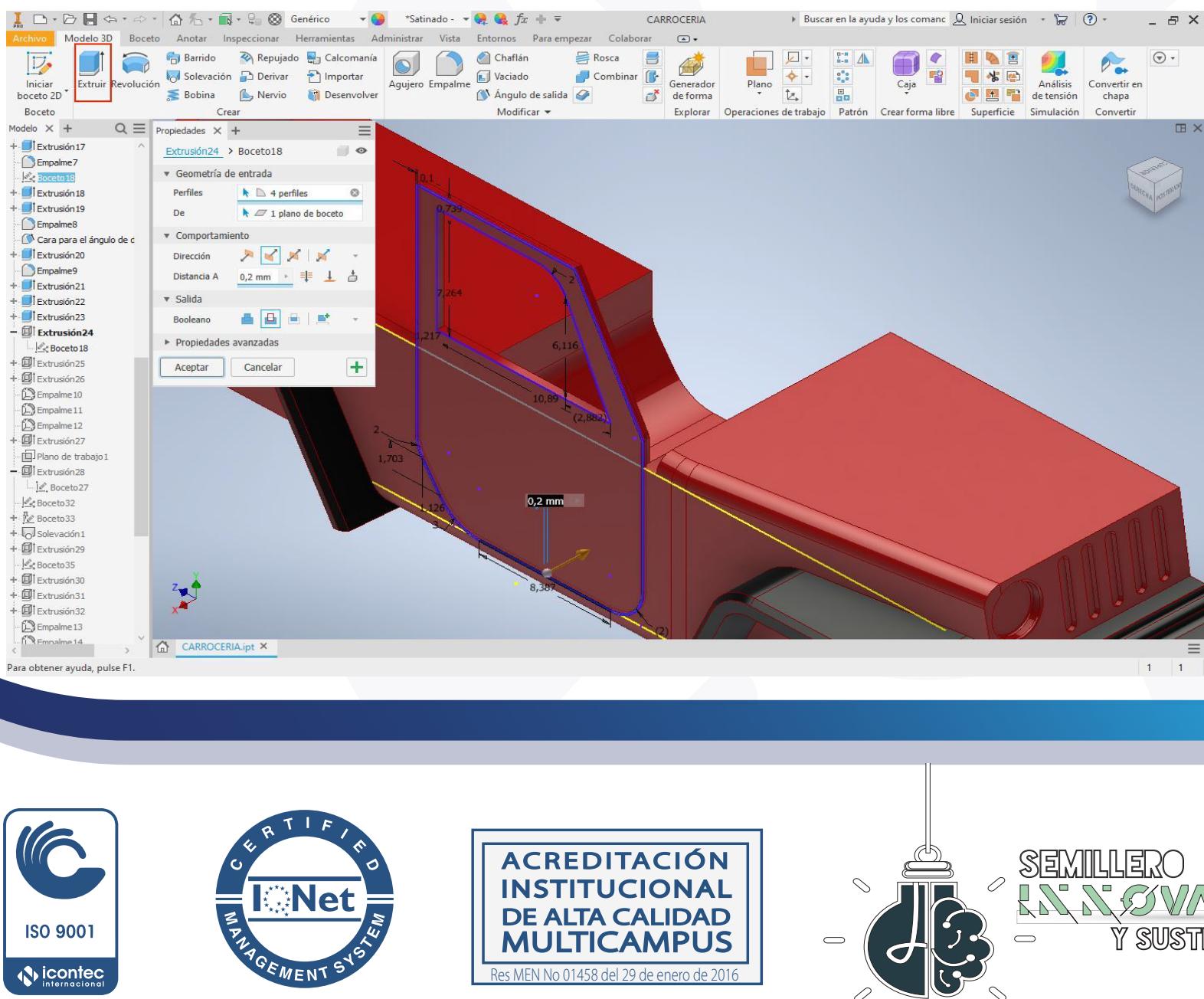

ACREDITACION INSTITUCIONAL DE ALTA CALIDAD MULTICAMPUS

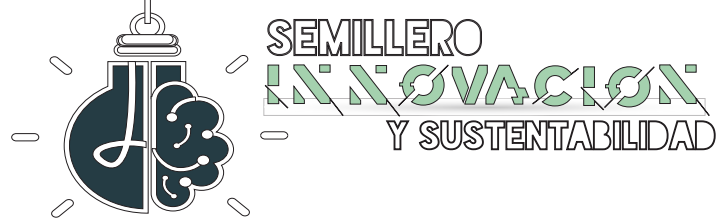




\section{Procedimiento}

Crear un boceto en la vista derecha sobre la carrocería del Jeep con ayuda de líneas y con la herramienta cota se parametrizará como se observa en la ilustración.

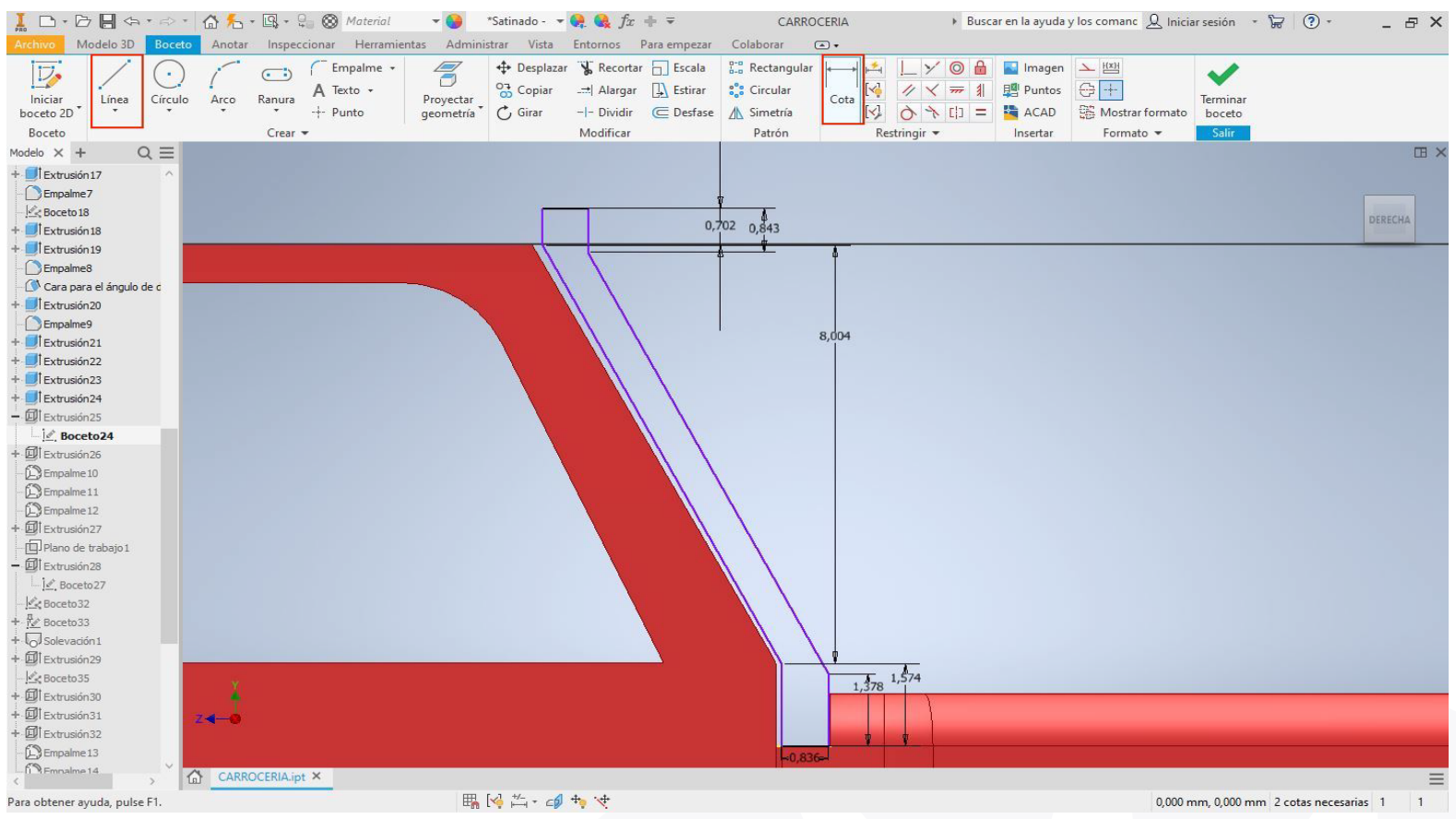

Crear una extrucción sobre el boceto activo (visible) con dirección única a una distancia de 15 mm, esta pieza será el marco del panorámico.
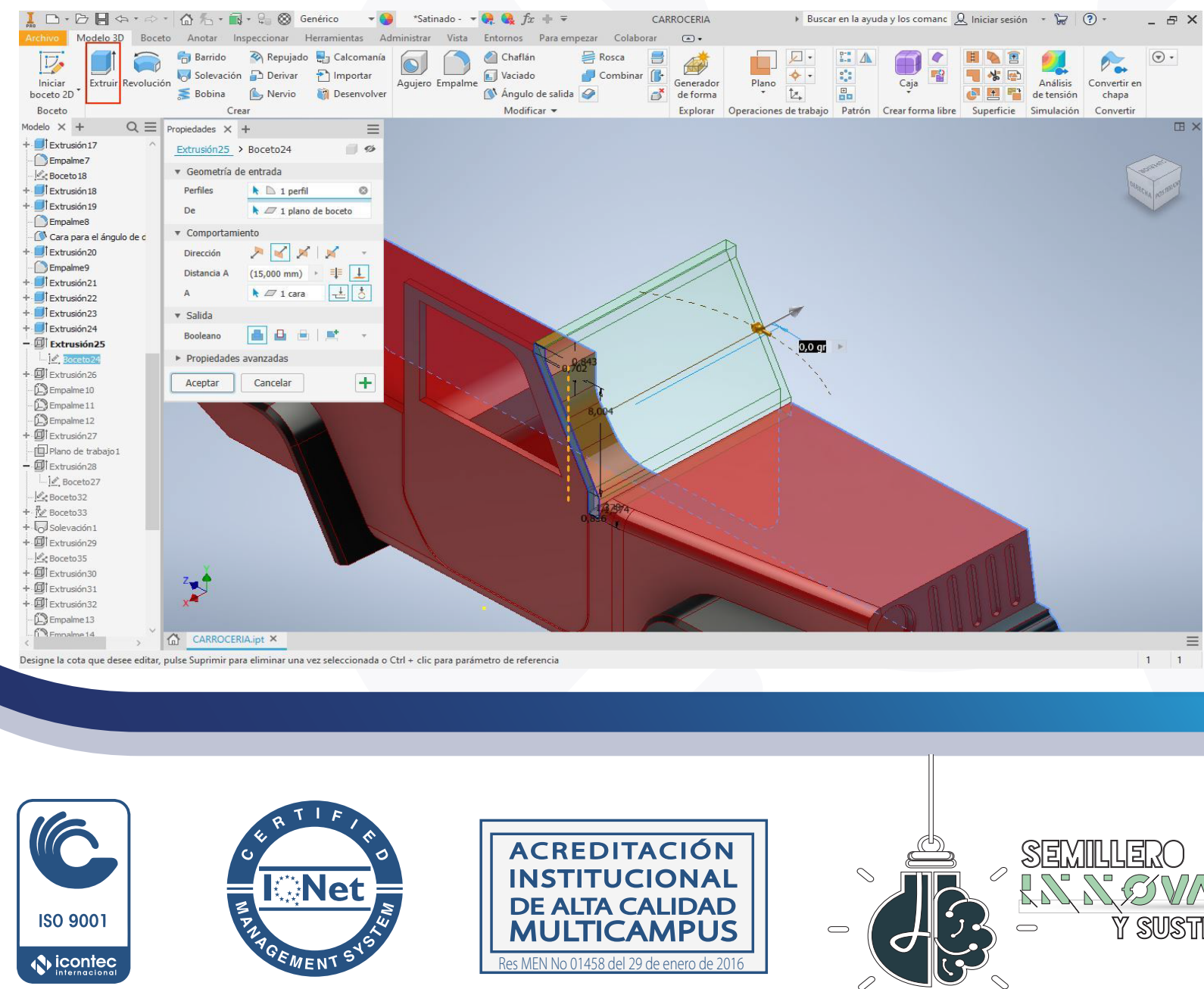

ACREDITACION INSTITUCIONAL DE ALTA CALIDAD MULTICAMPUS

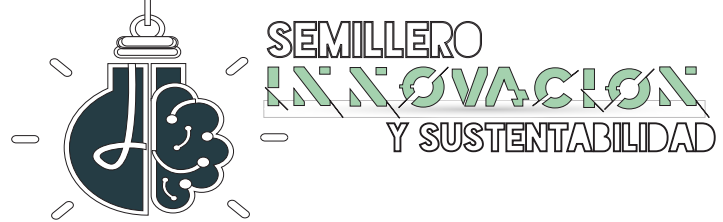




\section{Procedimiento}

Crear un empalme de $1 \mathrm{~mm}$ en la arista inferior horizontal del marco del panorámico.

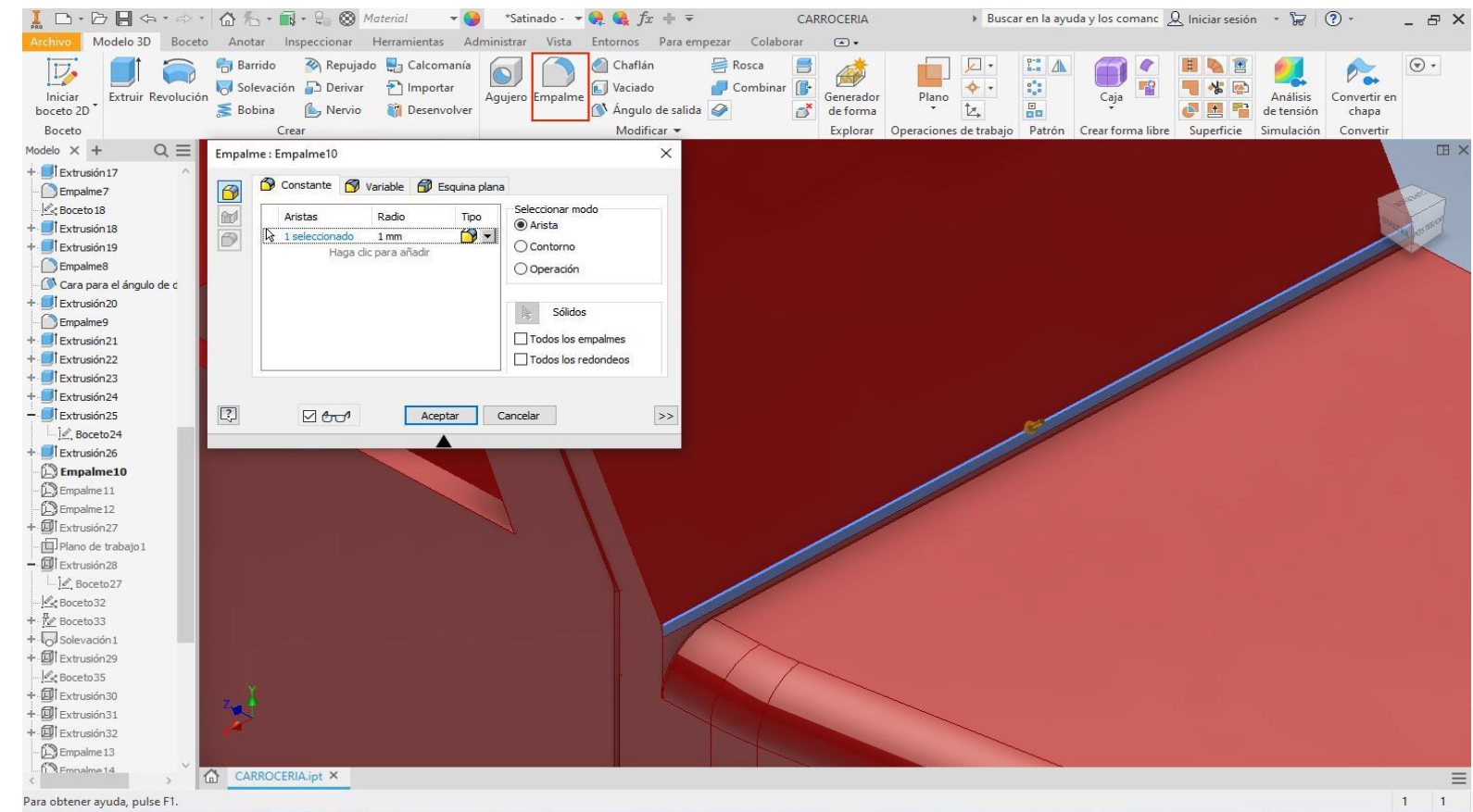

Crear un empalme de $2 \mathrm{~mm}$ en la arista superior horizontal del marco del panorámico.

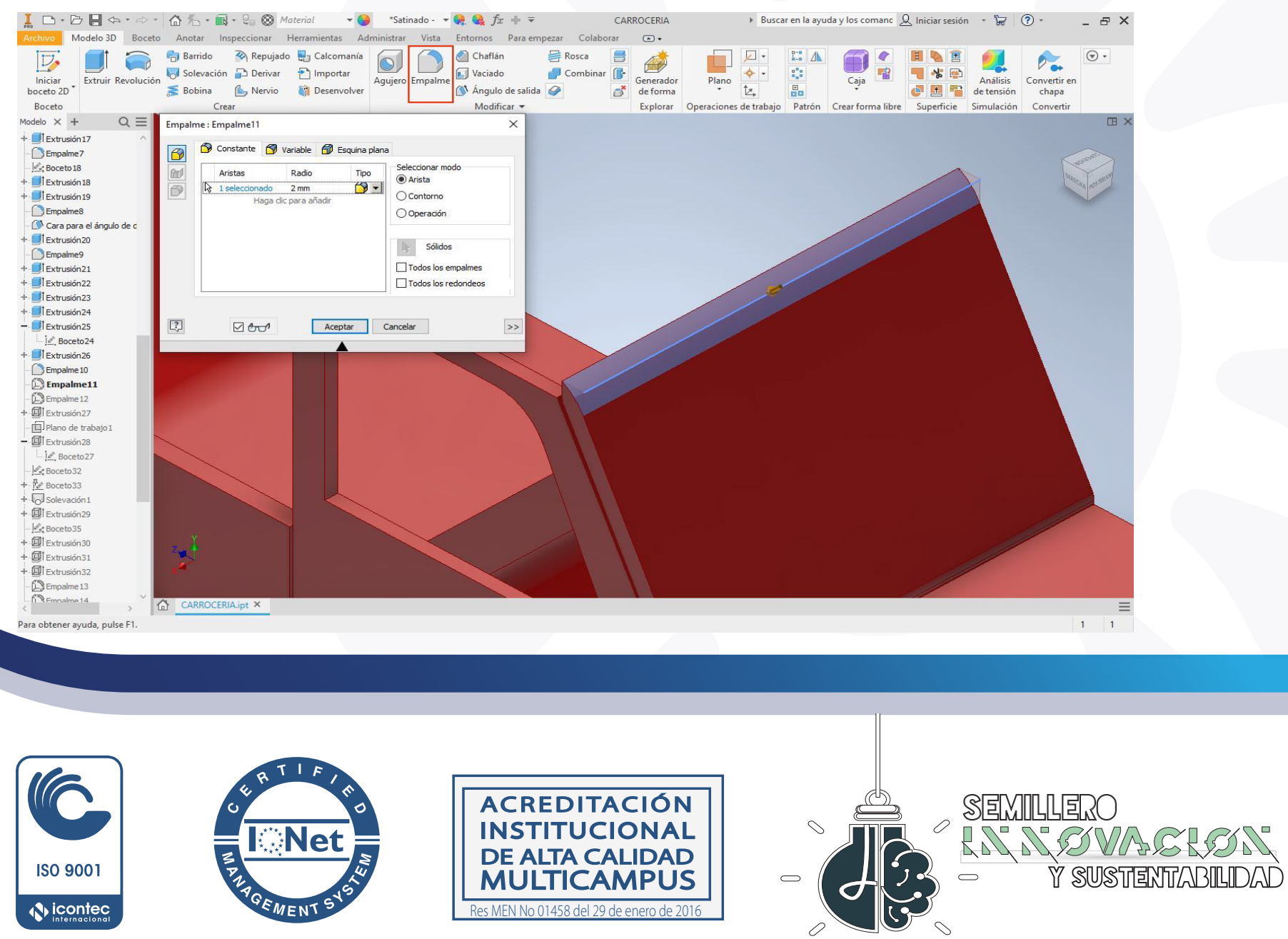




\section{Procedimiento}

Crear un boceto en la vista frontal en el marco del panorámico del Jeep con ayuda de proyectar geometría y líneas de 14,44 mm y 8,125 mm como se observa en la ilustración.

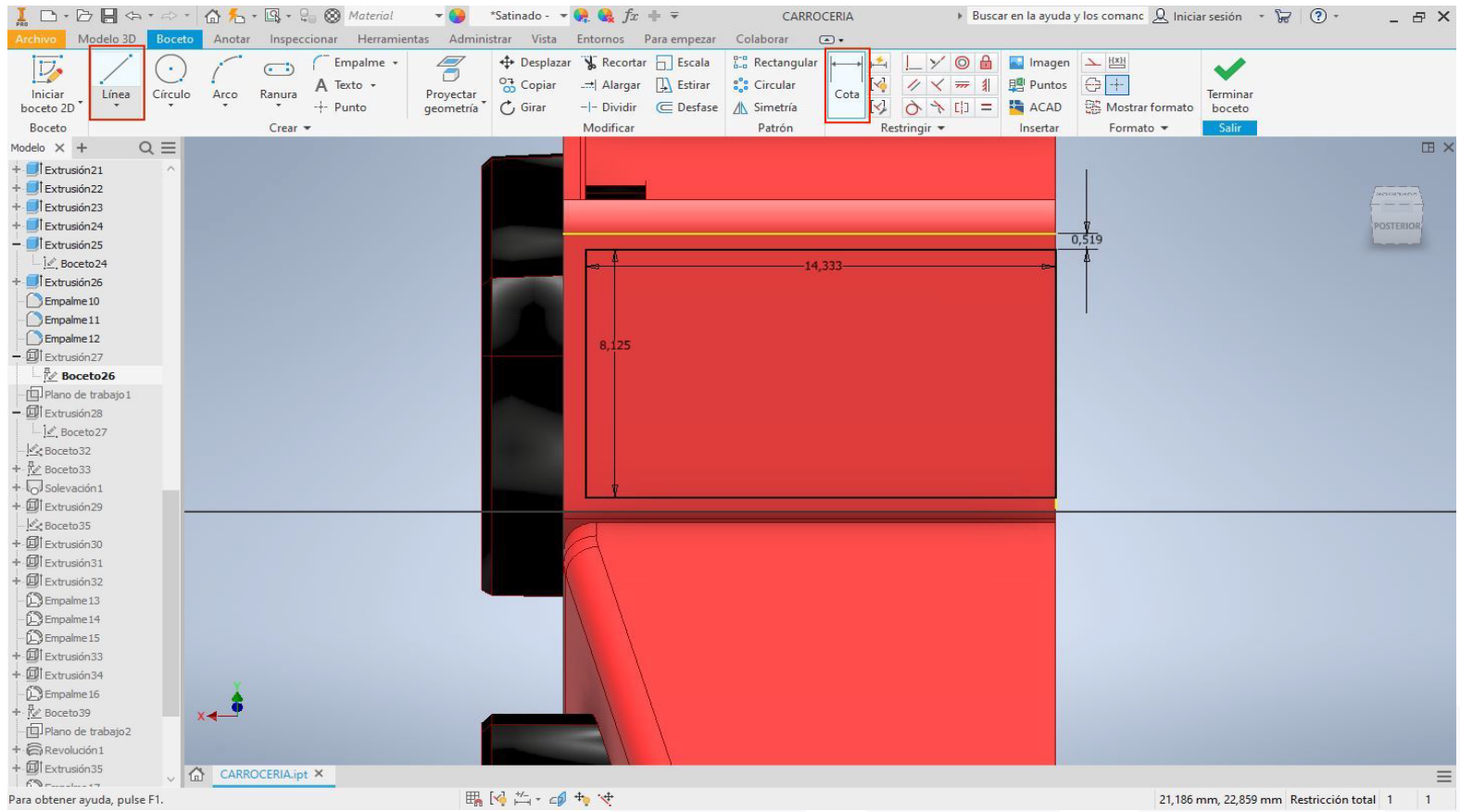

Crear una extrucción de corte sobre el boceto activo (visible) con dirección única a una distancia de 0,646 mm, esta pieza será el espacio para el vidrio panorámico.
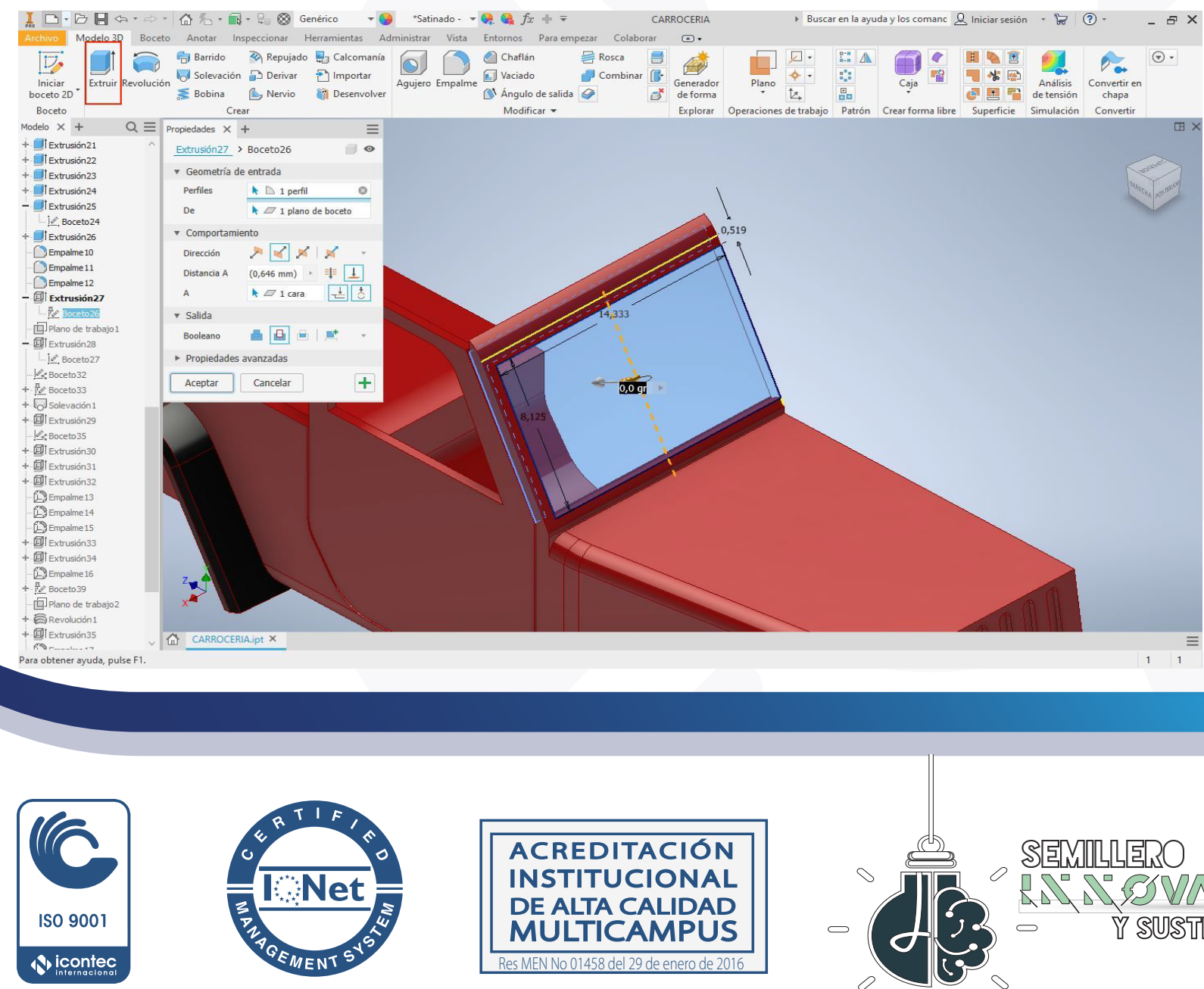

ACREDITACION INSTITUCIONAL DE ALTA CALIDAD MULTICAMPUS

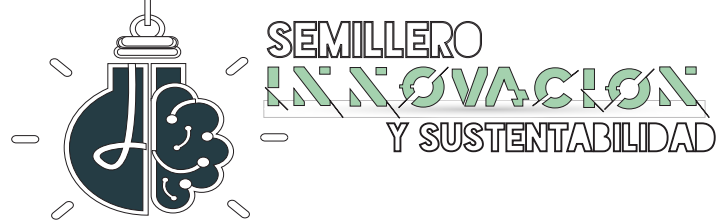




\section{Procedimiento}

Crear un plano paralelo a la vista superior sobre el punto más alto del marco panorámico, ahí se creará un boceto con proyectar geometría, líneas y empalme como se observa en la ilustración

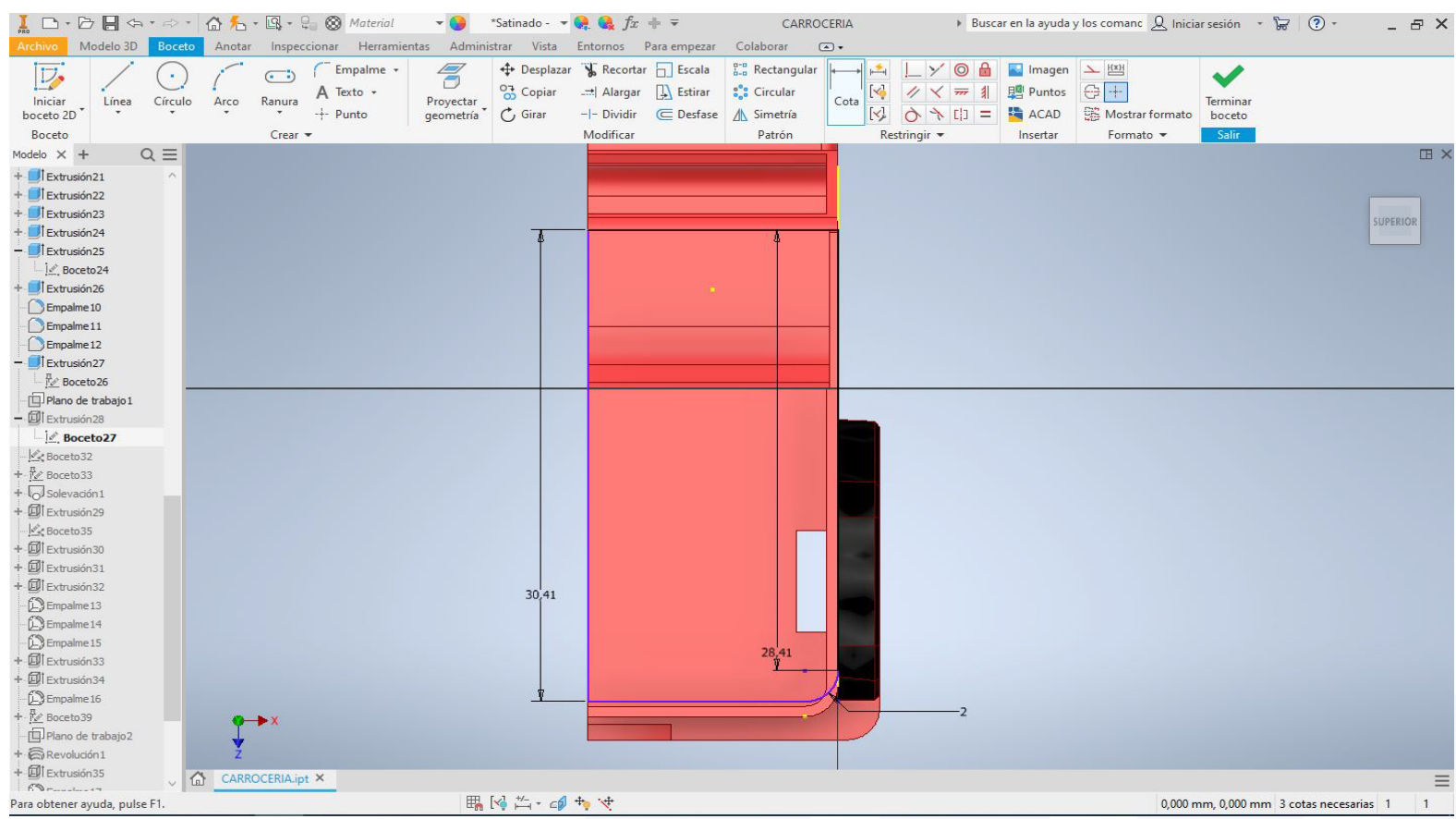

Crear una extrucción sobre el boceto activo (visible) con dirección única a una distancia de 0,5 mm, esta pieza será el techo del Jeep.
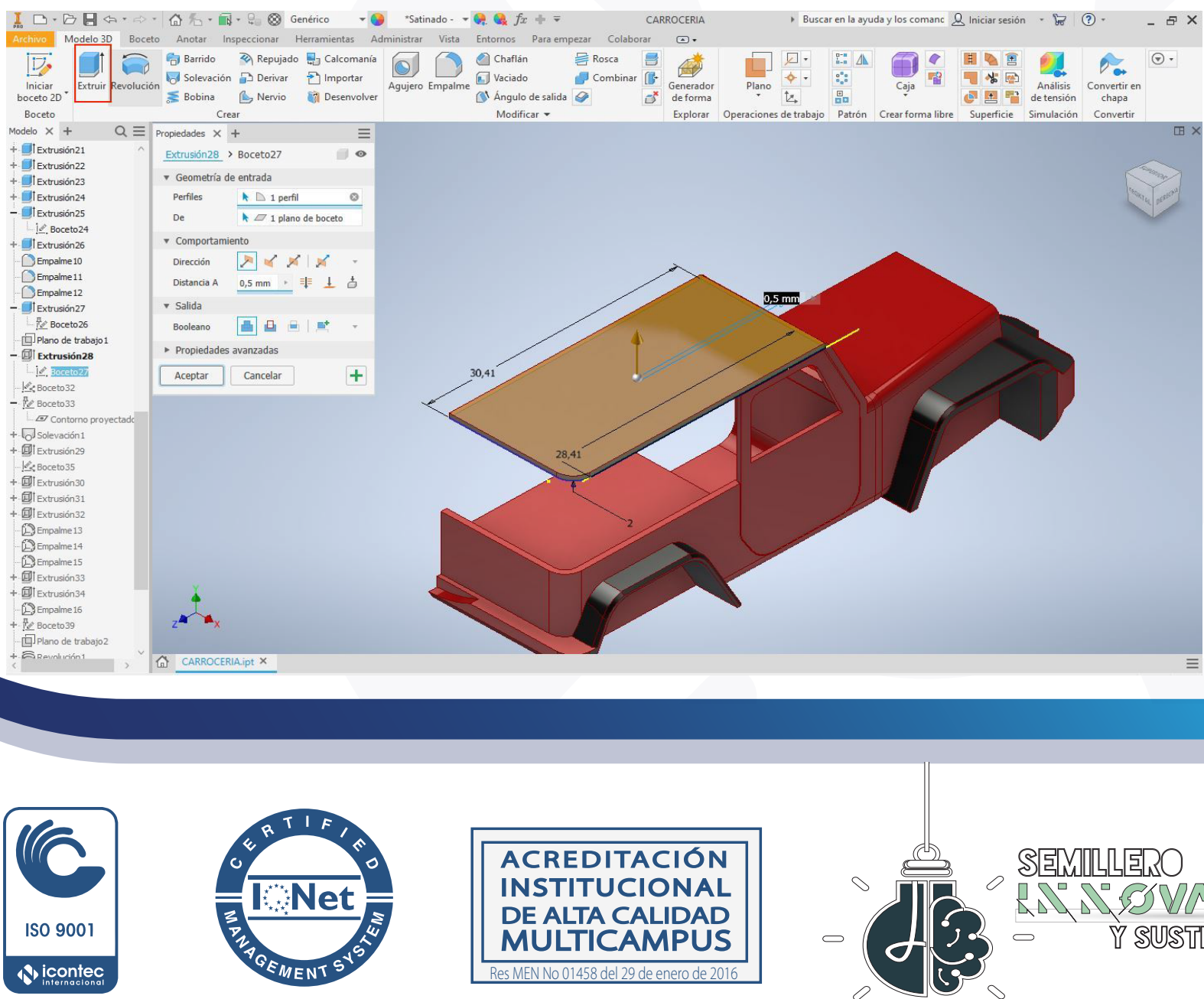

ACREDITACION INSTITUCIONAL DE ALTA CALIDAD MULTICAMPUS

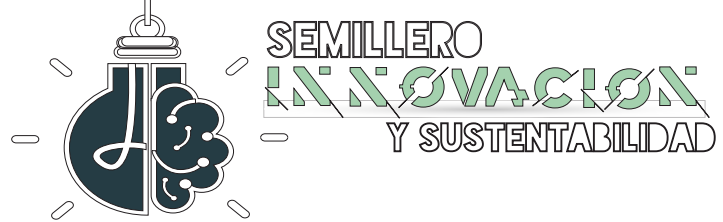




\section{Procedimiento}

Crear un boceto sobre el plano de la vista inferior del techo, para acceder a esta vista se utilizará la función plano de corte (ubicada en la parte inferior), lo que permite obtener una mejor perspectiva del plano de trabajo, y con proyectar geometría y desfase de 0,667 mm se elaborará el boceto de la ilustración.

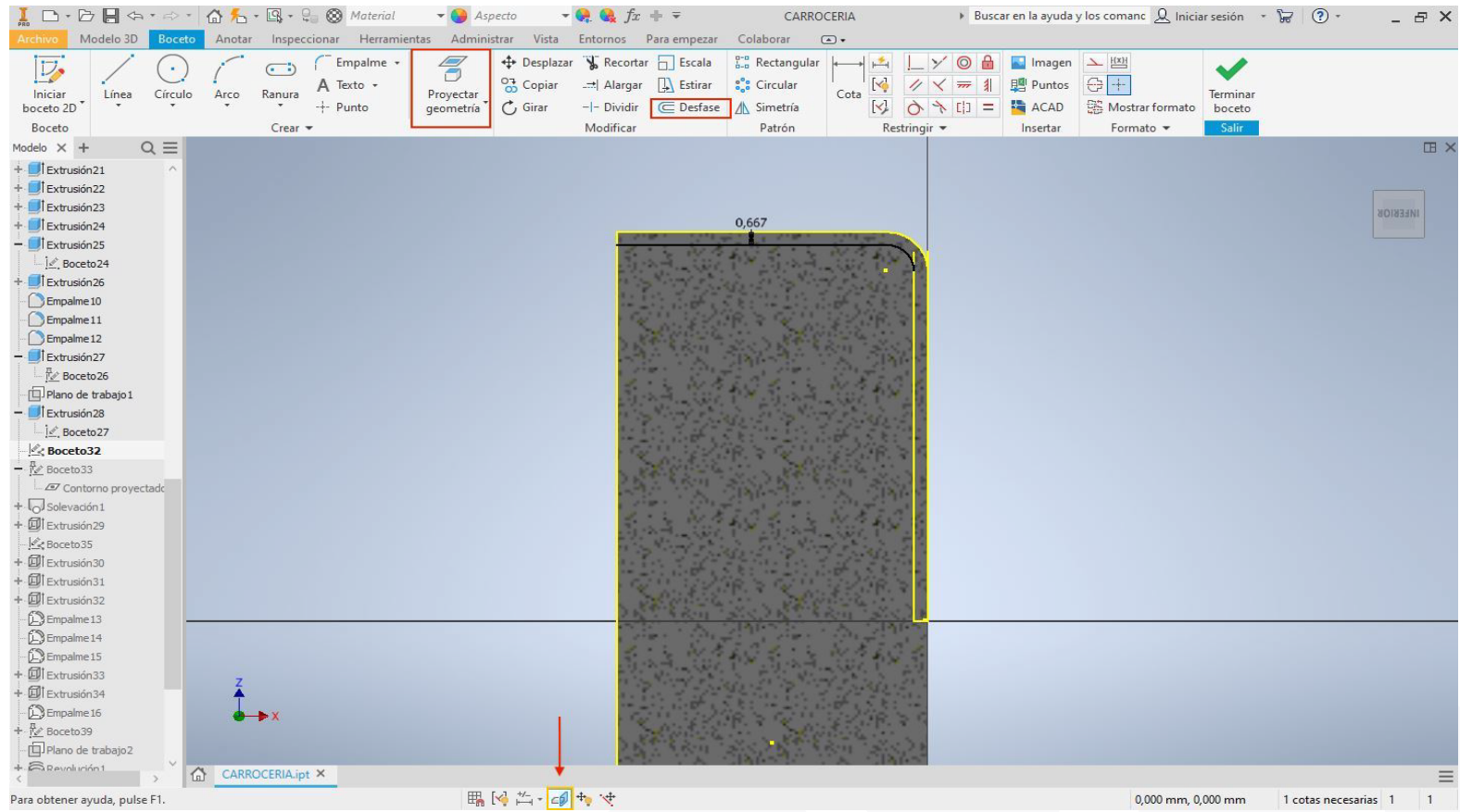

Crear un boceto sobre el plano de la vista superior del borde de la carrocería, para acceder a esta vista se utilizará la función plano de corte (ubicada en la parte inferior), lo que permite obtener una mejor perspectiva del plano de trabajo, y con proyectar geometría se elaborará el boceto de la ilustración.
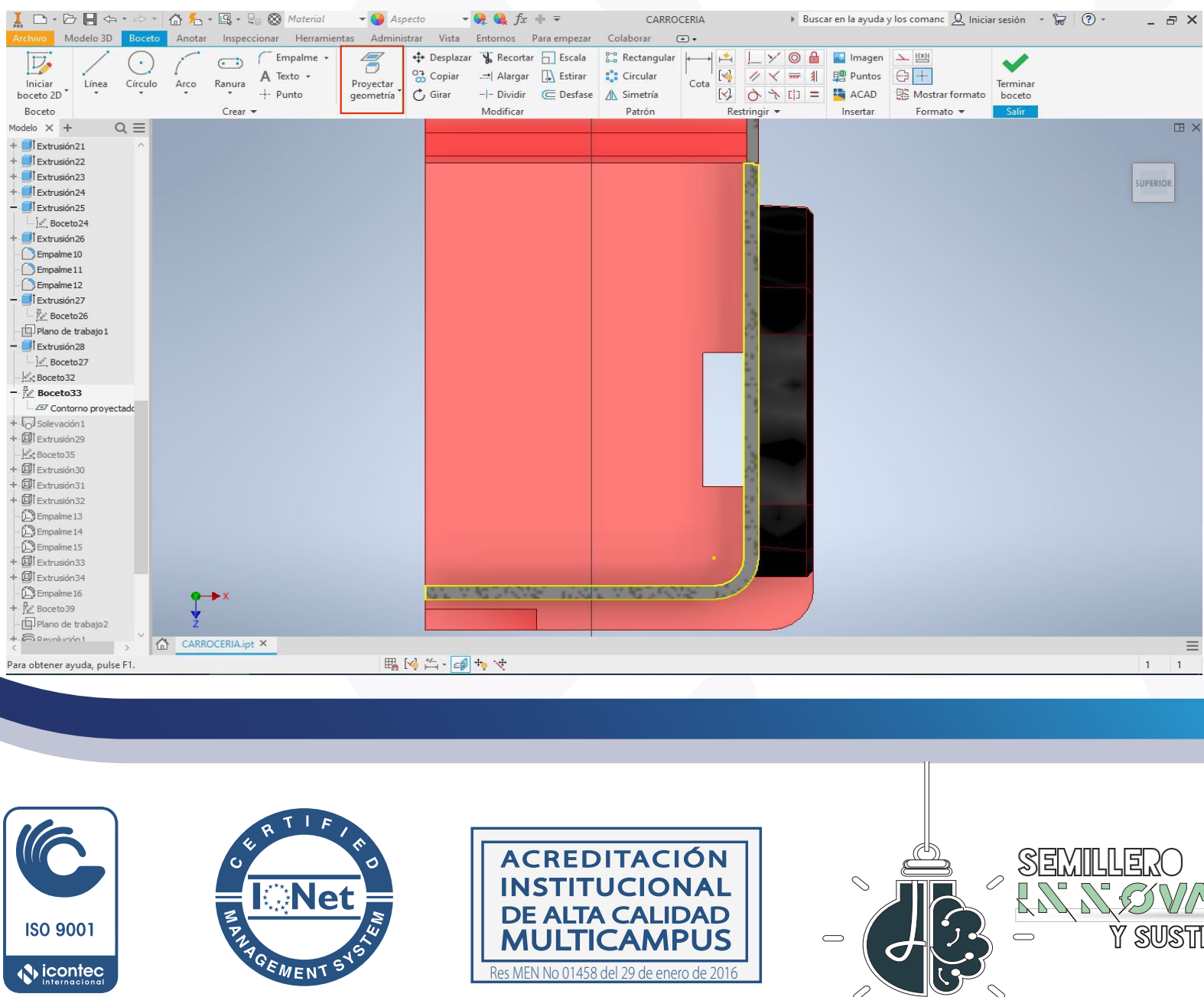

ACREDITACION INSTITUCIONAL DE ALTA CALIDAD MULTICAMPUS

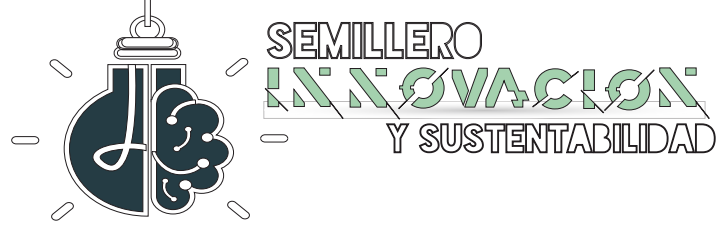




\section{Procedimiento}

Crear una solevación seleccionando los dos bocetos anteriormente realizados y creando así una pieza sólida entre los dos planos.

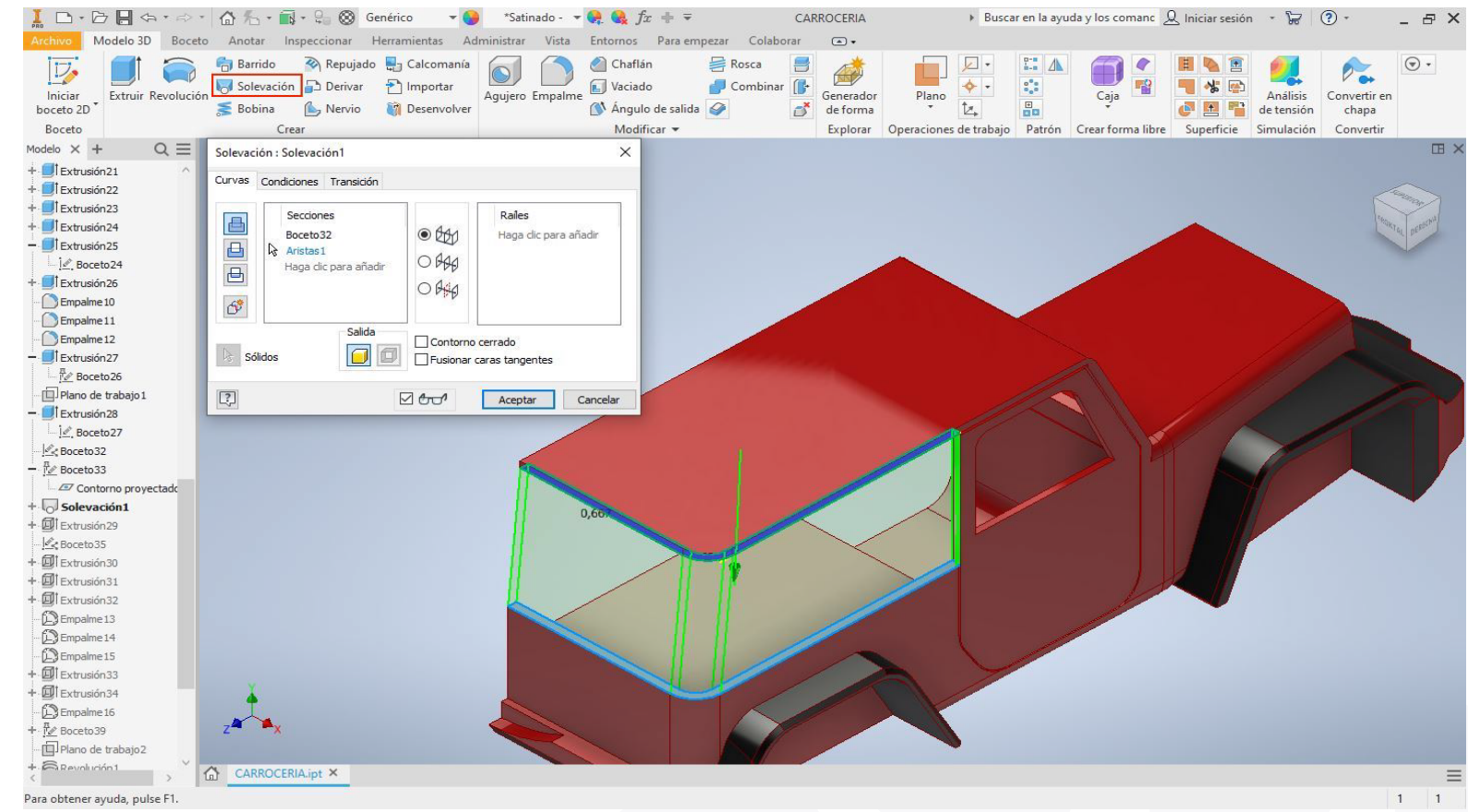

Crear un boceto sobre vista derecha del chasís inferior, elaborando un rectángulo de ancho donde termina la puerta a la parte trasera del Jeep y de alto 0,2 mm, teniendo como guía la arista entre el chasís y el techo de la cabina del Jeep.
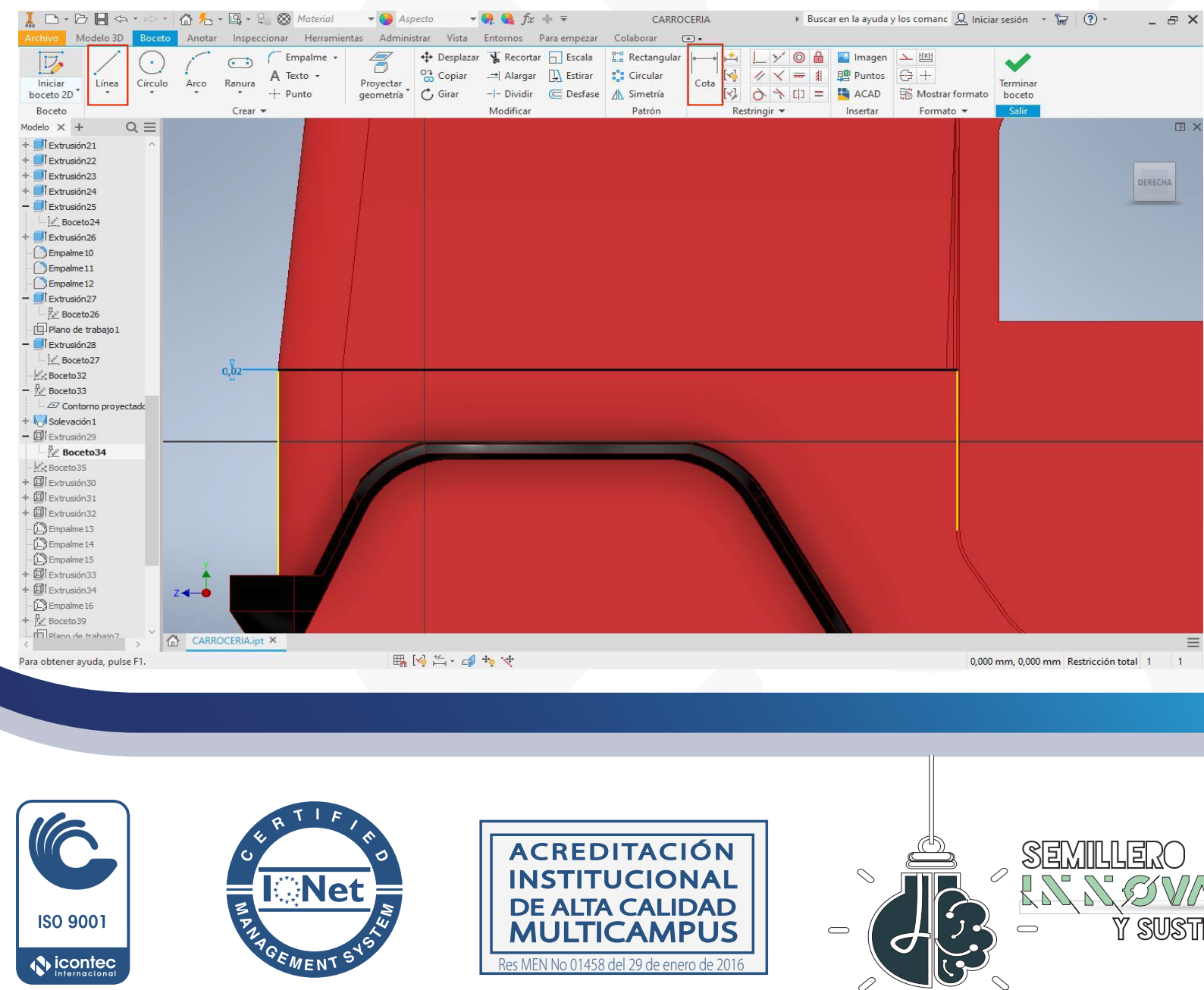

ACREDITACION INSTITUCIONAL DE ALTA CALIDAD MULTICAMPUS

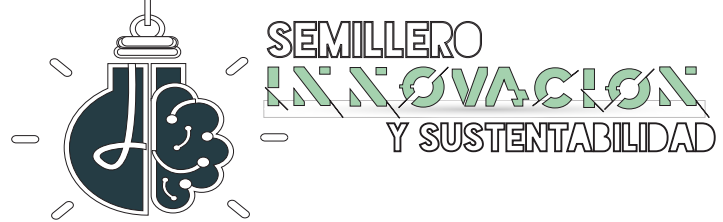




\section{Procedimiento}

Crear una extrucción de corte sobre el boceto activo (visible) con única dirección a una distancia de $0,5 \mathrm{~mm}$.

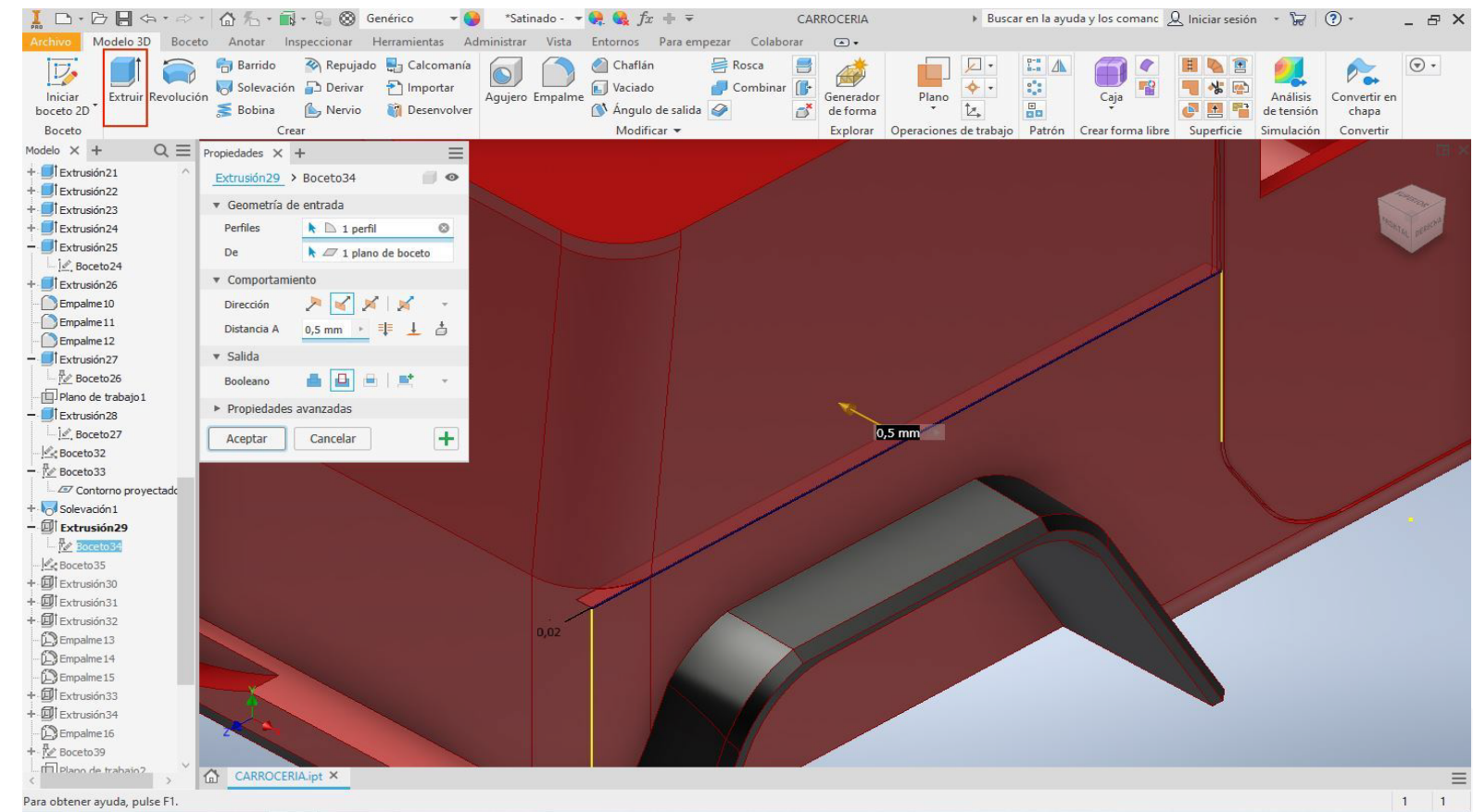

Crear un boceto en la vista derecha en chasís superior (cabina) del Jeep con ayuda de un rectángulo, empalmes, cotas y proyección de geometría, por último se realizará un desfase de 0,2 mm hacia el exterior como se observa en la ilustración.
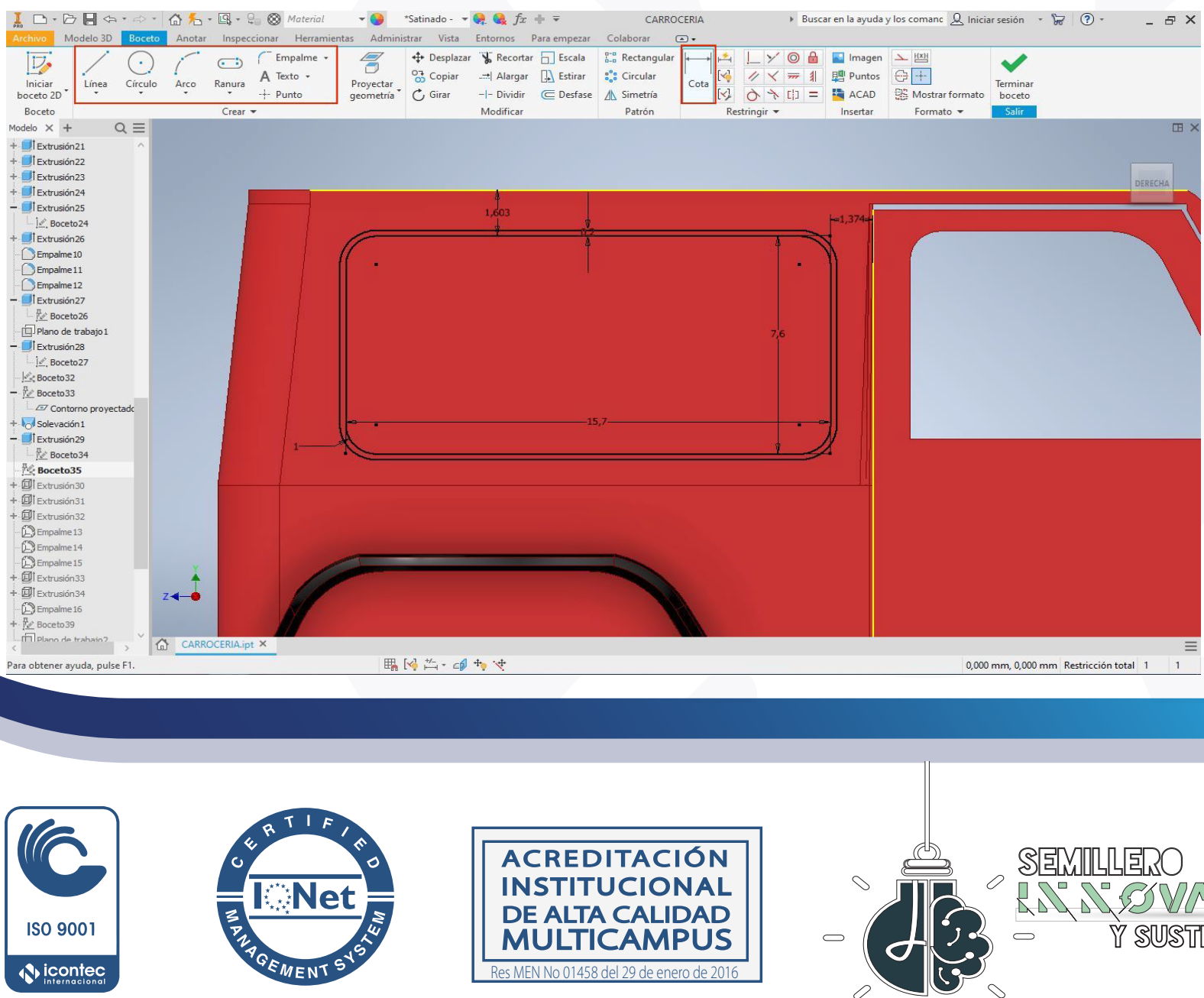

ACREDITACION INSTITUCIONAL

DE ALTA CALIDAD MULTICAMPUS 


\section{Procedimiento}

Crear una extrucción sobre el desfase con única dirección simétrica a una distancia de 0,2 $\mathrm{mm}$, siendo este el marco de la ventana trasera del Jeep.

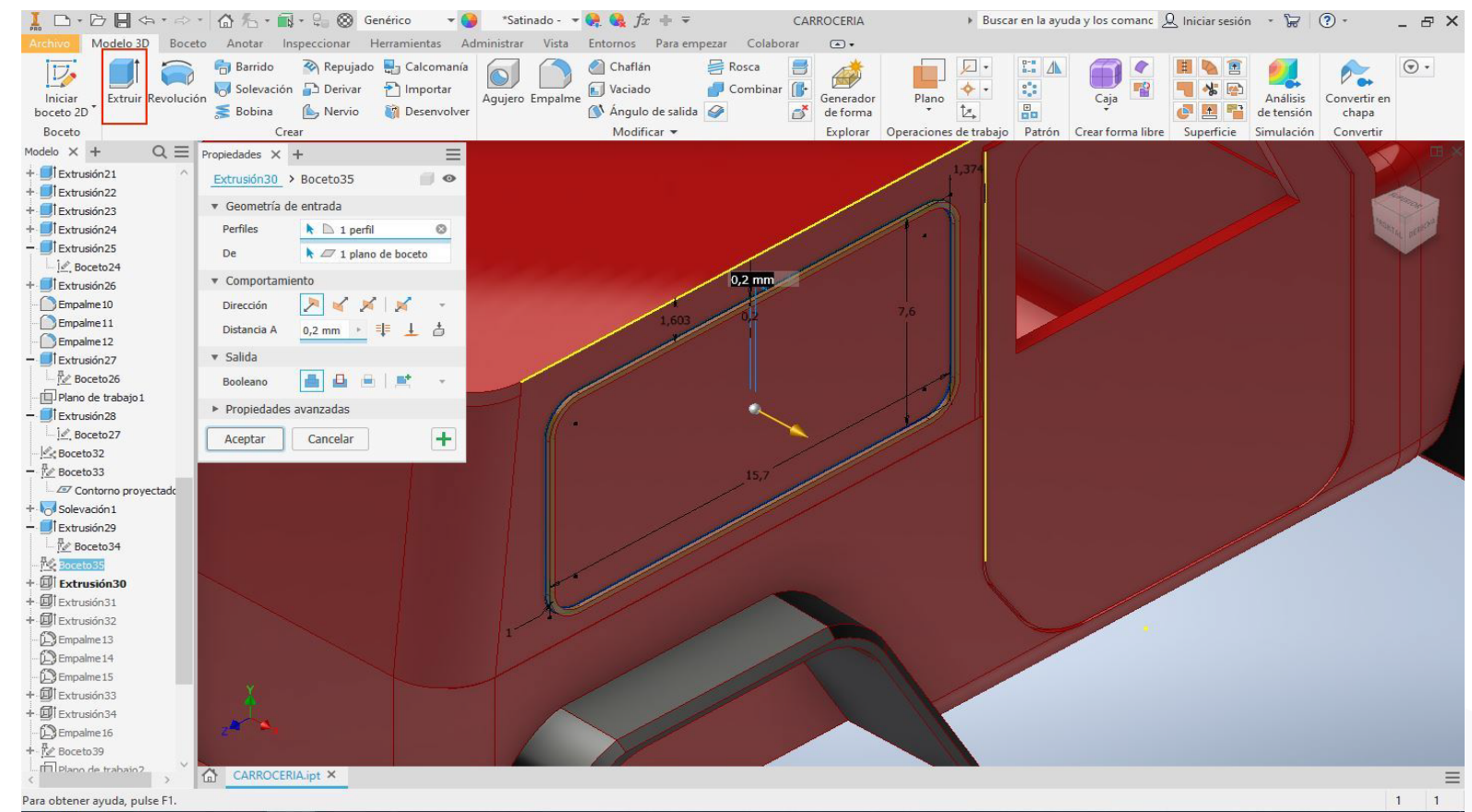

Volver a activar el anterior boceto para así crear la extrucción de corte al interior de la ventana.
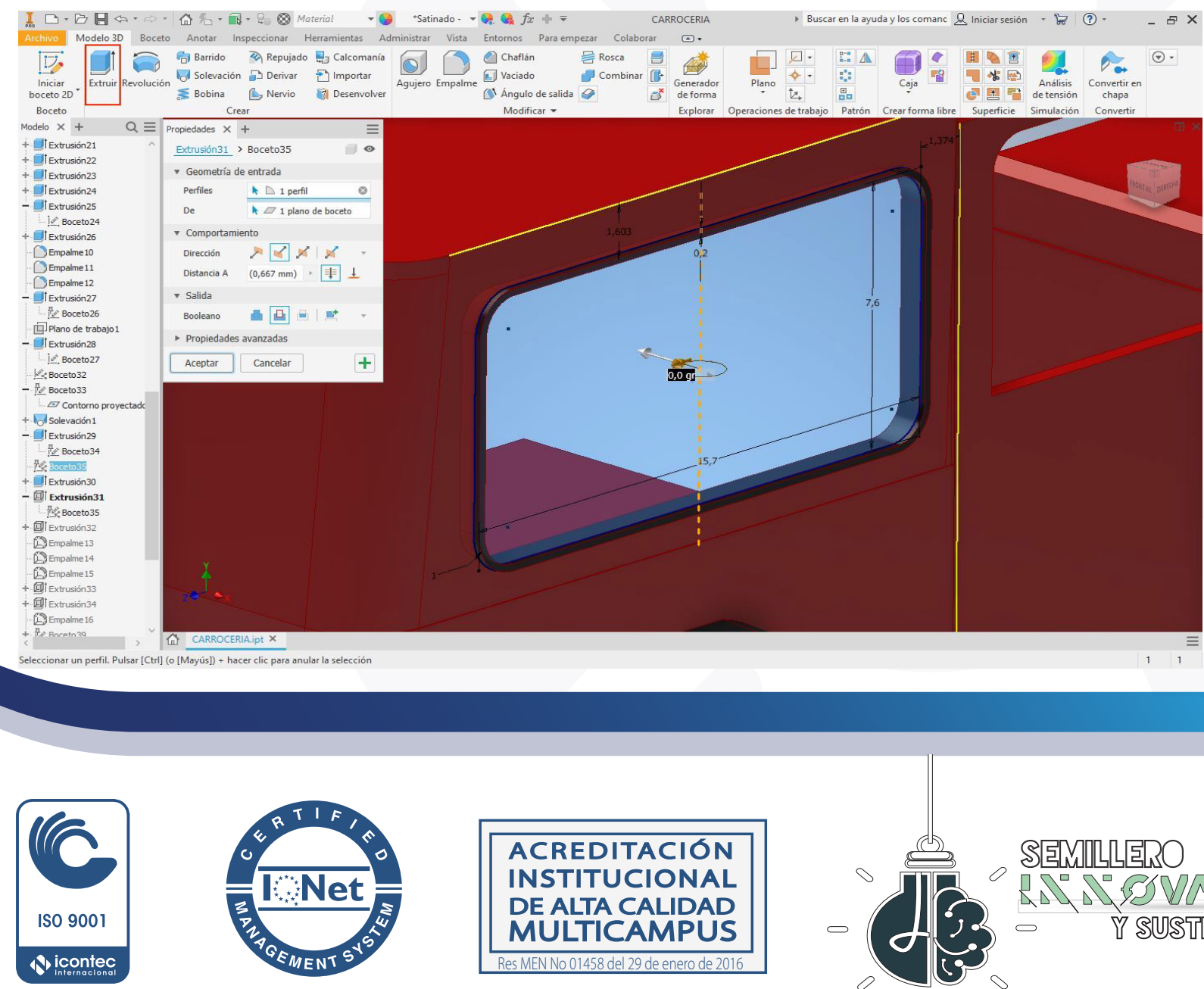

ACREDITACION INSTITUCIONAL

DE ALTA CALIDAD MULTICAMPUS

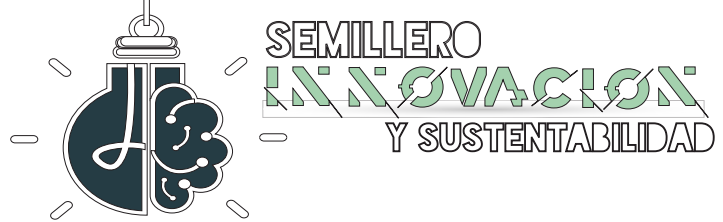




\section{Procedimiento}

Crear un boceto en la vista posterior del chasís superior (cabina) del Jeep con ayuda de un rectángulo, empalmes, cotas y proyección de geometría como se observa en la ilustración.

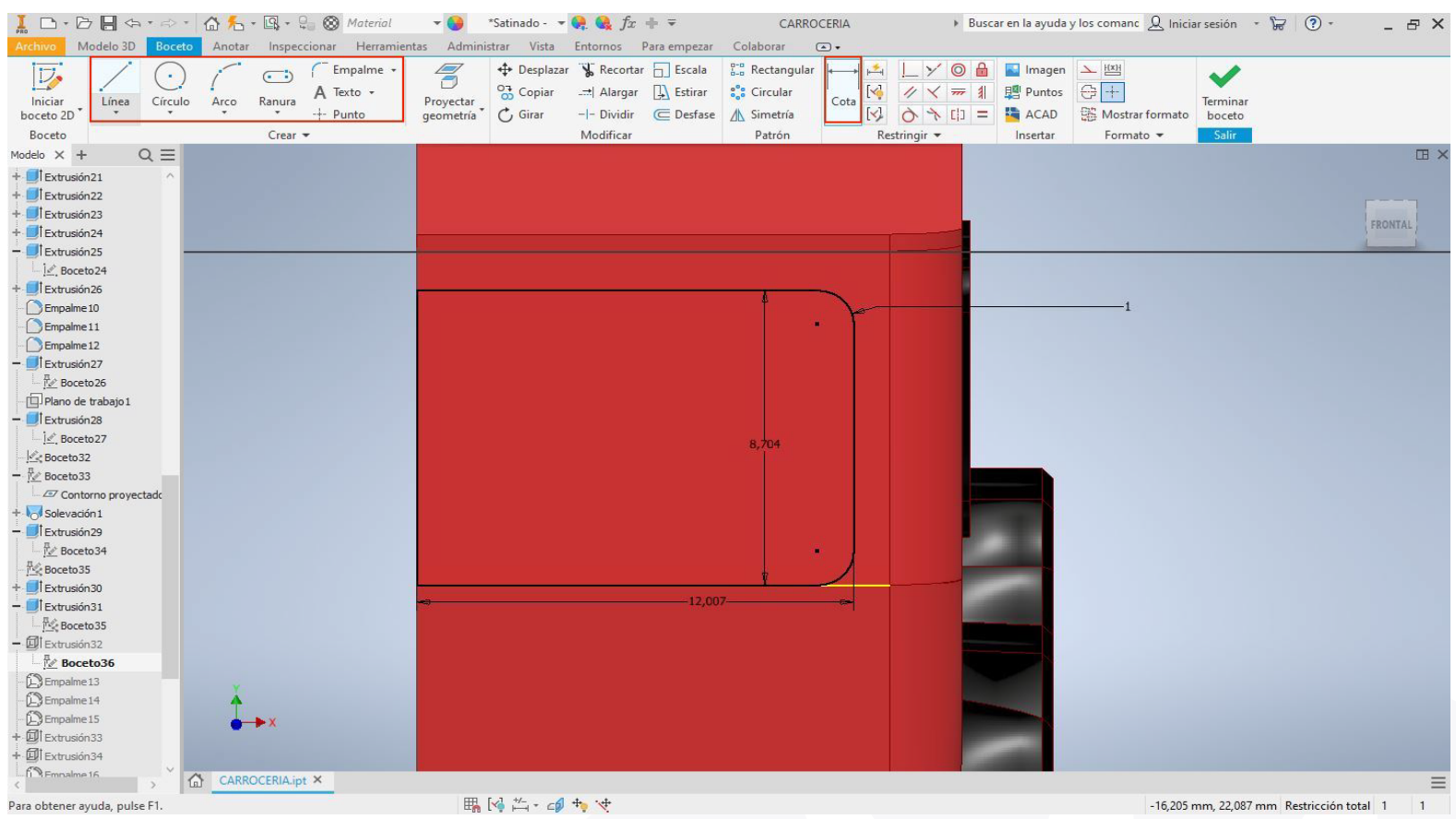

Crear una extrucción de corte sobre el boceto activo (visible) con dirección única a una distancia de 0,7 mm, esta pieza será la ventana trasera del Jeep.
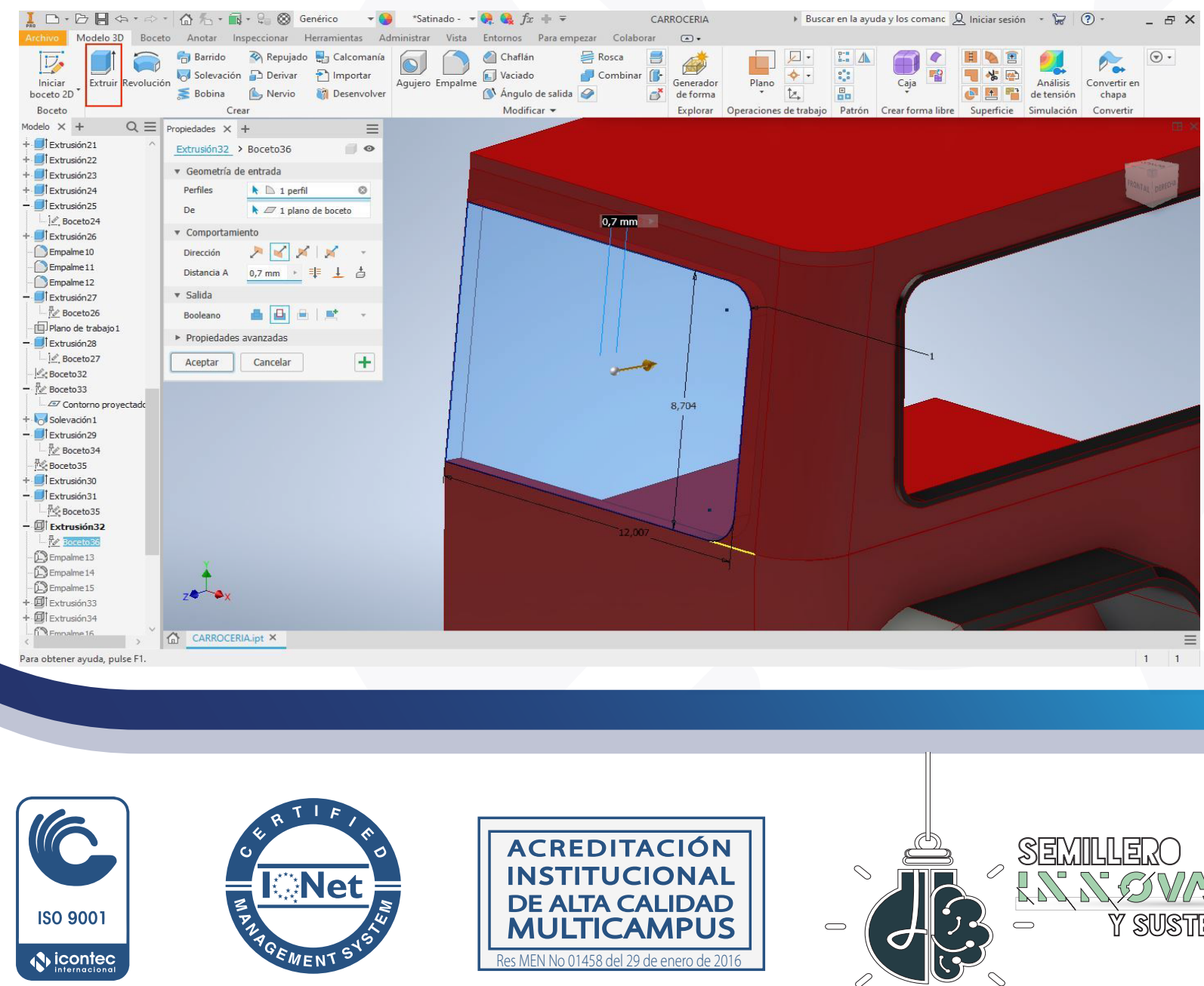

ACREDITACION INSTITUCIONAL DE ALTA CALIDAD MULTICAMPUS

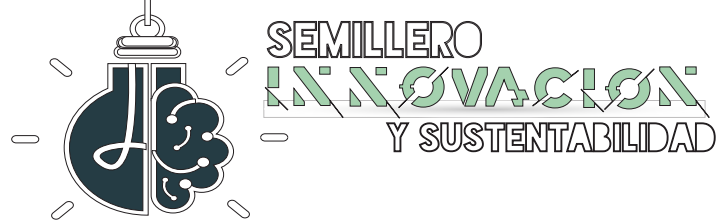




\section{Procedimiento}

Crear un empalme de 0,5 mm sobre las aristas del cuadrado frontal del parachoques delantero del Jeep.

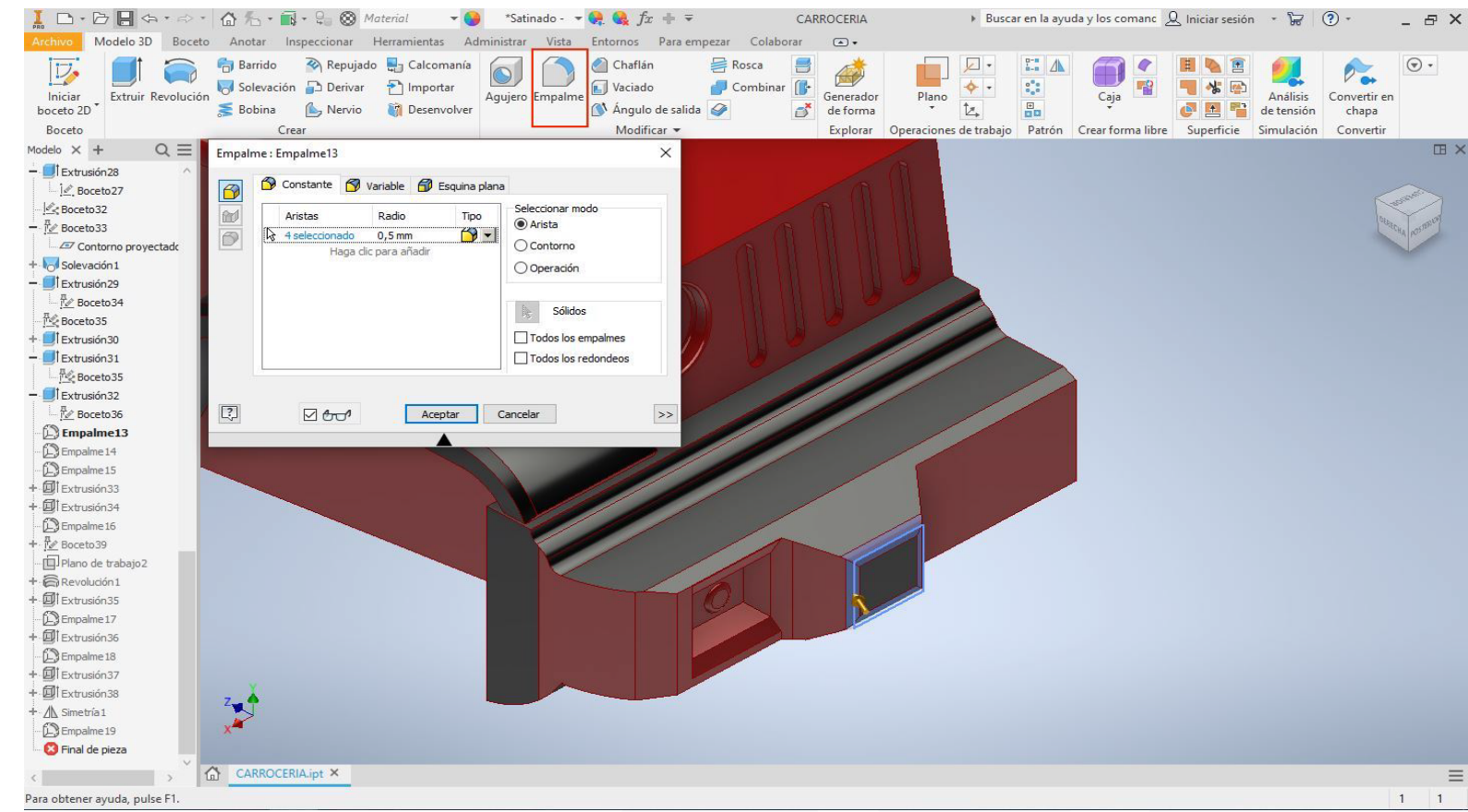

Crear un empalme de 0,5 mm sobre las aristas del prisma frontal del parachoques delantero del Jeep.
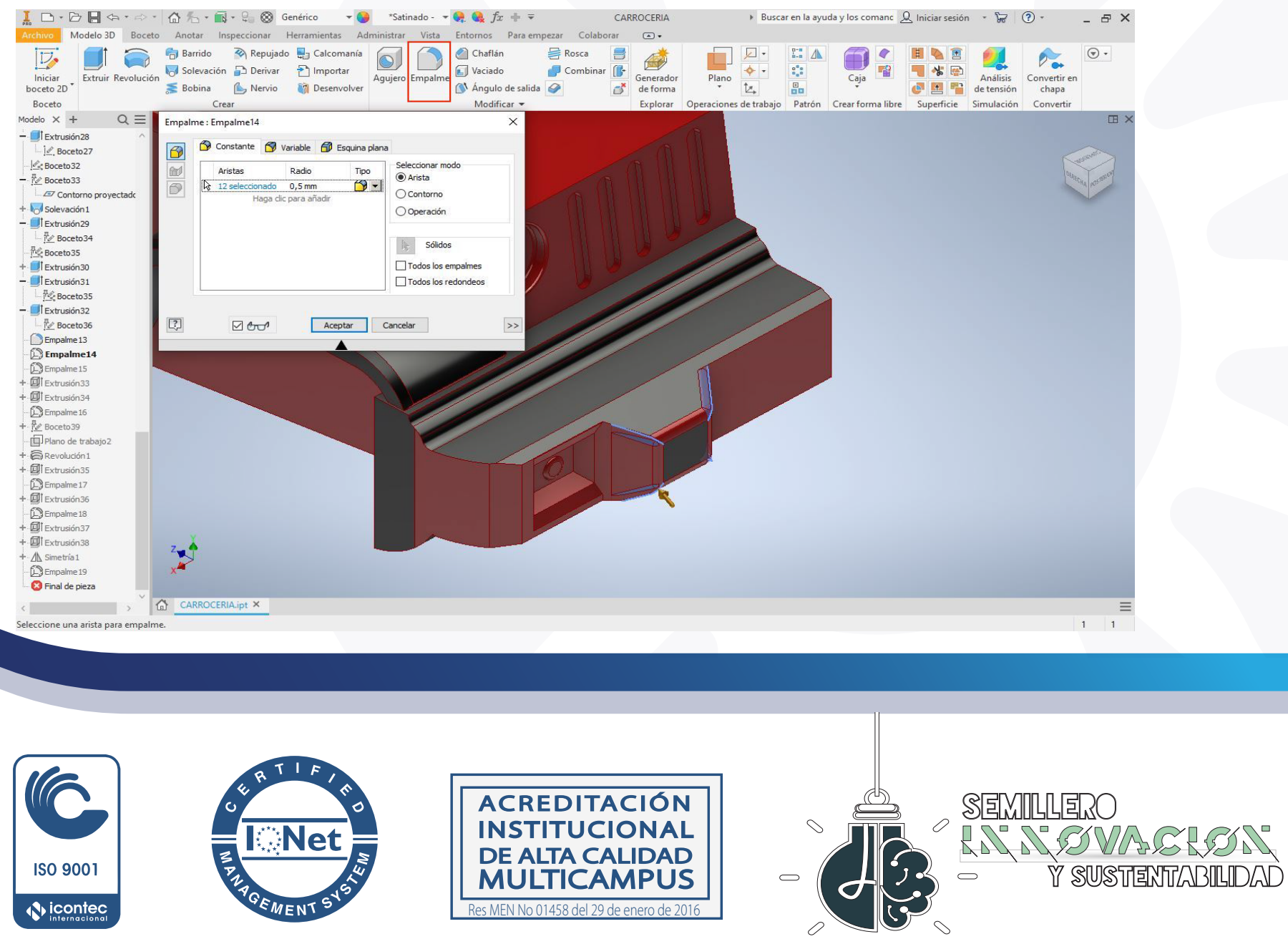


\section{Procedimiento}

Crear un empalme de 0,5 mm sobre la arista exterior del techo del Jeep.

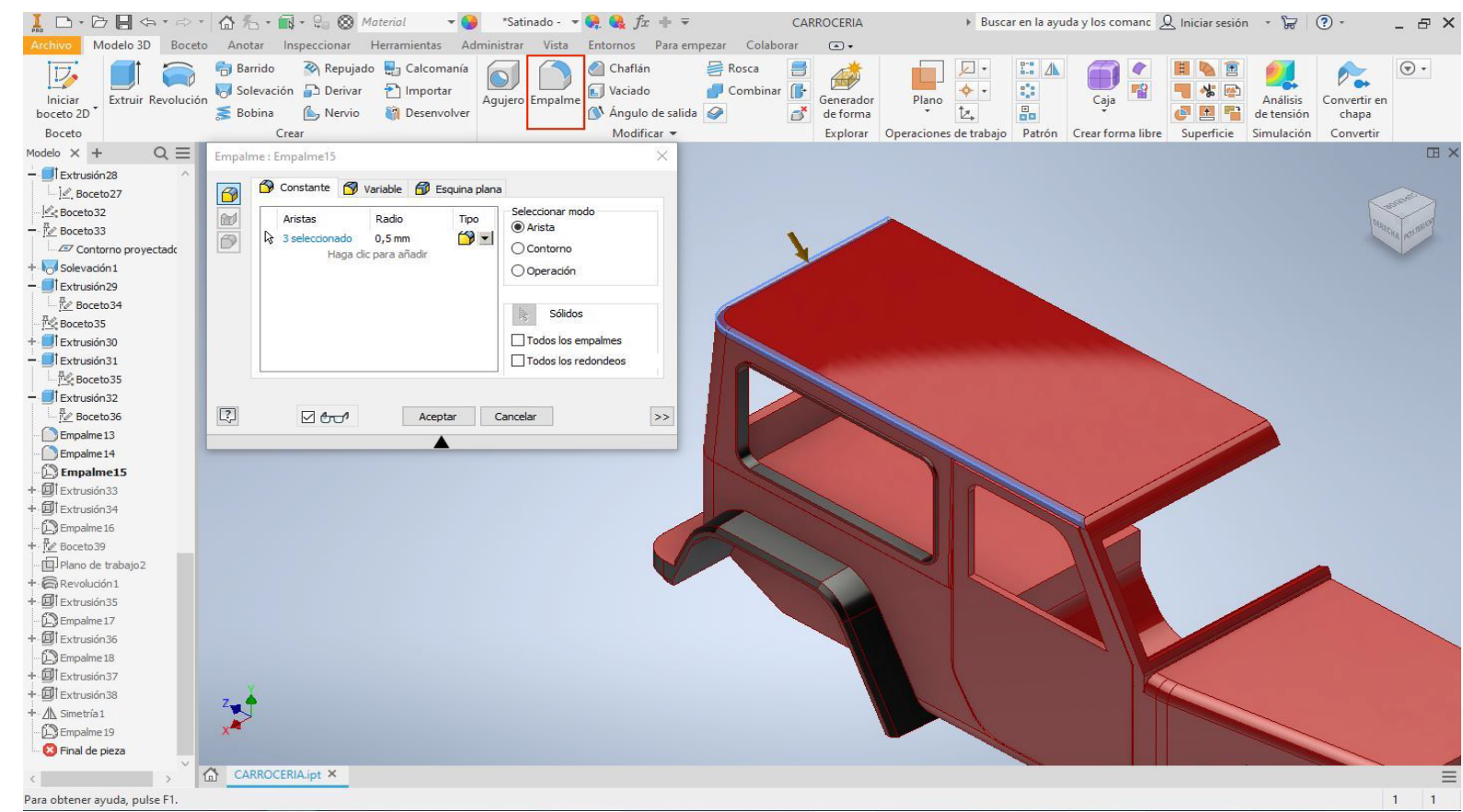

Crear un plano paralelo al plano XZ con un desfase de 10,85 mm hacia arriba seleccionando plano de corte, posteriormente iniciar un boceto con un círculo de $1 \mathrm{~mm}$ de diámetro y proyectar la geometría de la arista exterior de la puerta la cual servirá como eje.
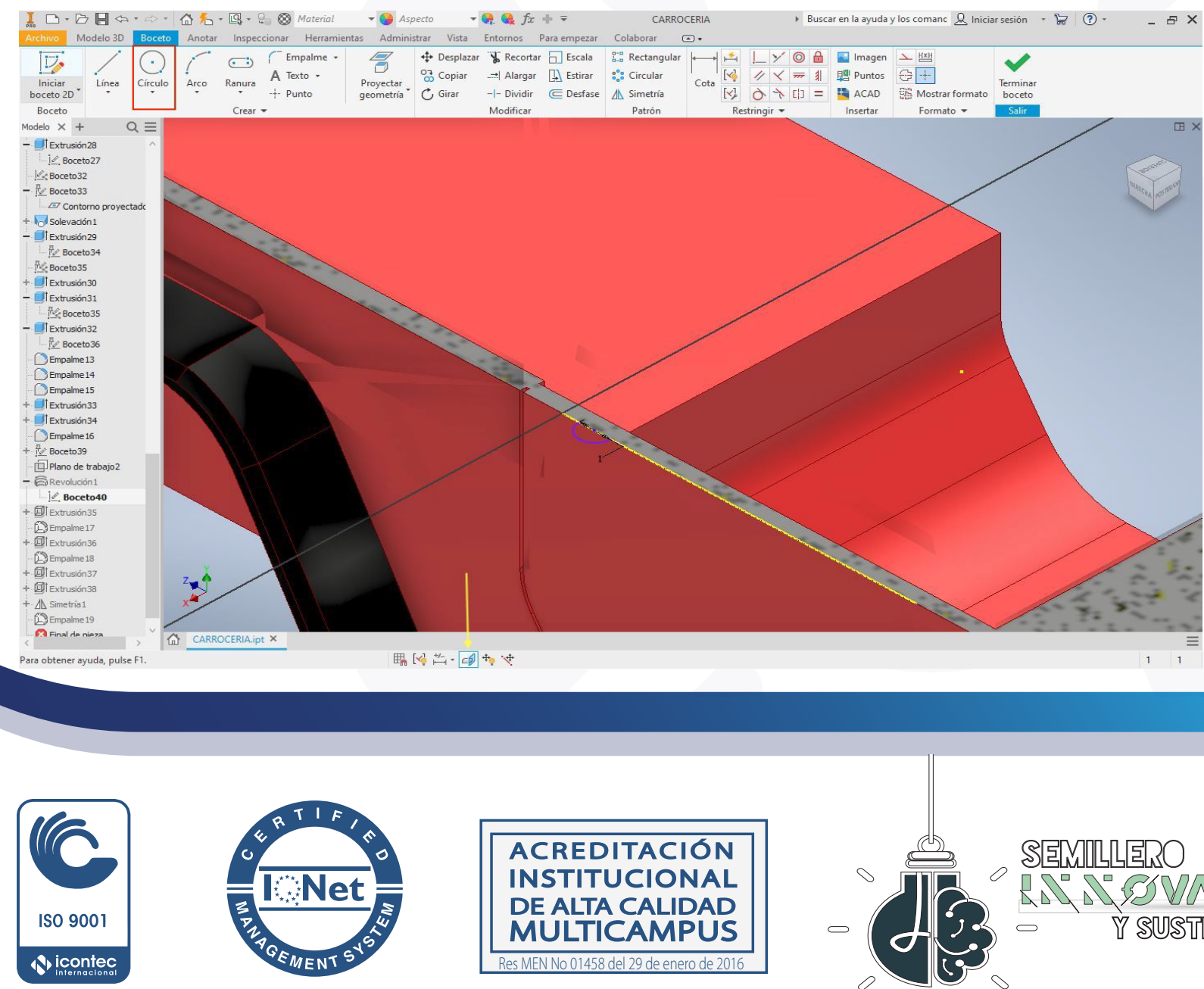

ACREDITACION INSTITUCIONAL DE ALTA CALIDAD MULTICAMPUS

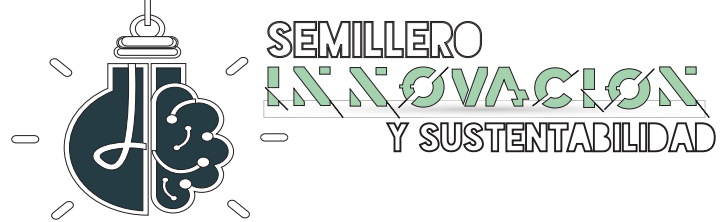




\section{Procedimiento}

Crear una revolución de corte seleccionando como pefil el círculo y el eje la arista proyectada.

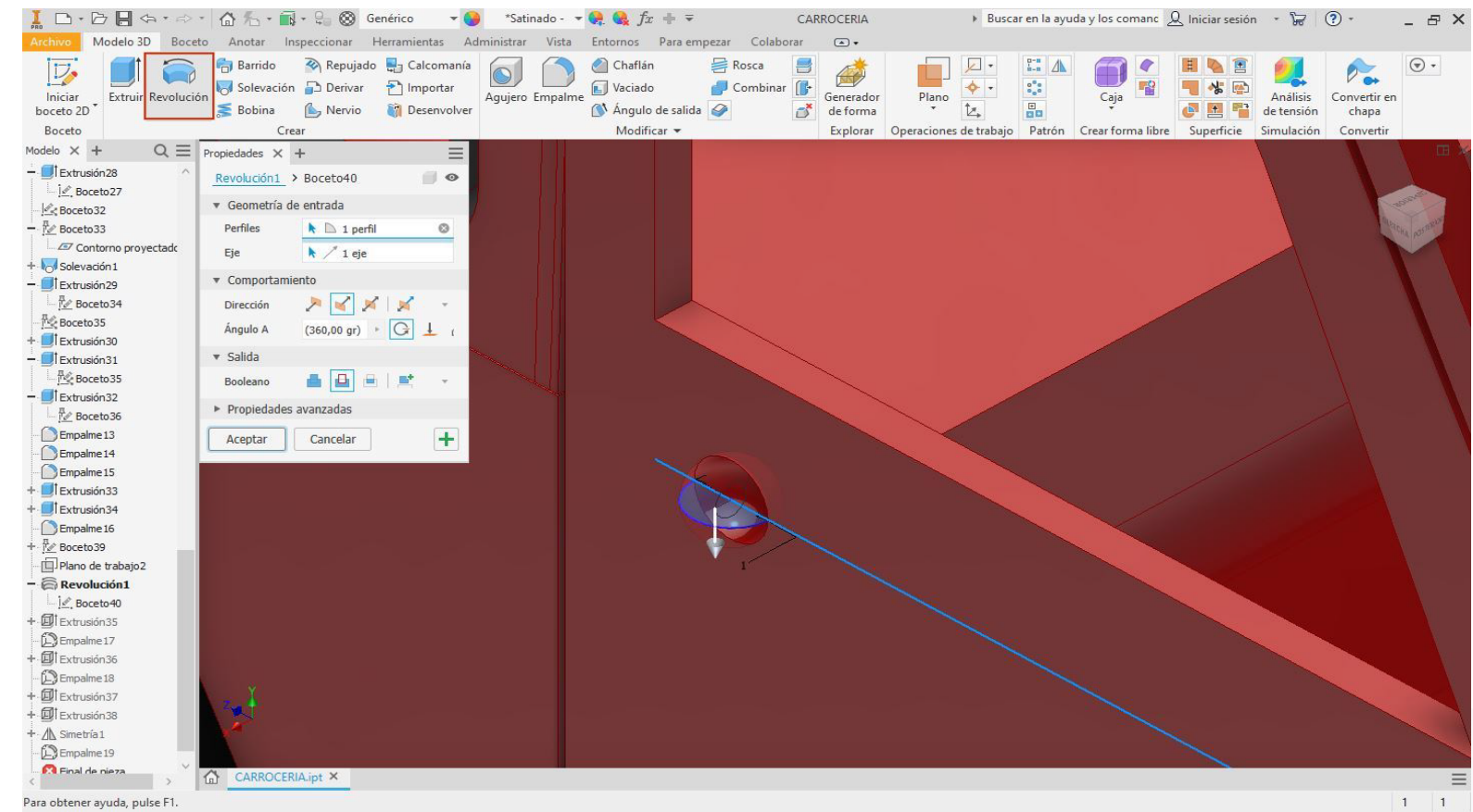

Crear un boceto sobre el plano anteriormente creado para hacer la manija de la puerta a partir de líneas y cotas.
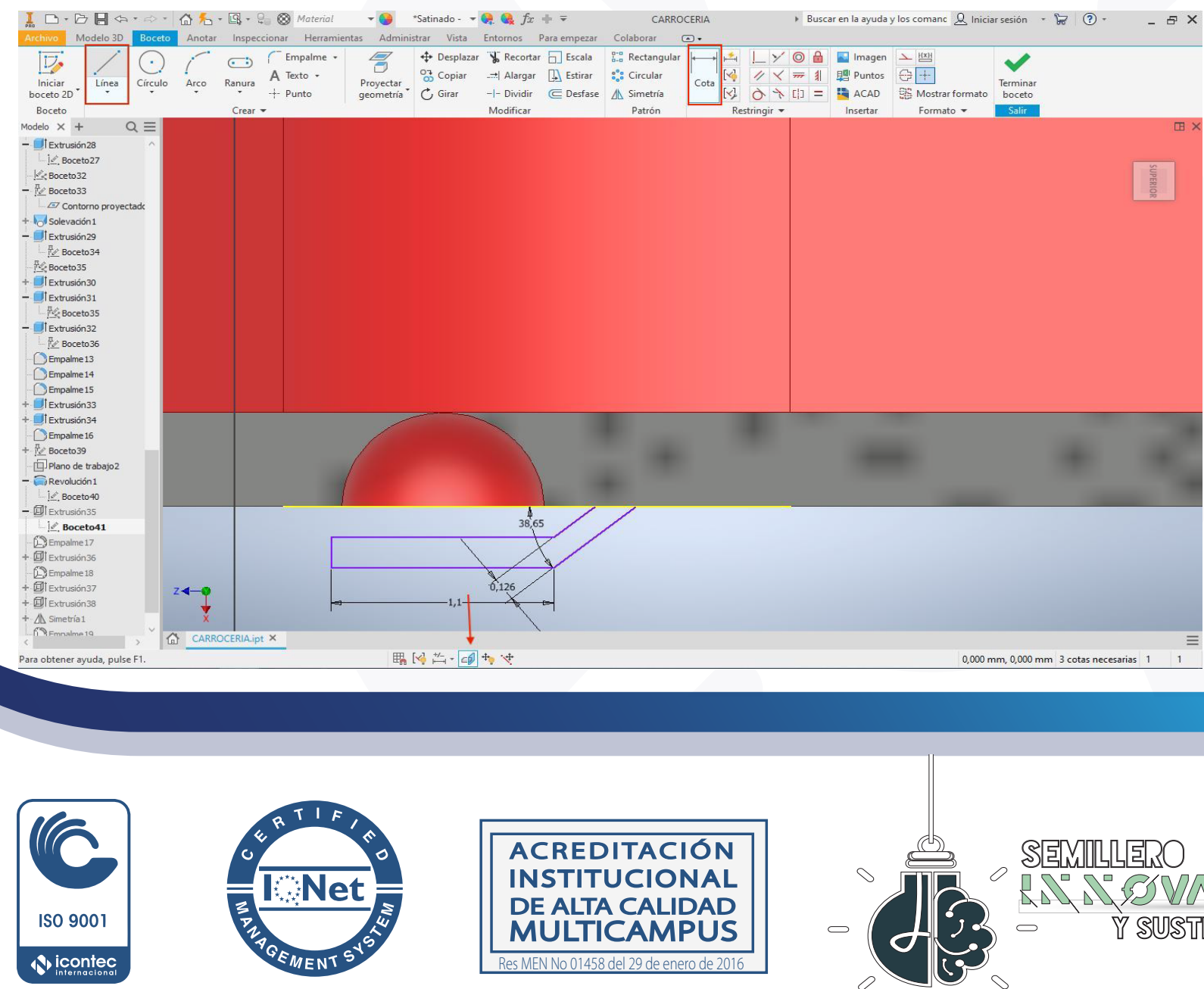

ACREDITACION INSTITUCIONAL DE ALTA CALIDAD MULTICAMPUS 


\section{Procedimiento}

Crear una extrucción sobre el boceto activo (visible) con dirección simétrica a una distancia de 0,2 $\mathrm{mm}$.

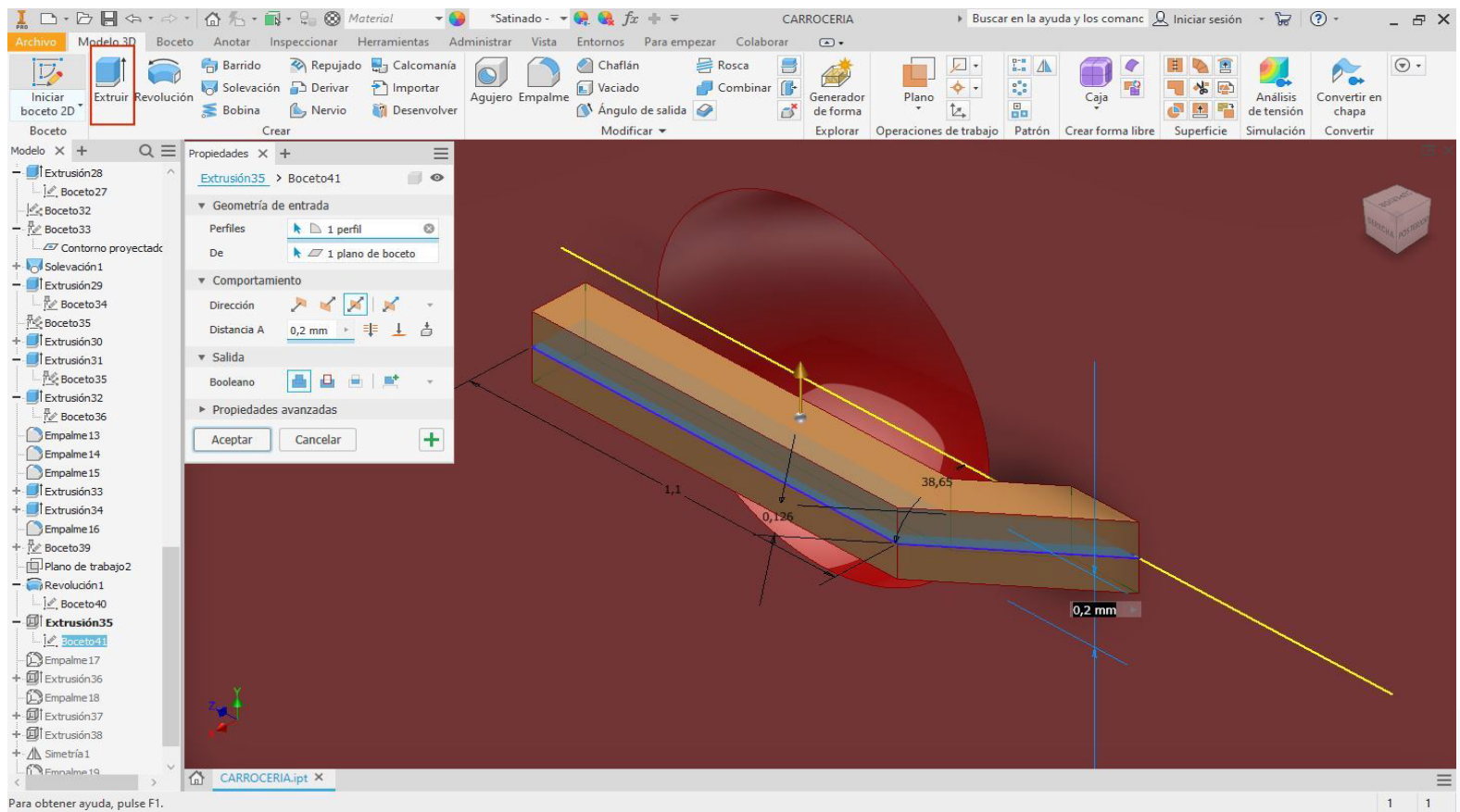

Crear un empalme de 0,06 mm en las aristas exteriores superior e inferior de la manija.
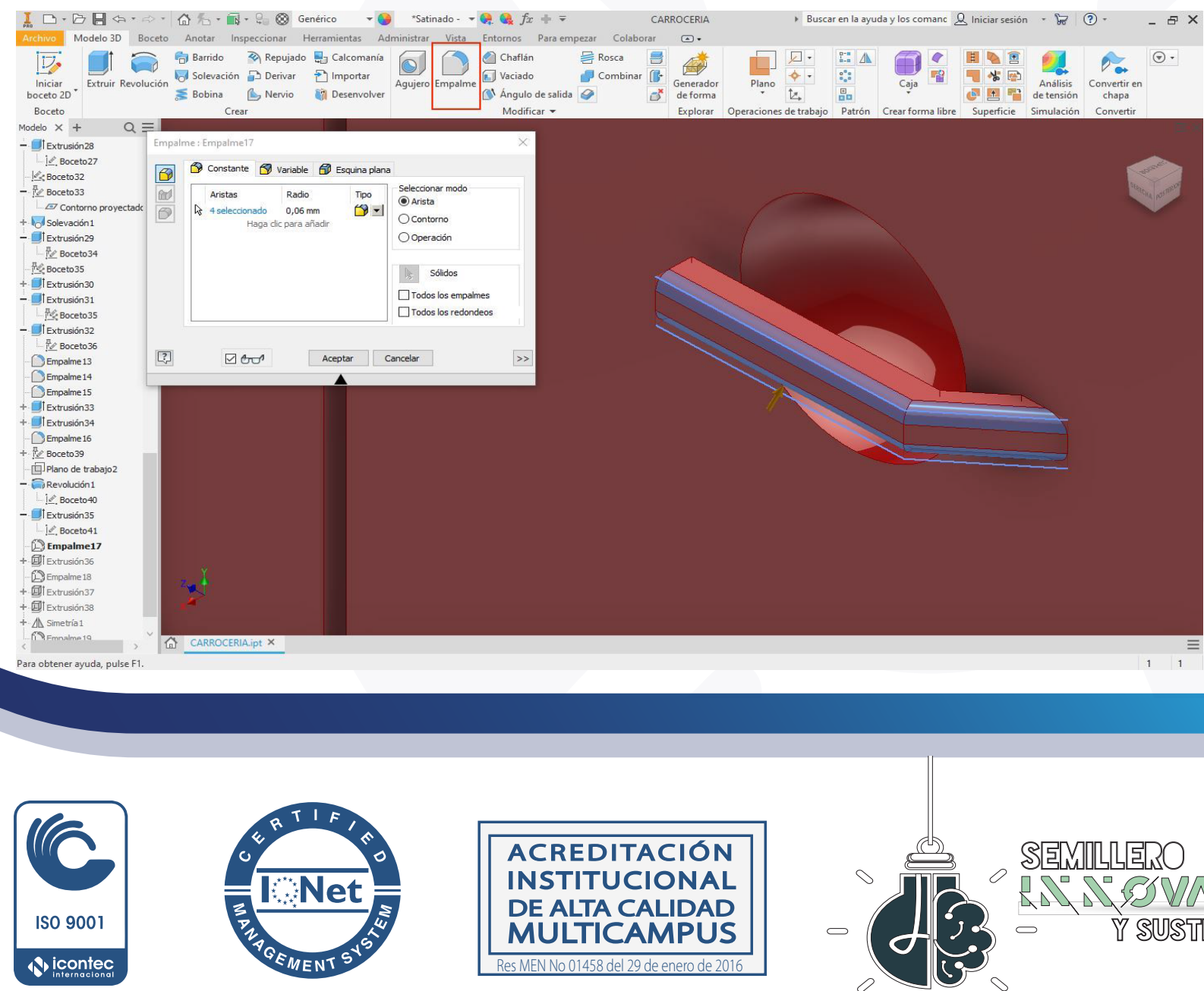

ACREDITACION INSTITUCIONAL

DE ALTA CALIDAD MULTICAMPUS

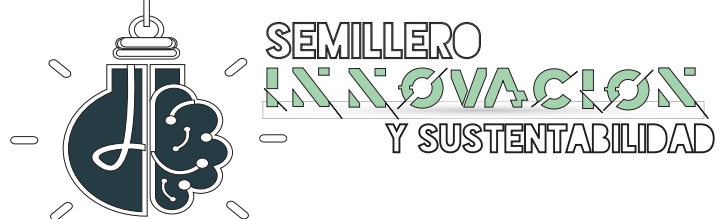




\section{Procedimiento}

Crear un boceto sobre la vista derecha de la puerta, creando un circulo de 0,292 mm de diámetro, siendo la manija una línea cuerda sobre el círculo.

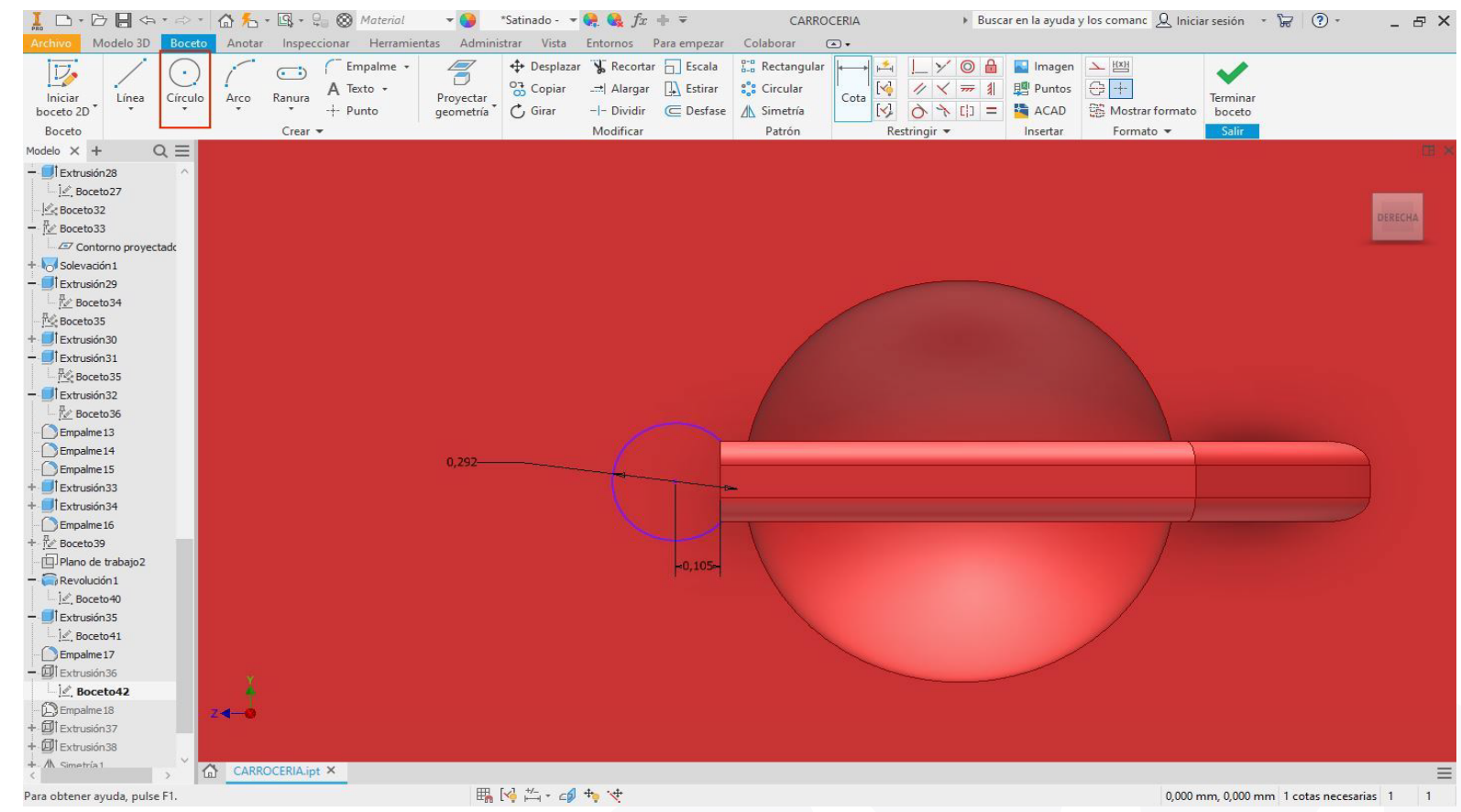

Crear una extrucción sobre el boceto activo (visible) con dirección única a una distancia de 0,322 mm.
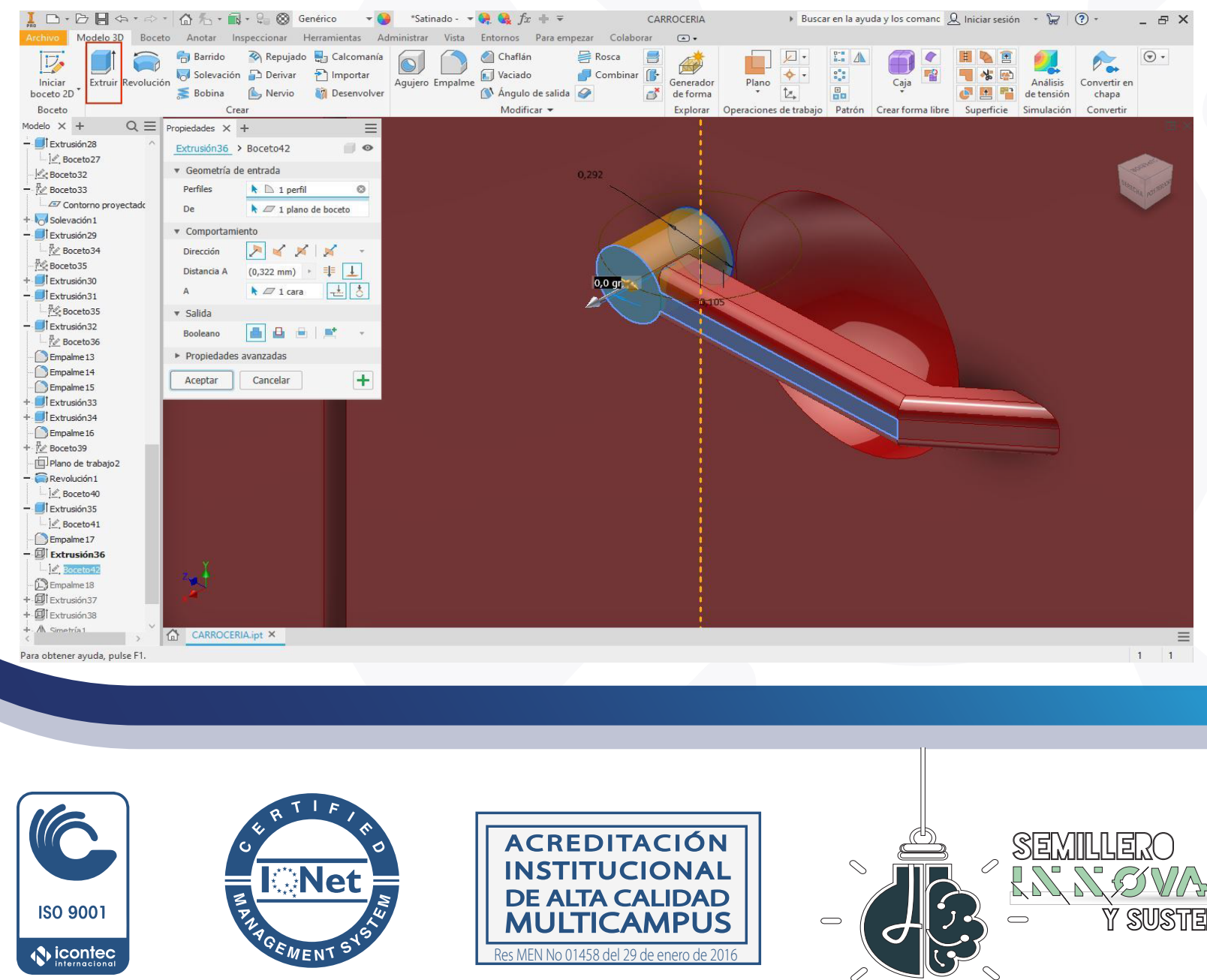

ACREDITACION INSTITUCIONAL DE ALTA CALIDAD MULTICAMPUS

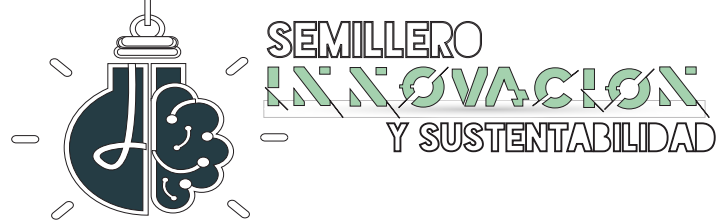




\section{Procedimiento}

Crear un empalme de 0,02 mm en las arista exterior del cilindro de la manija.

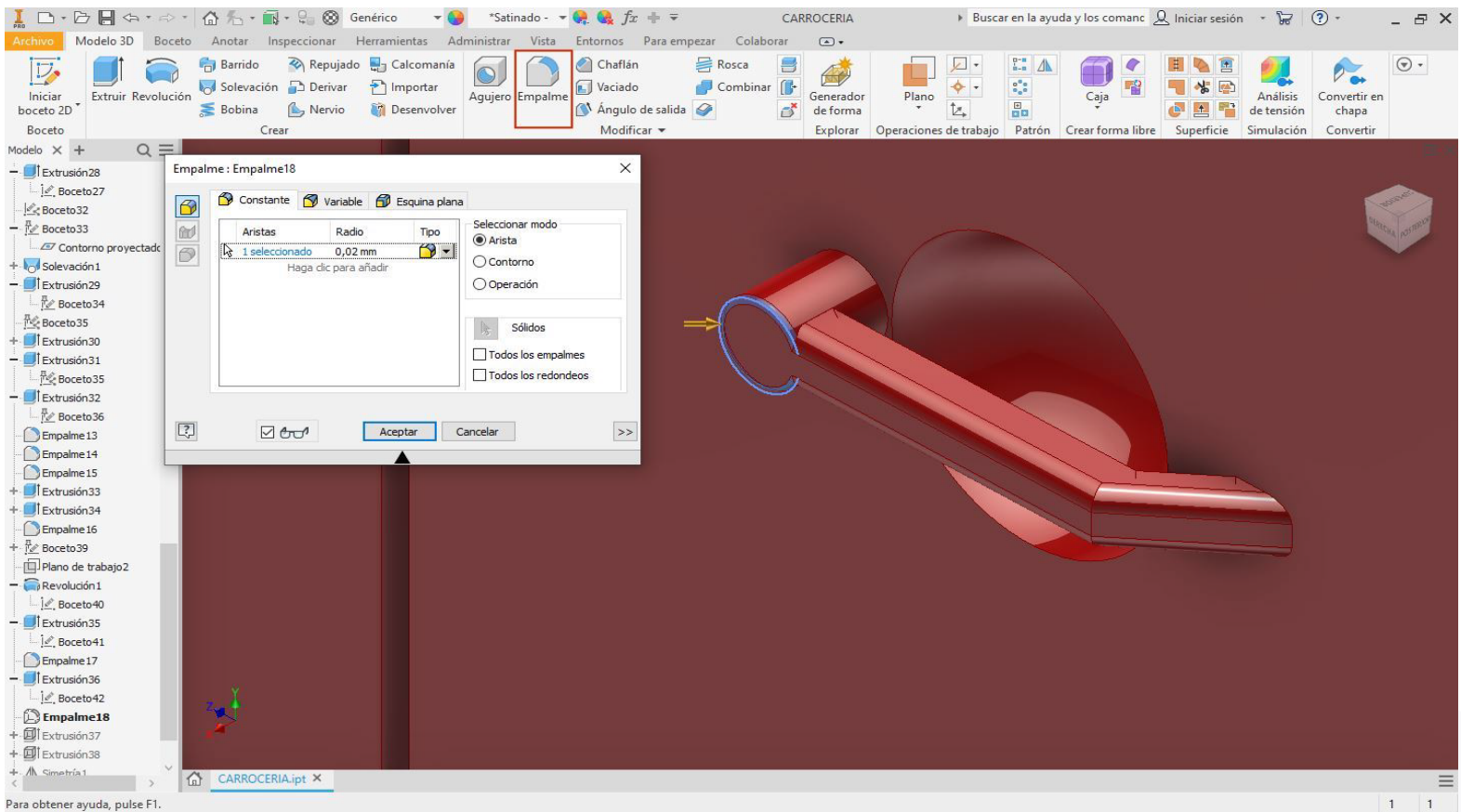

Crear una simetría de la pieza de la carrocería seleccionando todo el sólido y como plano de simetría el lado izquierdo de esta.
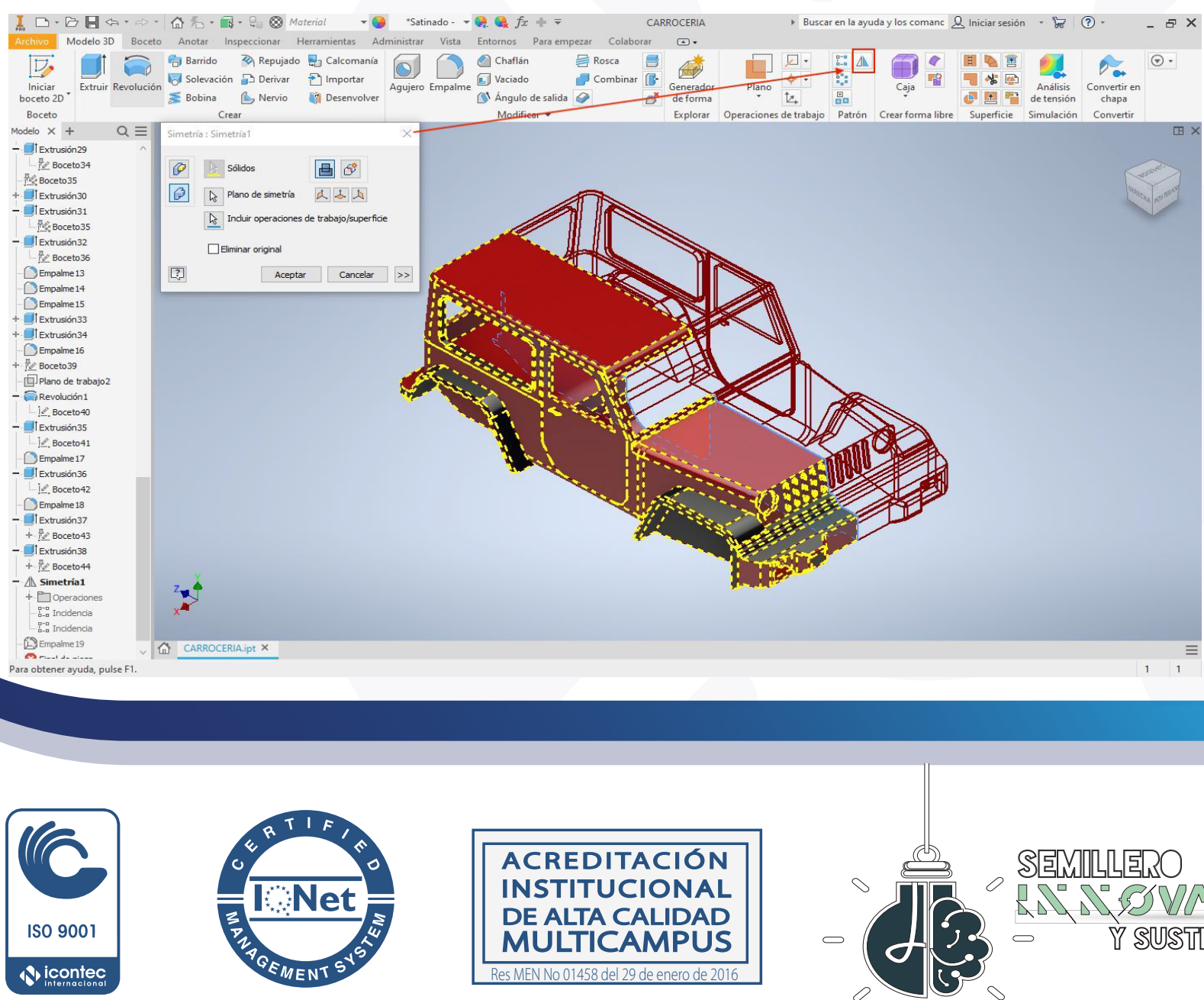

ACREDITACION INSTITUCIONAL DE ALTA CALIDAD MULTICAMPUS

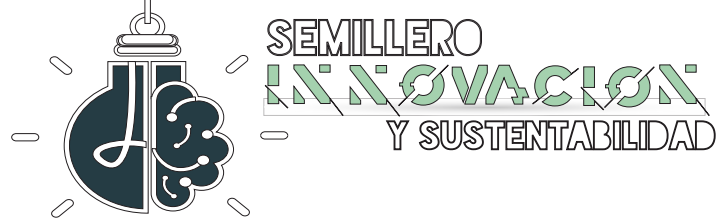




\section{Procedimiento}

Crear un boceto en la vista frontal con ayuda de líneas, empalmes, chaflán y cotas, como se observa en la ilustración.

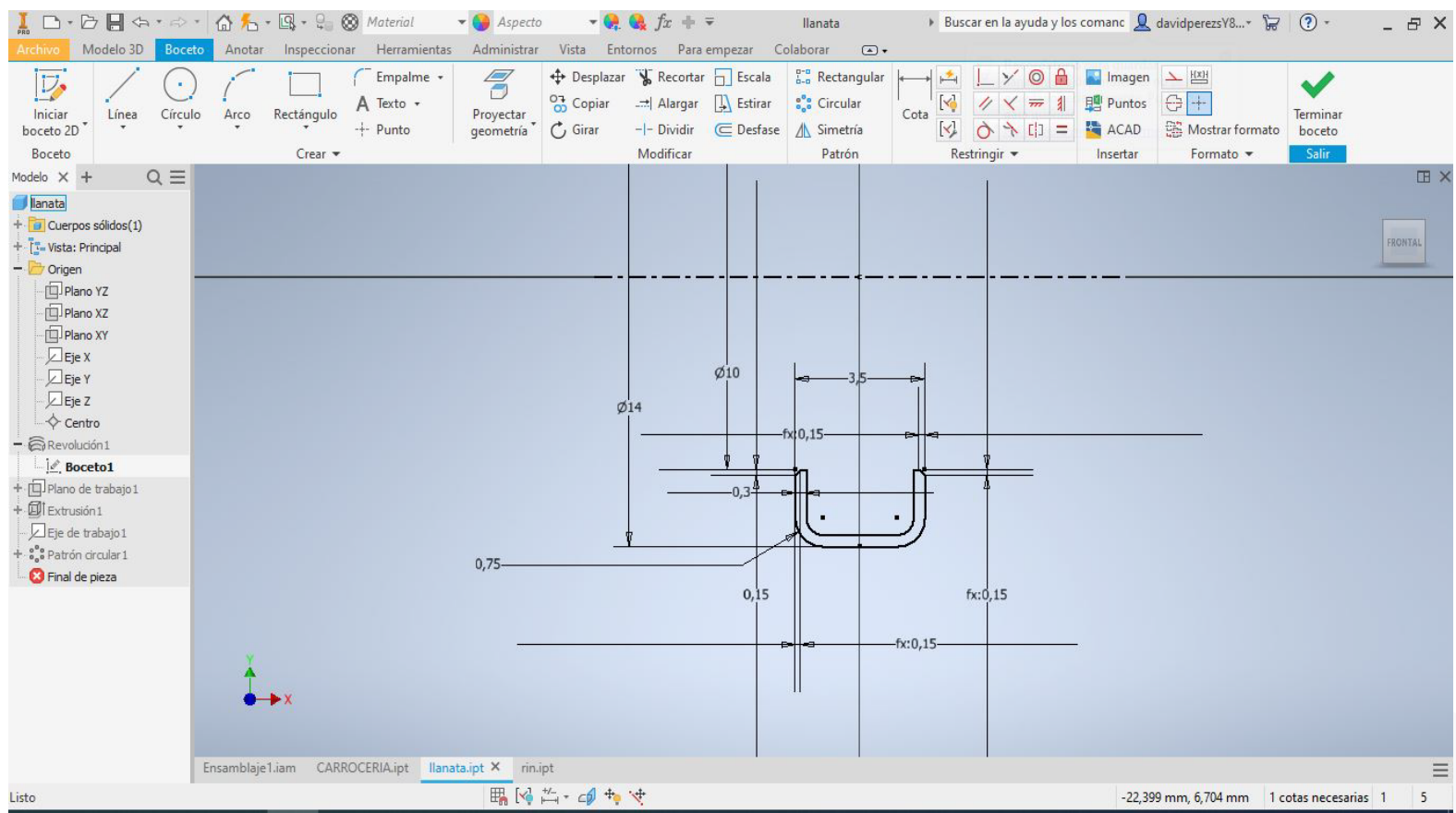

Nota: las

medidas con

el prefiio $\varnothing$

son cotas del

eje (línea

punteada) a

a línea selec-

cionada.

Crear una revolución de 360 para elaborar la llanta.
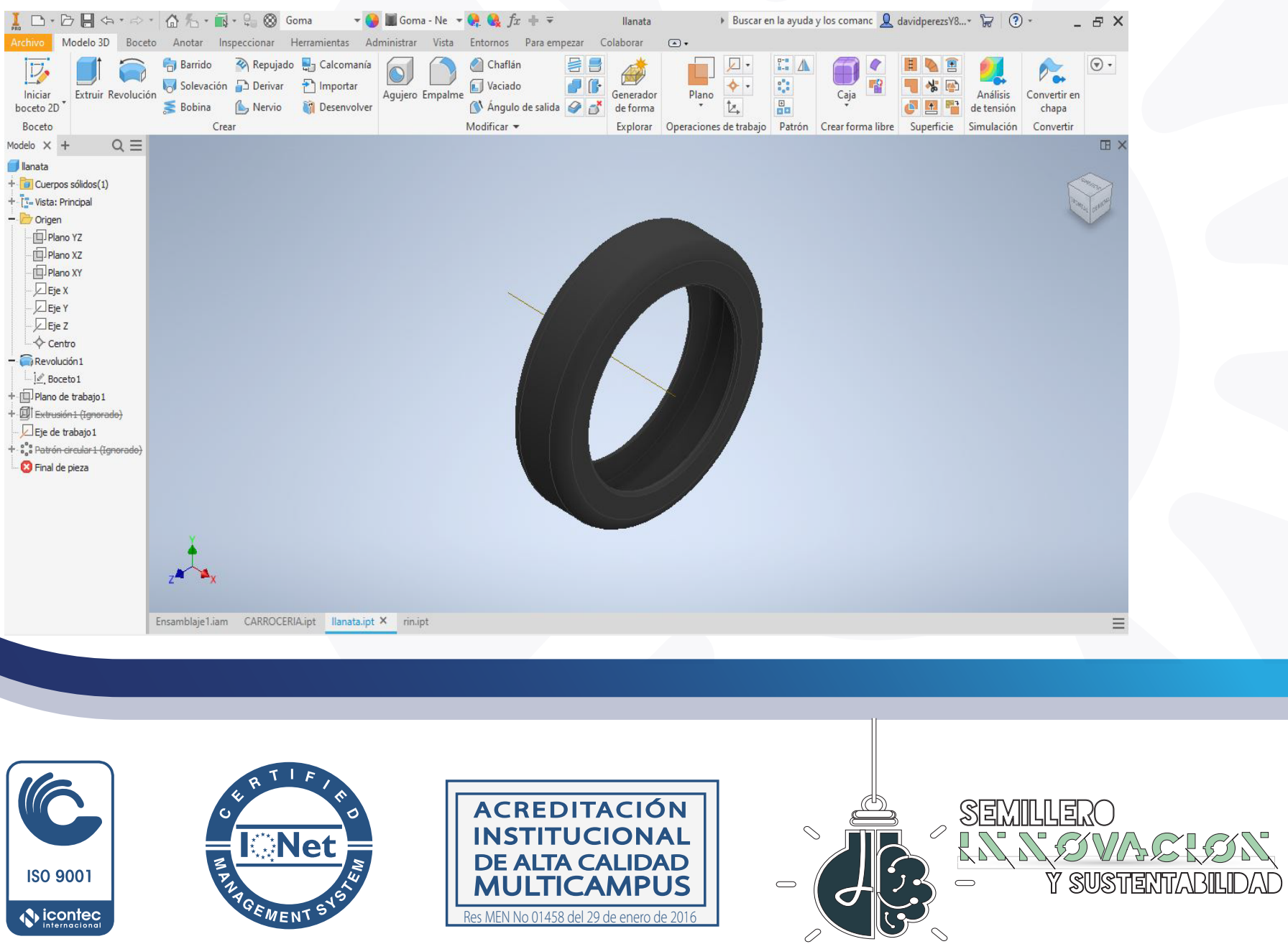


\section{Procedimiento}

Crear un boceto a partir de líneas, cotas, empalmes y chaflán el cual será el rin del carro Jeep.

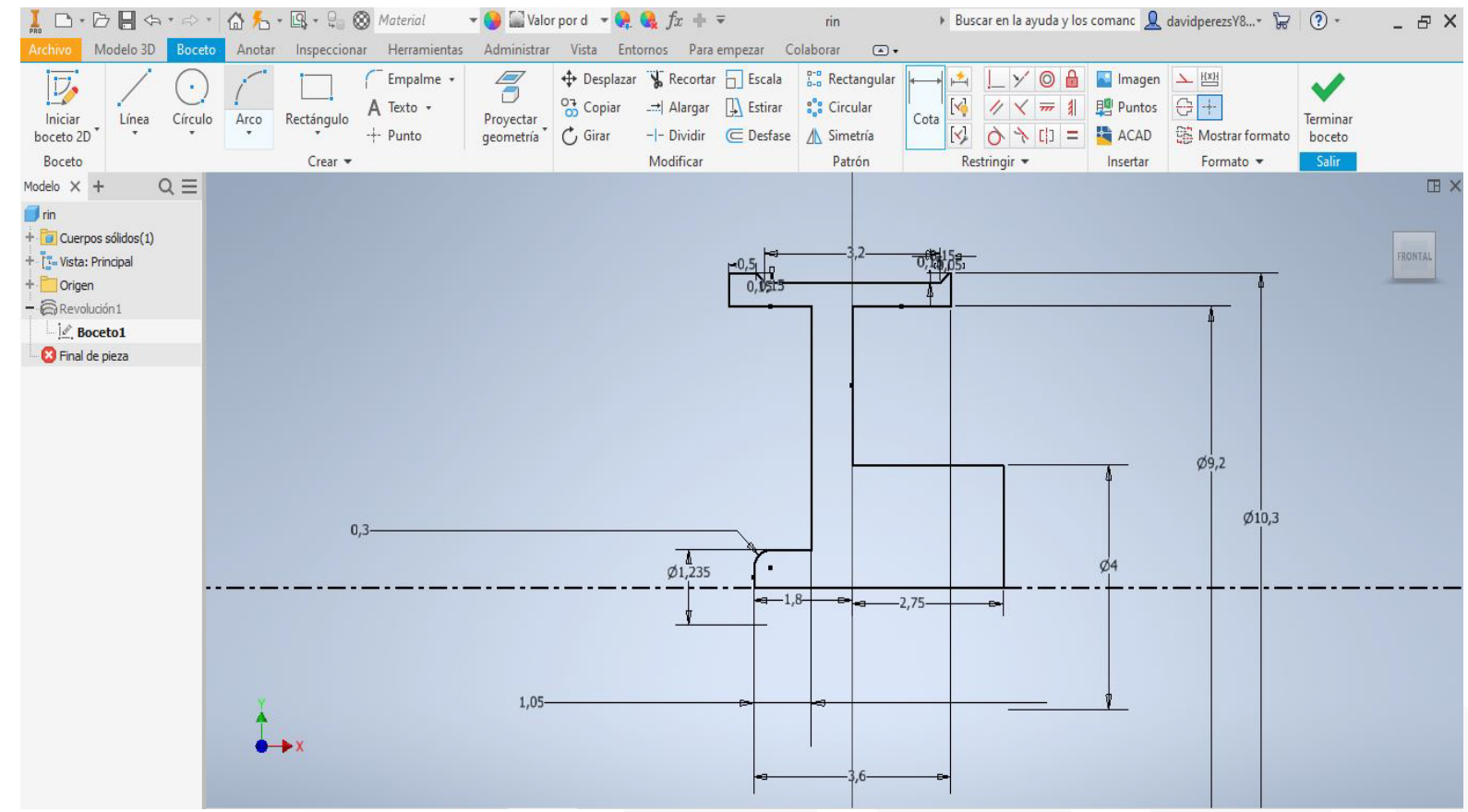

Vista de detalle de la parte superior de la ilustración anterior.
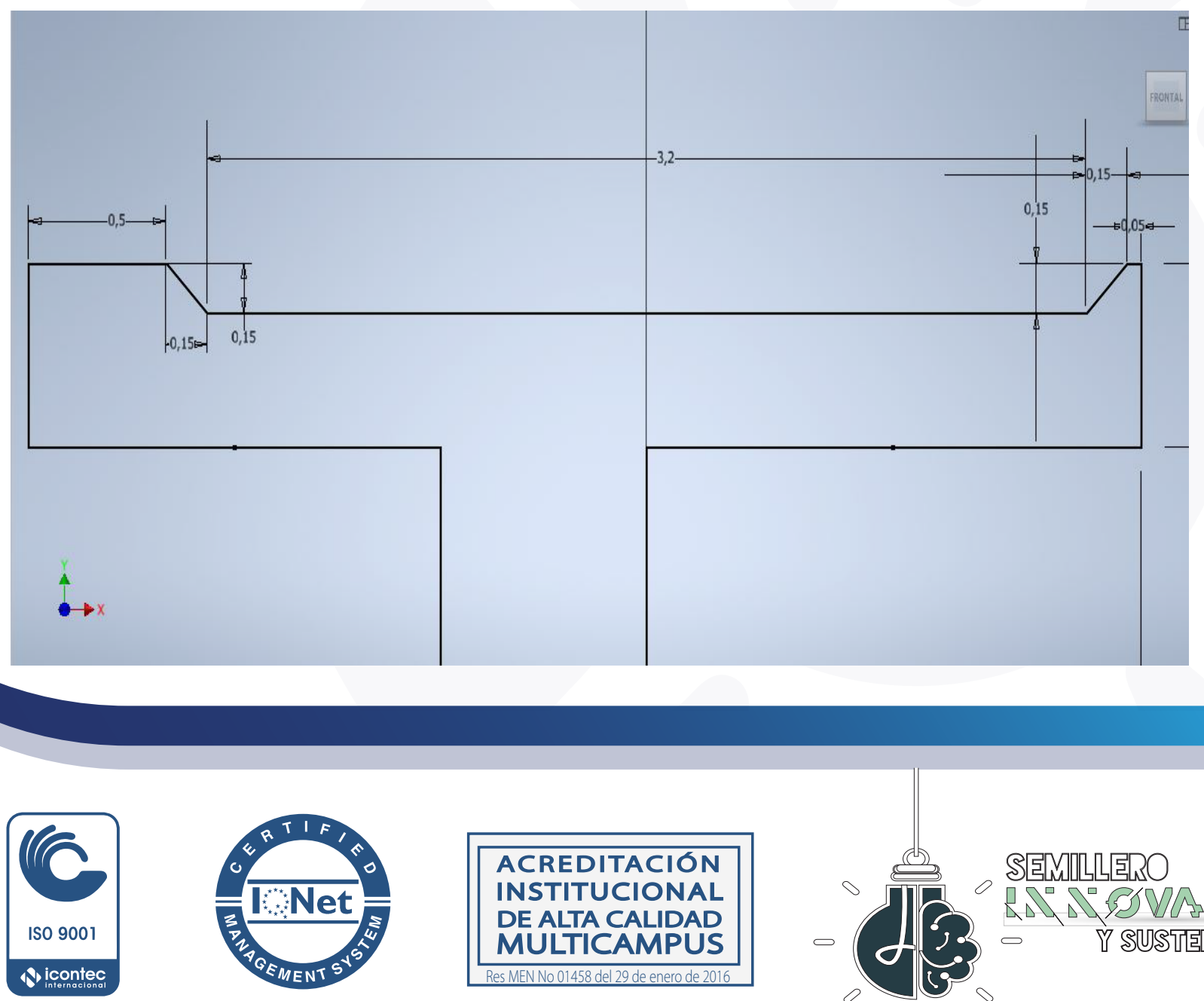

ACREDITACION INSTITUCIONAL

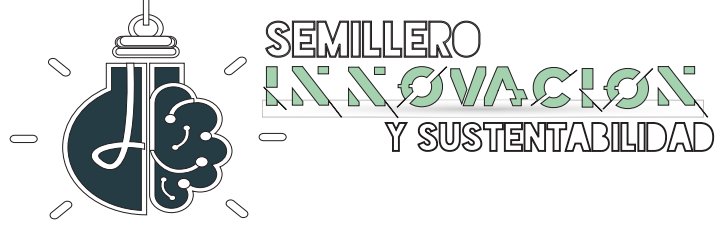




\section{Procedimiento}

Crear una revolución de $360^{\circ}$ para elaborar el rin del Jeep.

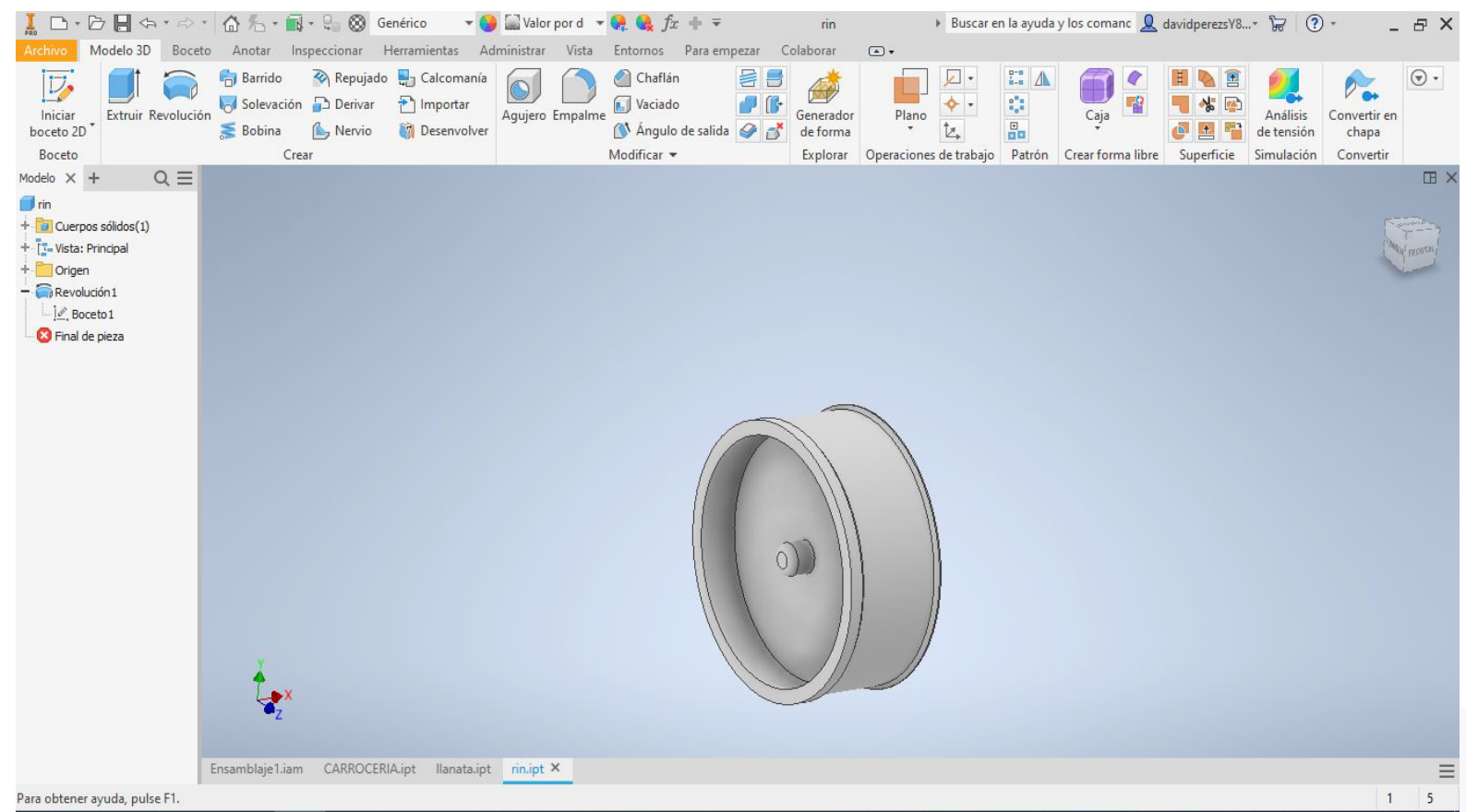

Crear un boceto en la parte derecha de la carrocería por debajo del cubre llanta, utilizando un círculo de $4 \mathrm{~mm}$ de diámetro acotado por la parte trasera 8,5 mm y superior $8 \mathrm{~mm}$ de cubre llanta.
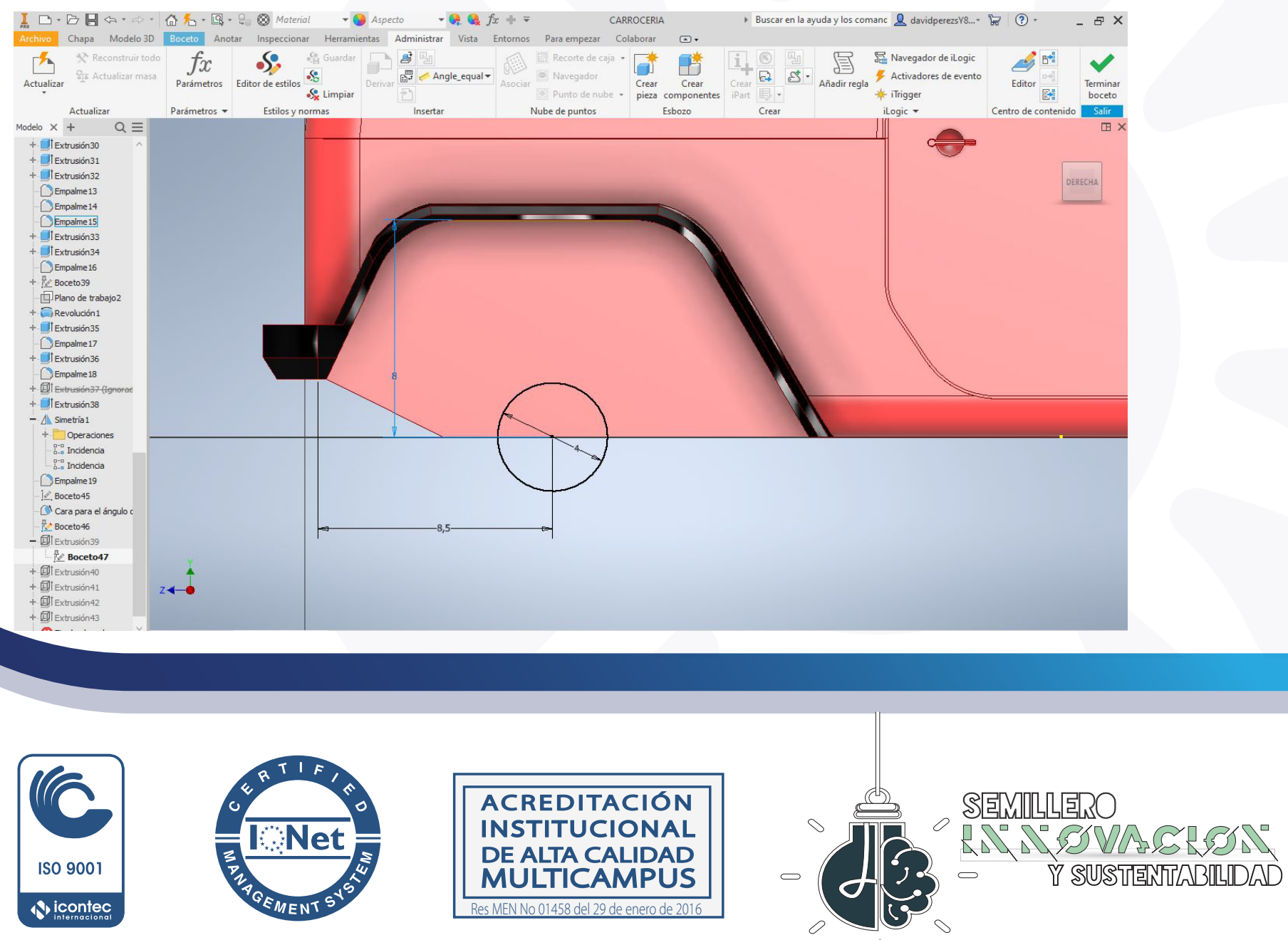


\section{Procedimiento}

Crear una extrucción con dirección diferentes distancias, distancia a: 1 mm y distancia b: $25,5 \mathrm{~mm}$.

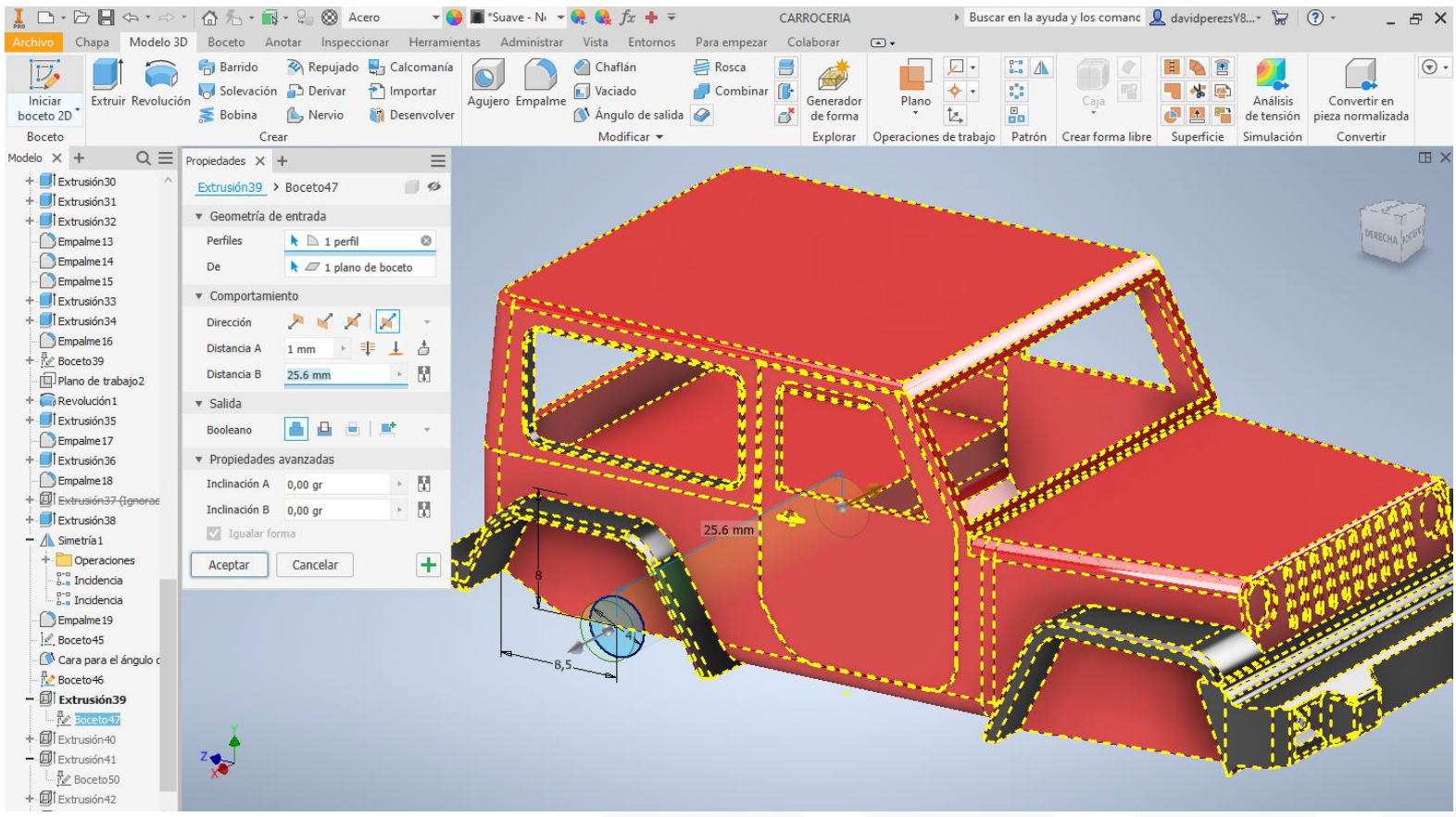

Con el mismo plano del boceto anterior se creará el eje de la parte delantera, con un círculo de $4 \mathrm{~mm}$ y acotado por el cubre llanta por la parte superior $8 \mathrm{~mm}$ y frontal 6,5 mm.
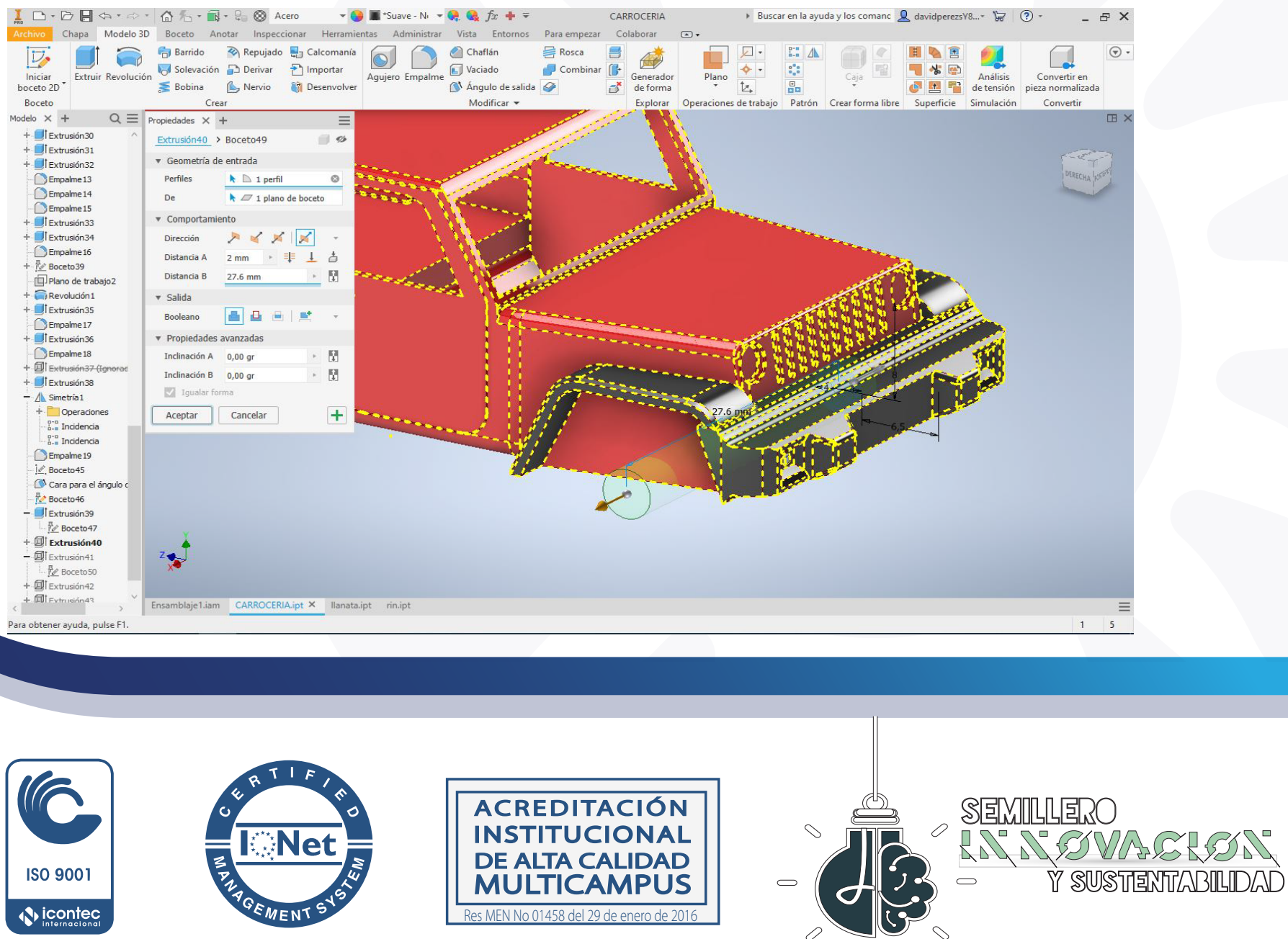


\section{Procedimiento}

Crear un boceto sobre el marco del panorámico y con la herramienta proyección de geometría se elaborará el respectivo boceto para el panorámico.

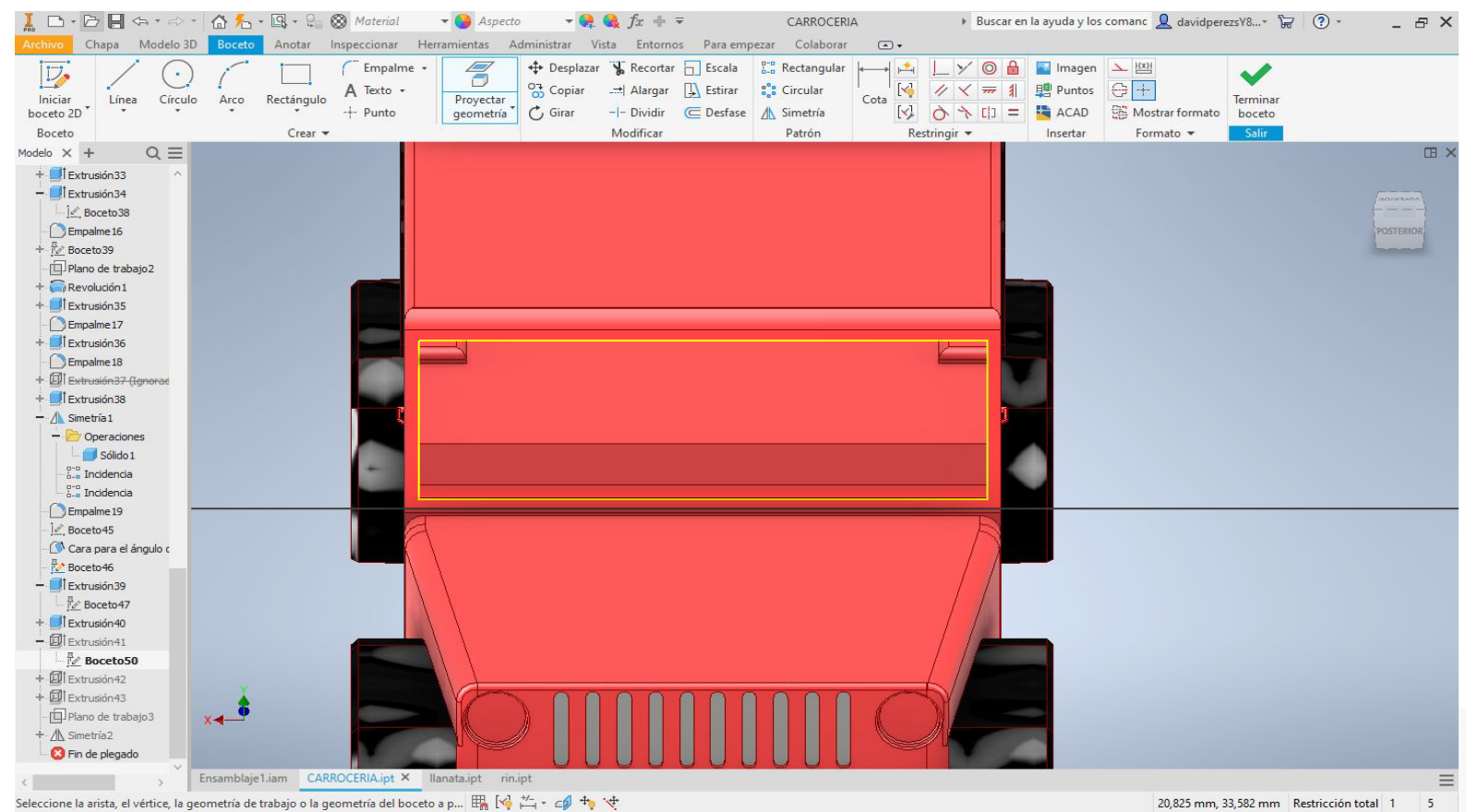

Crear una extrucción hacia el interior del Jeep de 0,1 mm, activando la función de nuevo sólido para que no se combine con el marco.
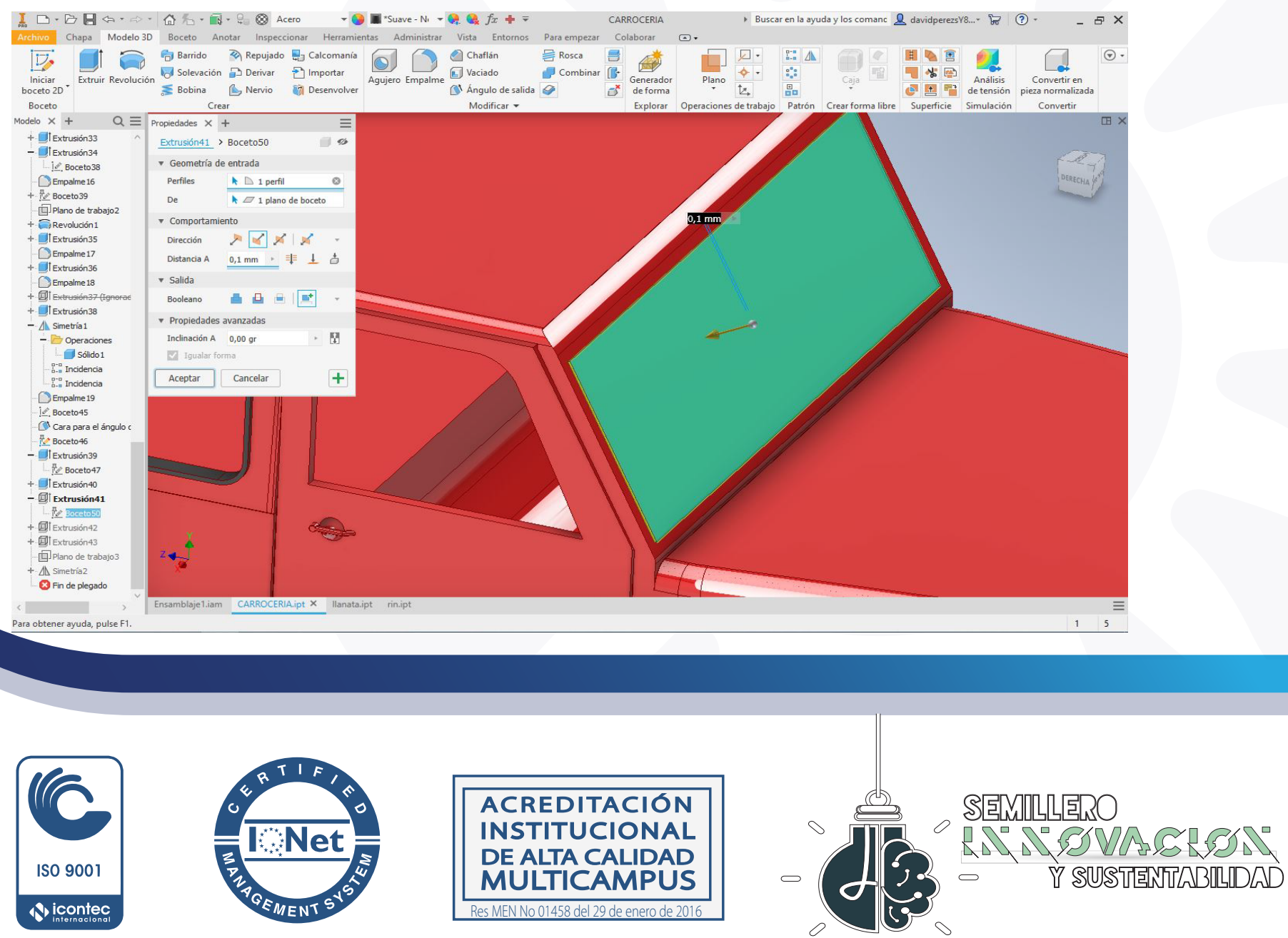


\section{Procedimiento}

Crear un boceto sobre el marco de las ventanas laterales y con la herramienta proyección de geometría se elabora el esquema para las ventanas laterales.

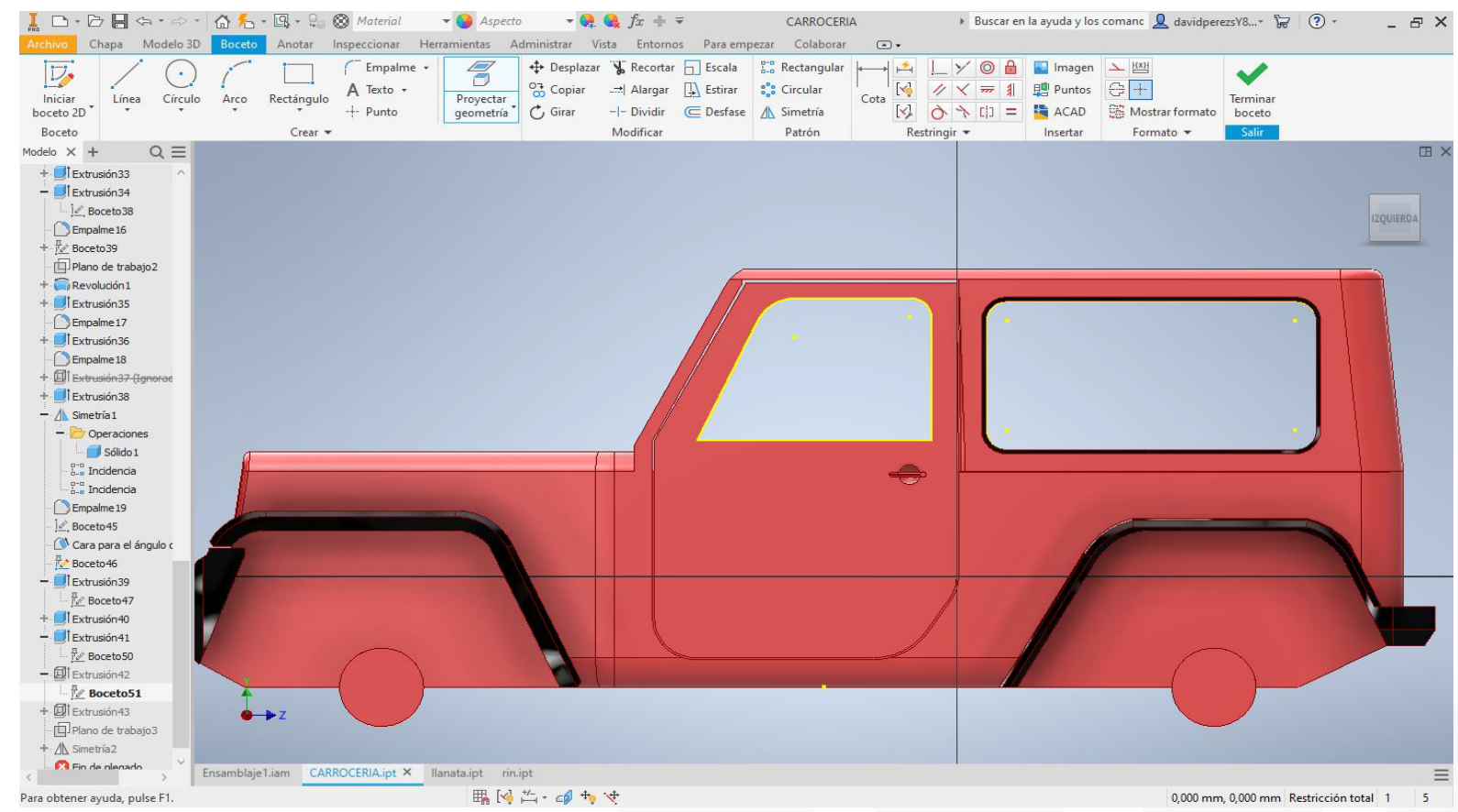

Crear una extrucción hacia el interior del Jeep de 0,1 mm activando la función de nuevo sólido para que no se combine con el marco.
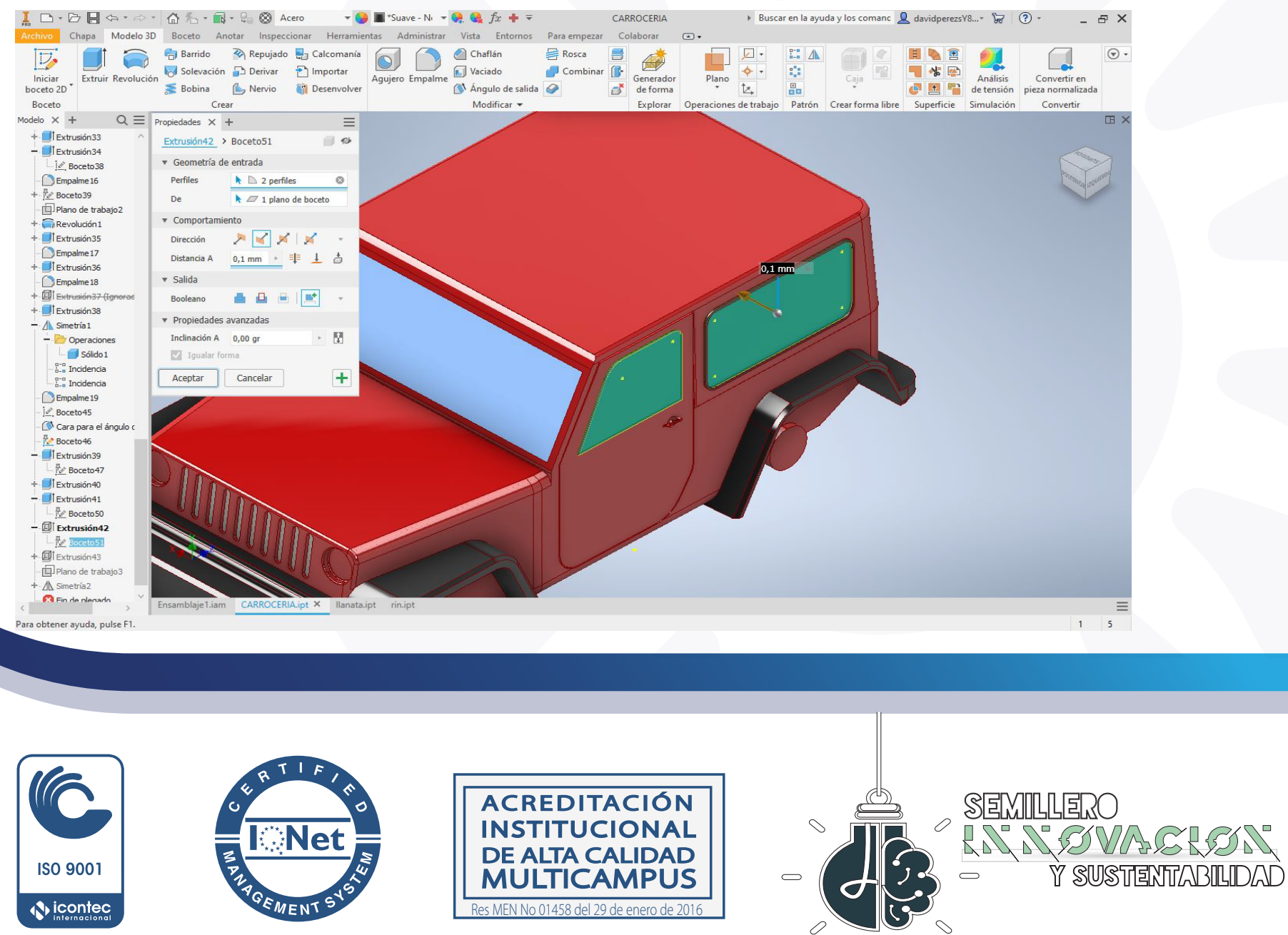


\section{Procedimiento}

Crear un boceto sobre el marco del vidrio trasero y con la herramienta proyección de geometría se elaborará el esquema para el vidrio trasero.

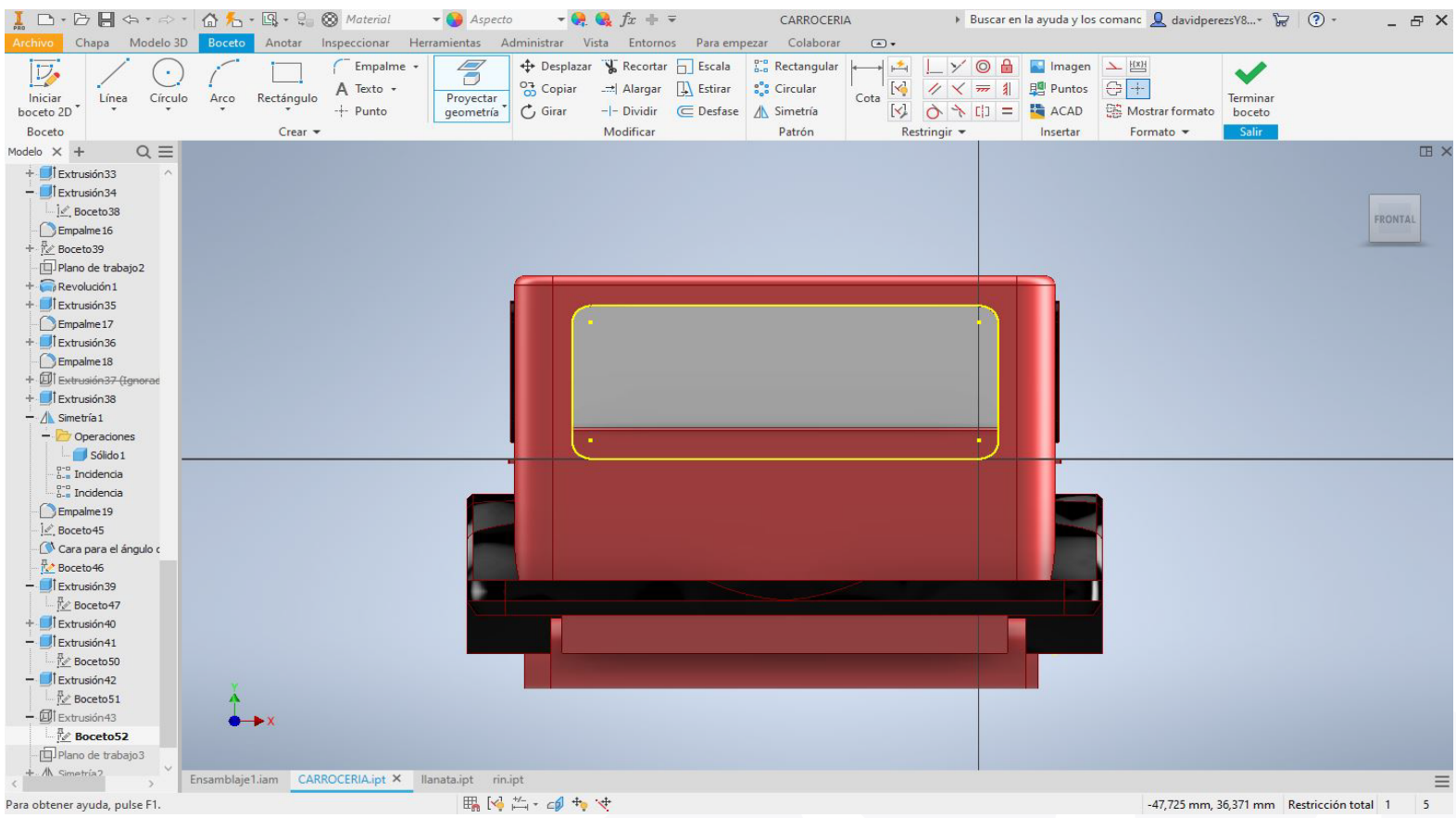

Crear una extrucción hacia el interior del Jeep de 0,1 mm activando la función de nuevo sólido para que no se combine con el marco.
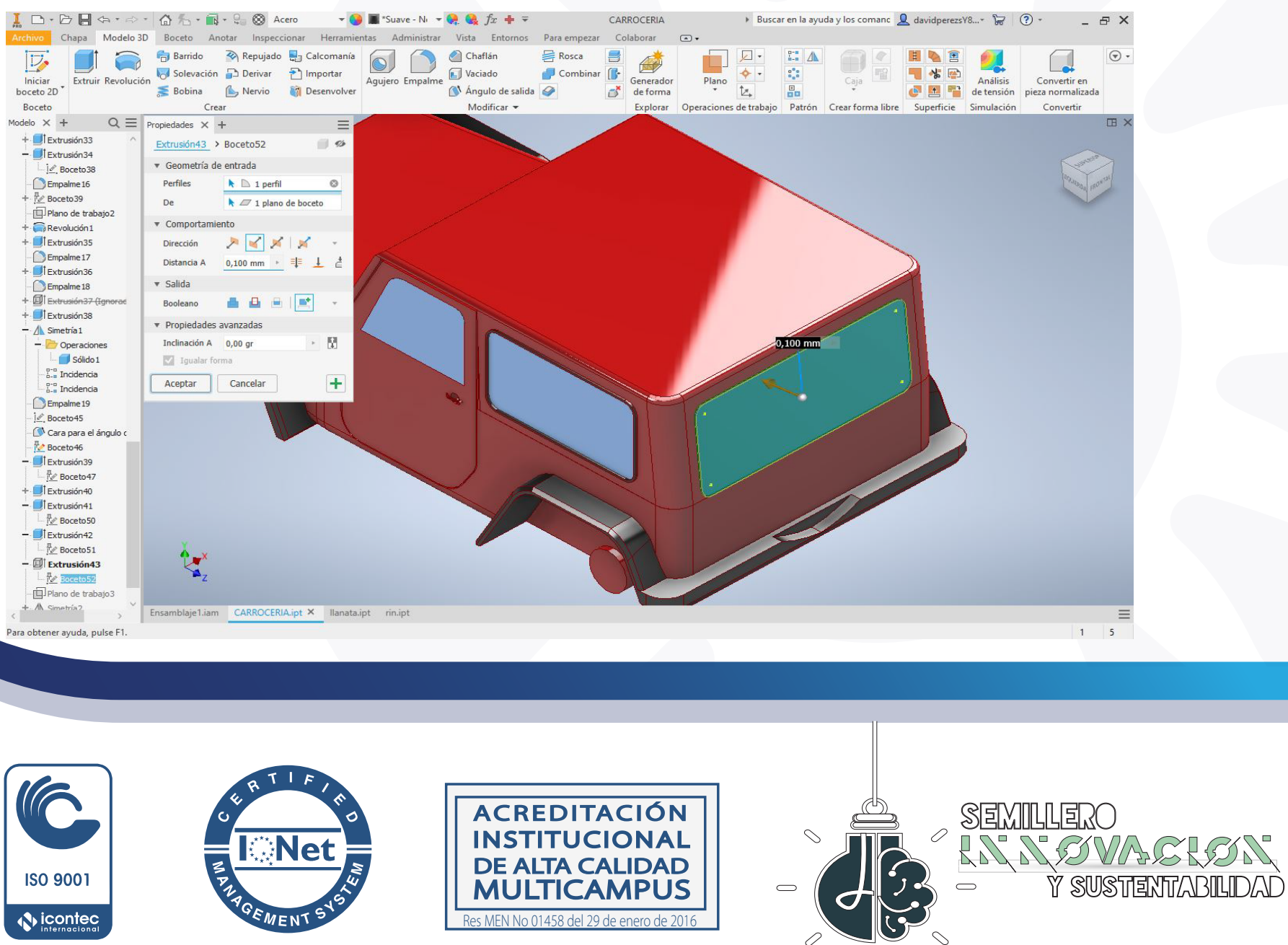


\section{Procedimiento}

Crear una simetría de las extrucciones de los vidrios laterales con un plano central creado entre las dos puertas del Jeep.

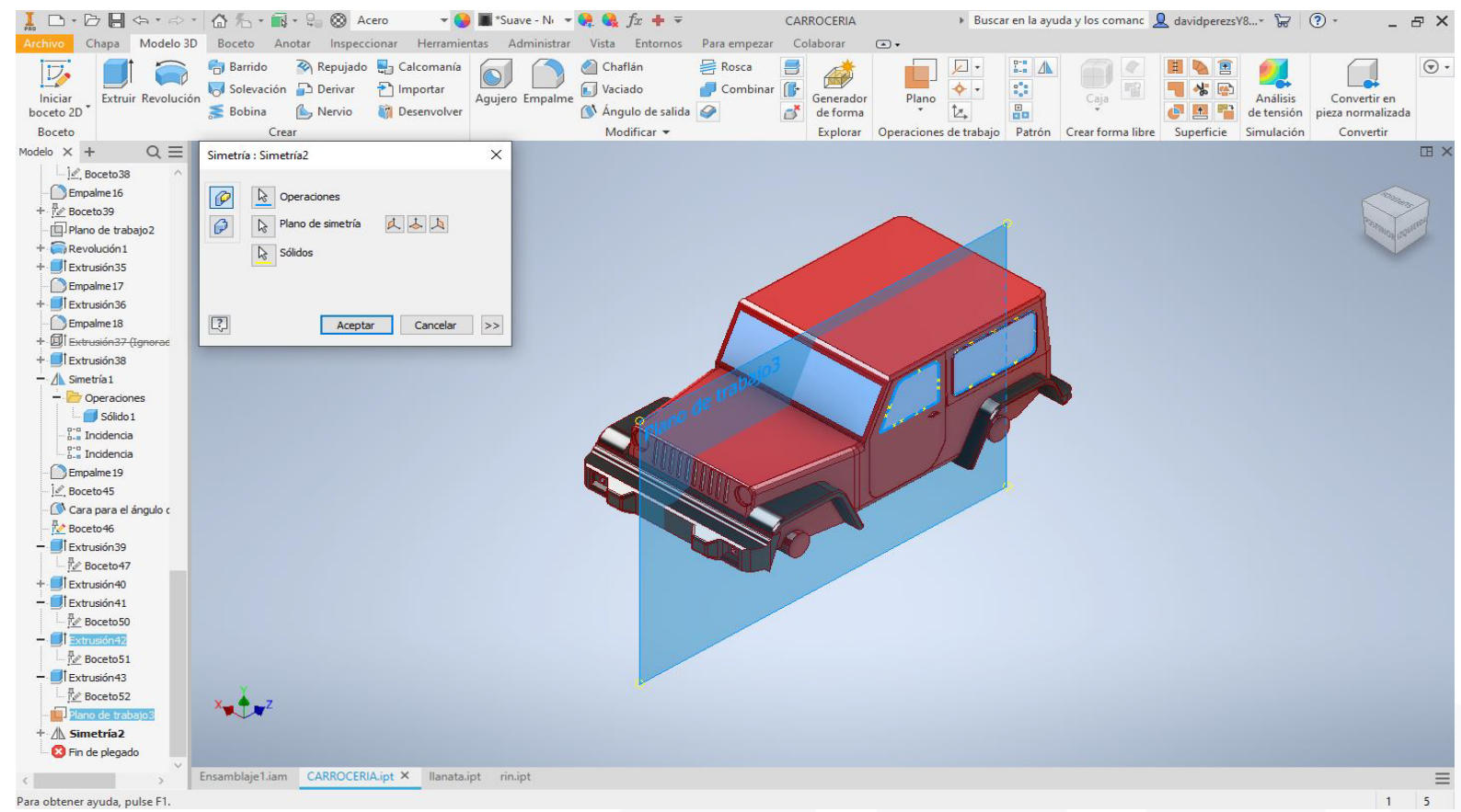

Insertar en un ensamble 4 llantas y 4 rines, creando una restricción de ensamblaje y seleccionando el chaflán interior de la llanta y el chaflán exterior del rin.
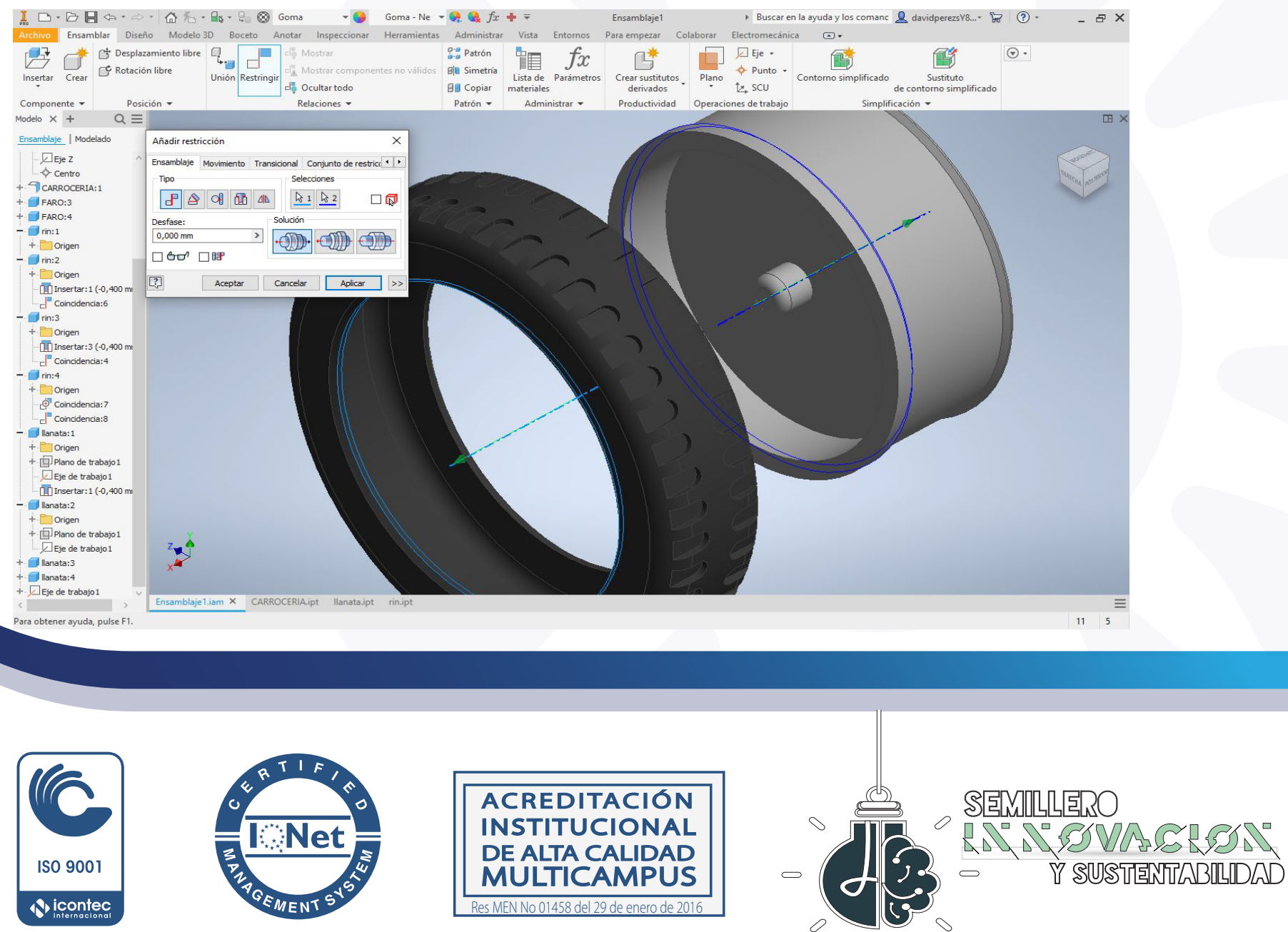


\section{Procedimiento}

Ensamblar las ruedas a los ejes con una restricción seleccionando los bordes de la circunferencia tanto del eje como de la llanta.

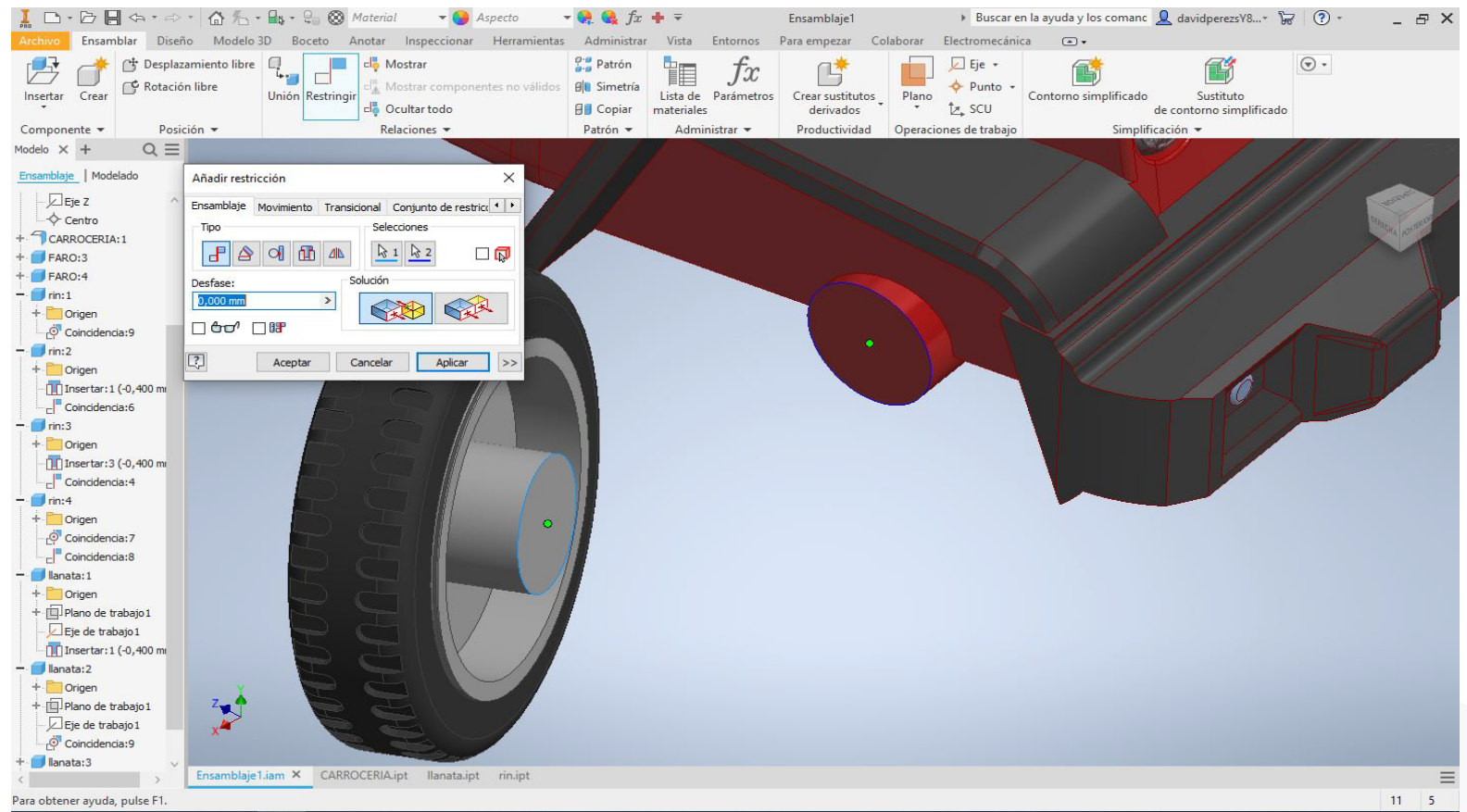

Crear un restricción de los ejes seleccionándolos por la parte exterior y asegurando que se active la línea que pasa por el centro de la circunferencia tanto en la rueda como en el eje.
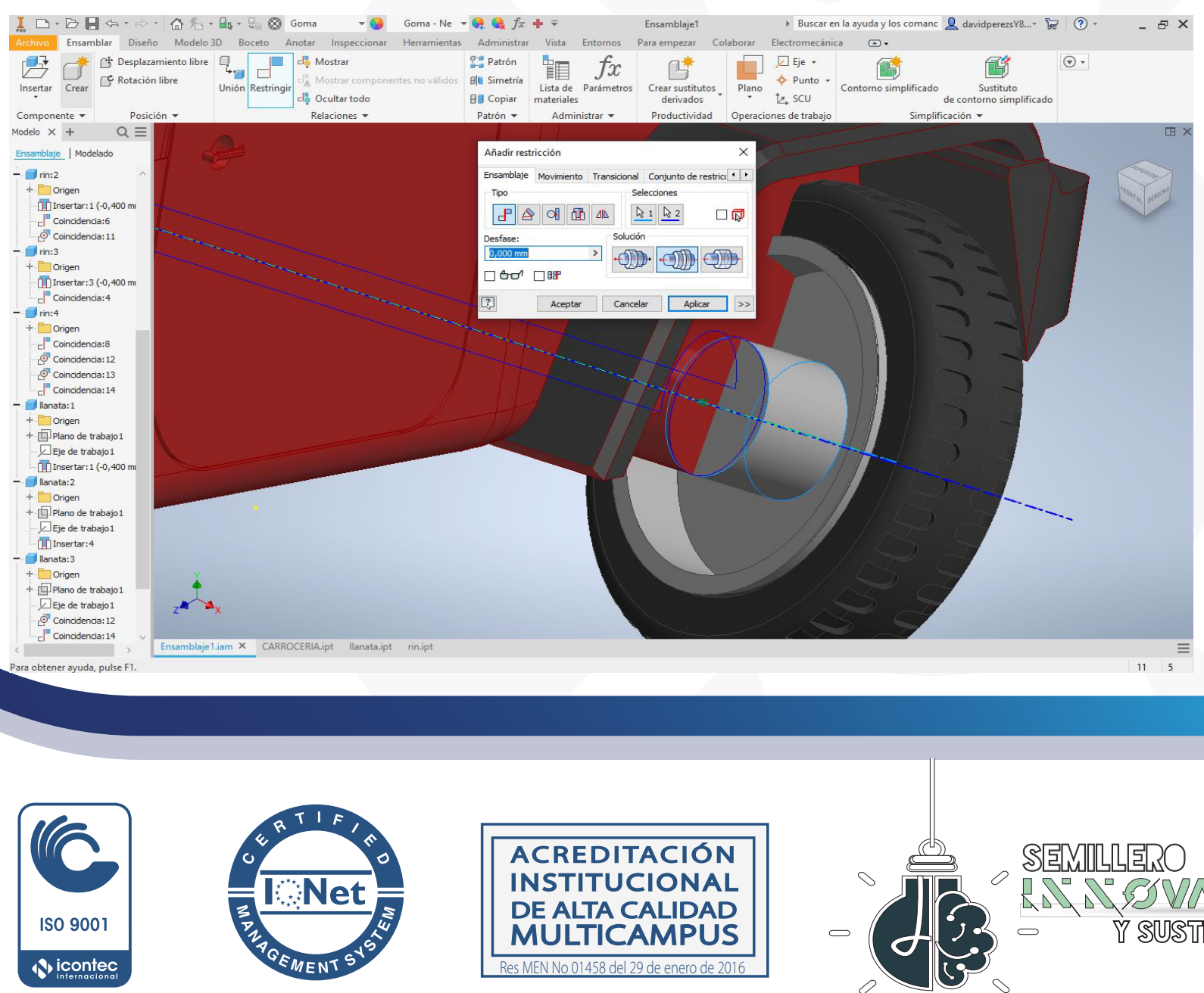

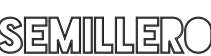

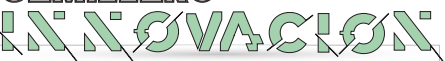

- Y SUSTENVIABMDAD 


\section{Procedimiento}

Finalmentese tendrá el Jeep Wrangler Sport 2018 parametrizado en el software CAD.
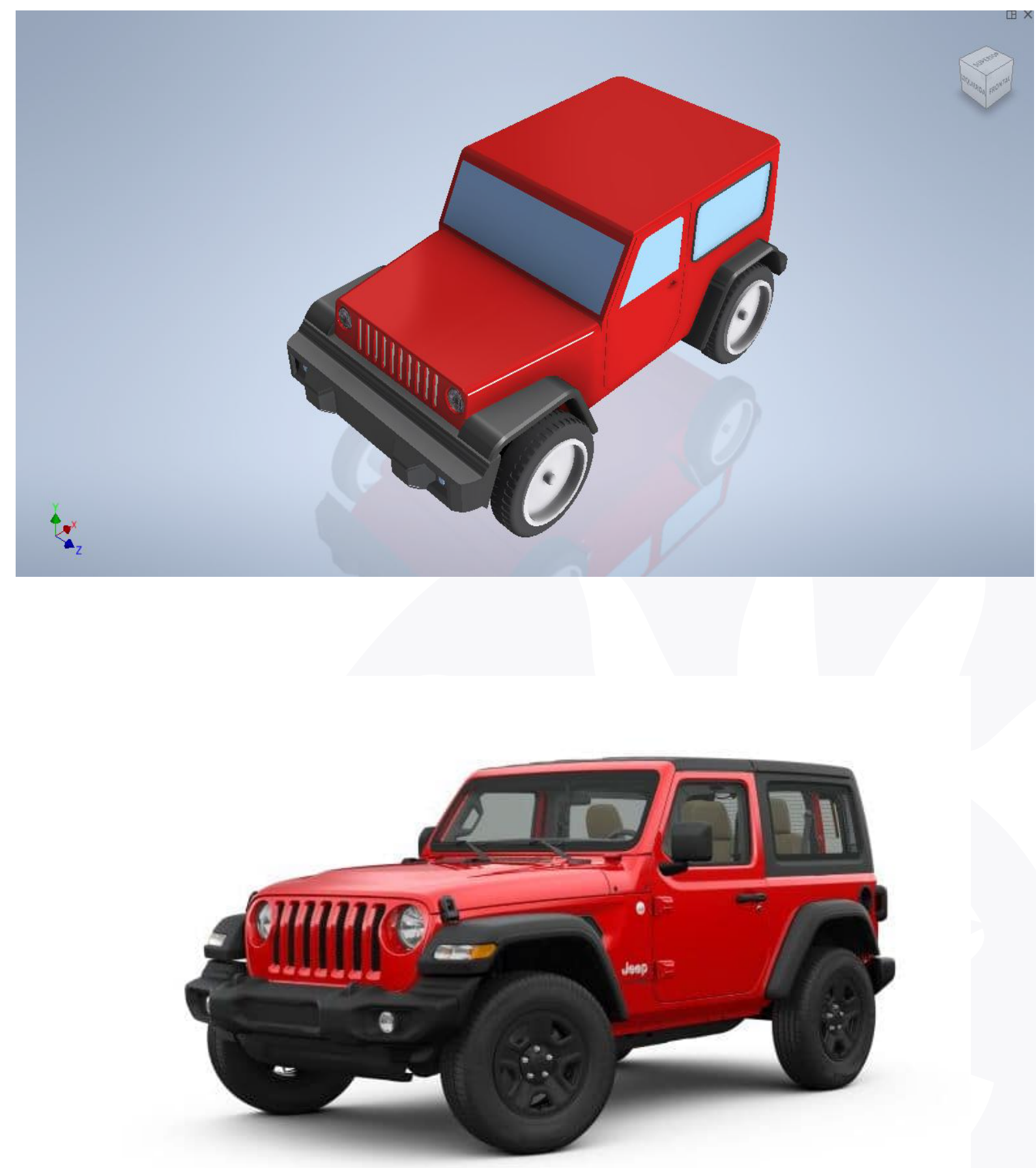

Fuente: Westpointe Chrysler Jeep Dodge, 2018
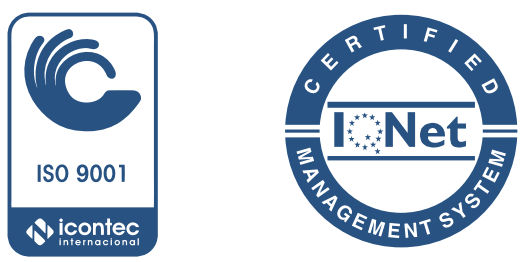

ACREDITACION INSTITUCIONAL DE ALTA CALIDAD MULTICAMPUS

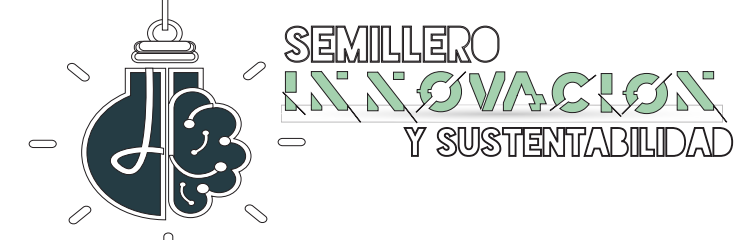




\section{RESULTADOS}

Se obtuvo la interacción entre los dos grupos que conformaban el proyecto, tanto de la Universidad Santo Tomás Sede Principal como del Tecnológico de Costa Rica, por medio de la herramienta de comunicación seleccionada Skype, realizando diferentes sesiones que permitieran despejar dudas y comentar sobre los problemas que fueron ocurriendo durante el proceso. Para el modelamiento y parametrización 3D del carro se contó con dos sesiones que permitió evidenciar el diseño 3D del Jeep Wrangler Sport 2018 por parte de los dos equipos y continuar con la manufactura del mismo.
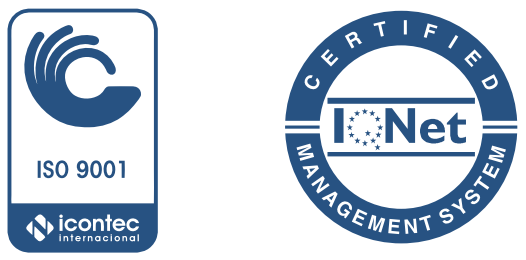


\section{CONCLUSIONES}

Se logró establecer medidas correspondientes a todas las piezas necesarias para el diseño y modelamiento 3D del Jeep Wrangler Sport 2018.

Se evidencian los pasos requeridos para el correcto ensamble en el Software CAD Inventor.

Es necesario tener una comunicación sincera, periódica y positiva, ya que es un factor clave para la realización de proyectos de cooperación internacional que permitan esclarecer una ruta de acción, en este caso para la realización del diseño, modelamiento y parametrización 3D del carro modelo.
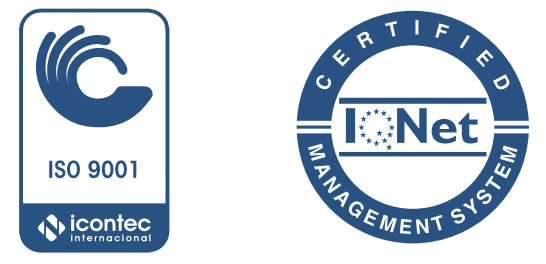


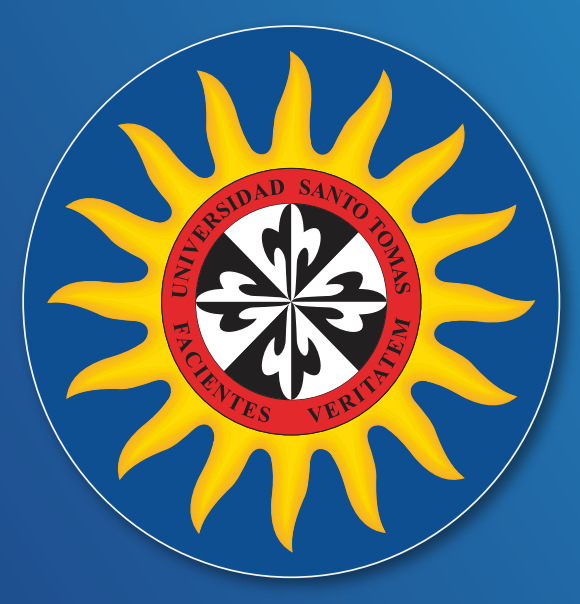

\section{UNIVERSIDAD SANTO TOMÁS} PRIMER CLAUSTRO UNIVERSITARIO DE COLOMBIA FACULTAD DE INGENIERIA INDUSTRIAL
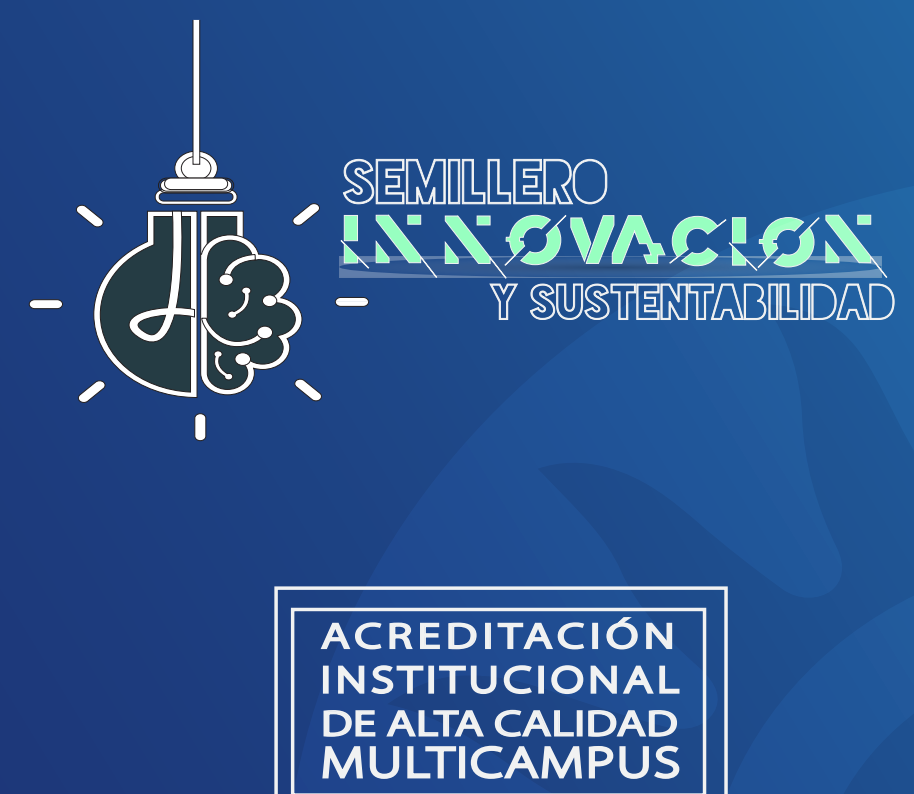

Res MEN No 01458 del 29 de enero de 2016
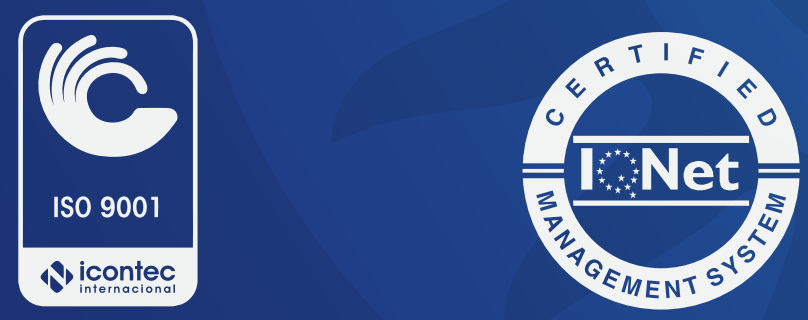